Florida International University FIU Digital Commons

11-18-2009

\title{
Think Before You Eat: Calories and Exercise Equivalents Presented on Menus at Point-of- Choice
}

Charles Stuart Platkin

Florida International University, charles@dietdetective.com

DOI: $10.25148 /$ etd.FI09120832

Follow this and additional works at: https://digitalcommons.fiu.edu/etd

\section{Recommended Citation}

Platkin, Charles Stuart, "Think Before You Eat: Calories and Exercise Equivalents Presented on Menus at Point-of-Choice" (2009). FIU Electronic Theses and Dissertations. 119.

https://digitalcommons.fiu.edu/etd/119 


\section{FLORIDA INTERNATIONAL UNIVERSITY}

Miami, Florida

THINK BEFORE YOU EAT: CALORIES AND EXERCISE EQUIVALENTS

PRESENTED ON MENUS AT POINT-OF-CHOICE

A dissertation submitted in partial fulfillment of the

requirements for the degree of

DOCTOR OF PHILOSOPHY

in

PUBLIC HEALTH

by

Charles Stuart Platkin

2009 
To: $\quad$ Dean Fernando M. Trevino

Robert Stempel College of Public Health and Social Work

This dissertation, written by Charles Stuart Platkin, and entitled Think Before You Eat: Calories and Exercise Equivalents Presented on Menus at Point-of-Choice, having been approved in respect to style and intellectual content, is referred to you for judgment.

We have read this dissertation and recommend that it be approved.

Dorothy Brooten

Victoria H. Castellanos

Jessy G. Devieux

Jésus Sanchez

$\overline{\text { Robert Malow, Major Professor }}$

Date of Defense: November 18, 2009

The dissertation of Charles Stuart Platkin is approved.

Dean Fernando M. Trevino Robert Stempel College of Public Health and Social Work

Dean George Walker University Graduate School

Florida International University, 2009 
(C) 2009 Copyright by Charles Stuart Platkin

All rights reserved. 


\section{DEDICATION}

This dissertation is dedicated to advancing the concept of nutrition awareness and to improvement of health behaviors. I truly believe that readily available nutrition information can help create responsible consumer decision-making and that this research will contribute to the current literature. I would also like to dedicate this to my daughter, Parker South, a constant inspiration, to my parents, Linda and Norton, who have always been and continue to be a driving force in my life, and to my wife, Shannon, a patient, considerate and caring friend. 


\section{ACKNOWLEDGMENTS}

I would like to thank Dr. Victoria Castellanos, for her tremendous contribution, mentoring and practical advice, as well as the shaping and honing only a true expert can provide - all which allowed this project to come to fruition. I would like to thank my major professor, Dr. Robert Malow for his guidance, practical knowledge and support through a long and demanding process. I would also like to thank Dr. Jessy Devieux, Dr. Jesus Sanchez and Dr. Dorothy Brooten for their encouragement, patience, and willingness to show support and provide direction. I would also like to thank Dr. H. Virginia McCoy, who has been a great force in my entire public health education, helping me to formulate a broader, more research-based approach to my professional and academic career. Lastly, I thank Dr. Michele Ciccazzo for her committed support, attention to detail and persistence in making sure this dissertation not only met University standards, but also that it met my own "personal best" standards. 


\title{
ABSTRACT OF THE DISSERTATION \\ THINK BEFORE YOU EAT: CALORIES AND EXERCISE EQUIVALENTS PRESENTED ON MENUS AT POINT-OF-CHOICE
}

\author{
by \\ Charles Stuart Platkin \\ Florida International University, 2009 \\ Miami, Florida \\ Professor Robert Malow, Major Professor
}

Although calorie information at the point-of-purchase at fast food restaurants is proposed as a method to decrease calorie choices and combat obesity, research results have been mixed. Much of the supportive research has weak methodology, and is limited. There is a demonstrated need to develop better techniques to assist consumers to make lower calorie food choices. Eating at fast food restaurants has been positively associated with weight gain. The current study explored the possibility of adding exercise equivalents (EE) (physical activity required to burn off the calories in the food), along with calorie information as a possible way to facilitate lower calorie choice at the pointof-choice in fast food restaurants. This three-group experimental study, in 18-34 year old, overweight and obese women, examines whether presenting caloric information in the form of EE at the point-of-choice at fast food restaurants, will lead to lower calorie food choices compared to presenting simple caloric information or no information at all. Methods: A randomized repeated measures experiment was conducted. Participants ordered a fast food meal from Burger King with menus that contained only the names of the food choices (Lunch 1). One week later (Lunch 2), study participants were given one 
of three menus that varied: no information, calorie information, or calorie information and EE. Study participants included 62 college aged students. Additionally, the study controlled for dietary restraint by blocking participants, before randomization, to the three groups.

Results: A repeated measures analysis of variance was conducted. The study was not sufficiently powered, and while the study was designed to determine large effect sizes, a small effect size of .026, was determined. No significant differences were found in the foods ordered among the various menu conditions.

Conclusion: Menu labeling alone might not be enough to reduce calories at the point-ofchoice at restaurants. Additional research is necessary to determine if calorie information and EE at the point-of-choice would lead to fewer calories chosen at a meal. Studies should also look at long-term, repeated exposure to determine the effectiveness of calories and or EE at the point-of-choice at fast food restaurants. 


\section{TABLE OF CONTENTS}

CHAPTER

PAGE

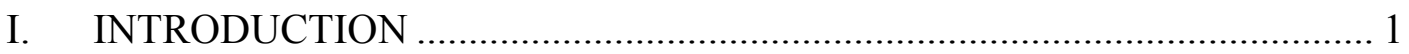

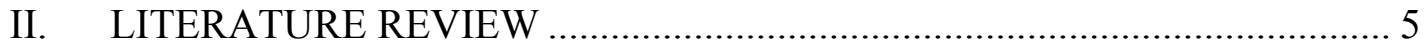

Food-Away-From-Home and Obesity ………………………….............. 5

Fast Food Restaurants ................................................................................... 7

Effectiveness of Nutrition Labeling ............................................................... 7

Effectiveness of Menu Labeling, Point-of-Sale and Point-Of-Choice

Nutritional Information ............................................................................ 11

Point-of-Purchase, Point-of-Choice and Food-Away-From-Home................. 13

Exercise Equivalents and Calories at Point-of-Purchase ................................ 20

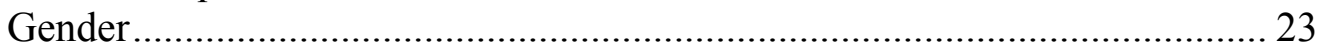

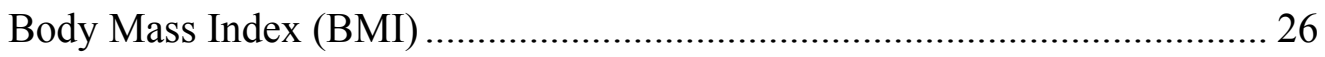

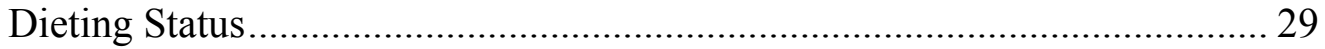

Activity Level ..................................................................................... 29

The Information-Motivation Behavioral Skills Conceptual Framework........ 31

Research Questions and Hypothesis ................................................................ 33

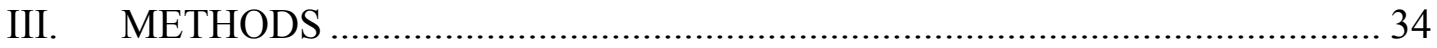

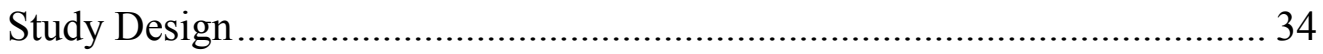

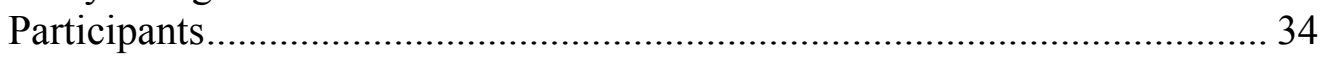

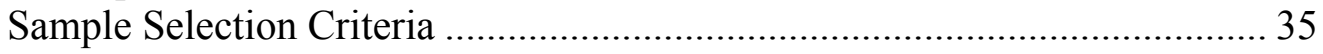

Recruitment and Randomization................................................................. 36

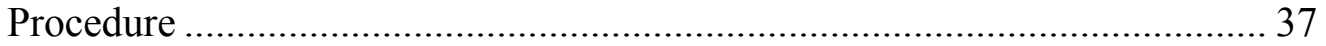

Confounding Variables And Random Assignment …………........................ 42

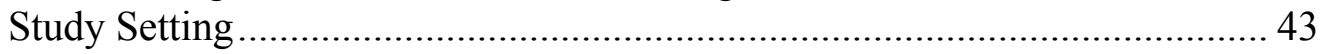

Data Collection ........................................................................................ 44

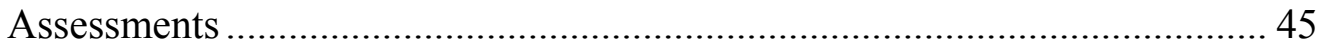

Instruments and Measurements................................................................ 45

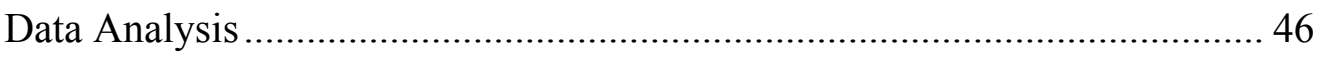

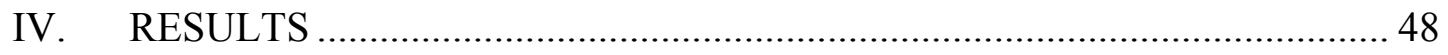

Participant Characteristics ..................................................................... 48

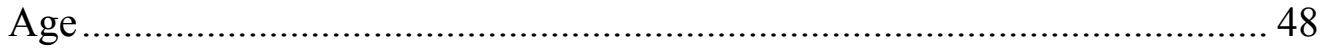

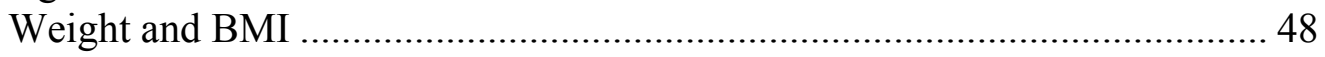

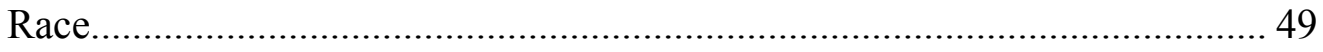

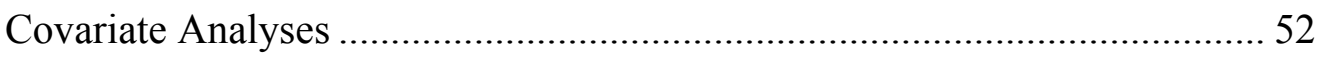

Physical Activity Reporting ........................................................................ 54

Restrained and Unrestrained Eaters as Covariates........................................ 55

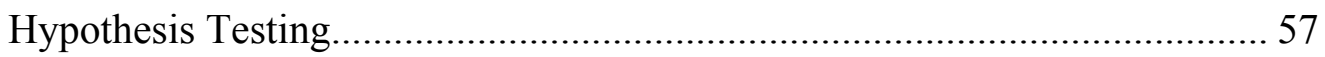

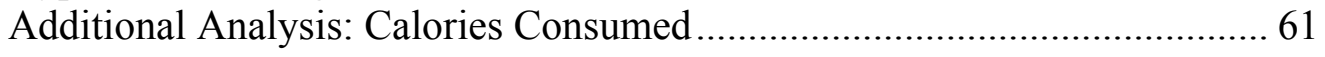


Additional Analysis: High to Low, Low to High, Same Foods Chosen......... 62

Additional Analysis: Number of Items Chosen ......................................... 63

Post-Hoc Analysis of Fast Food and Burger King Frequency....................... 64

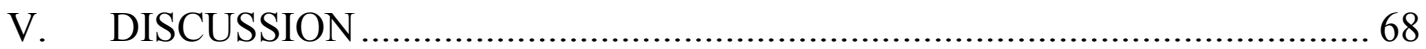

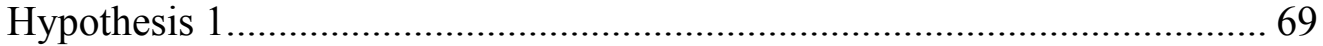

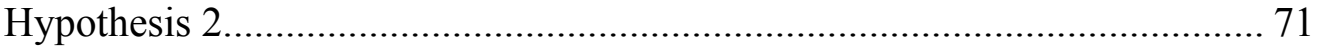

Additional Analysis: Calories Consumed ................................................... 72

Additional Analysis: Number of Items Chosen ......................................... 73

Additional Analysis: High to Low, Low to High, Same Foods Chosen......... 73

Activity Level ...................................................................................... 74

Post-Hoc Analysis of Fast Food and Burger King Frequency..................... 74

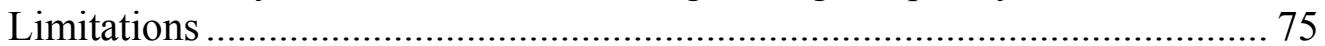

Power and Effect Size ...................................................................... 79

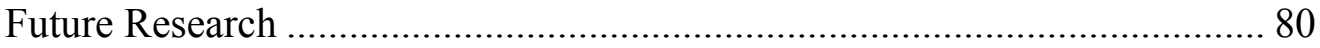

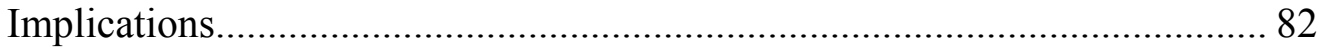

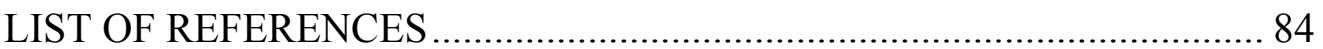

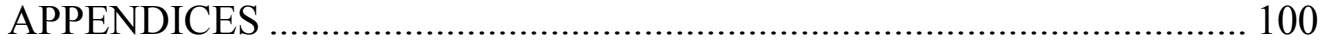

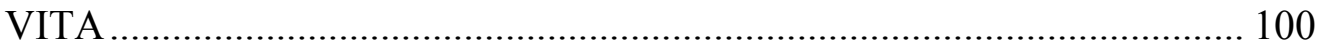




\section{LIST OF TABLES}

TABLE

PAGE

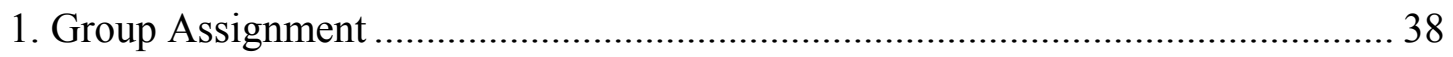

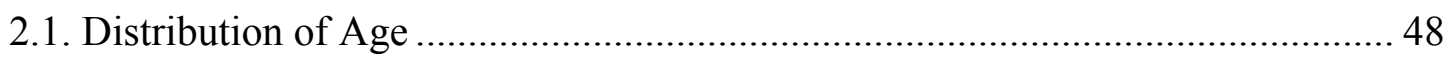

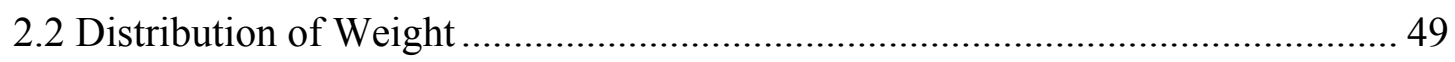

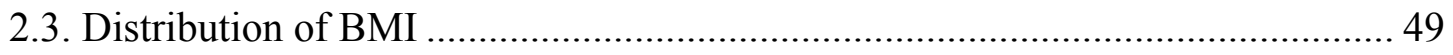

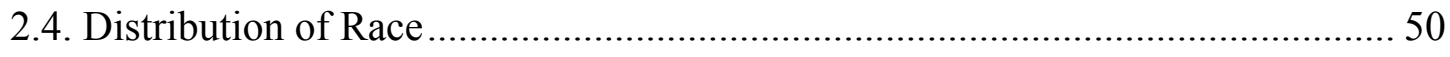

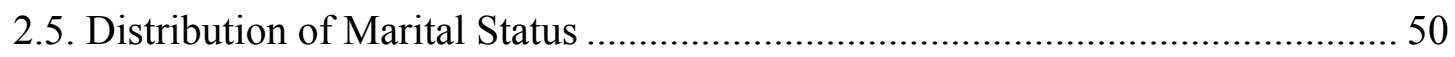

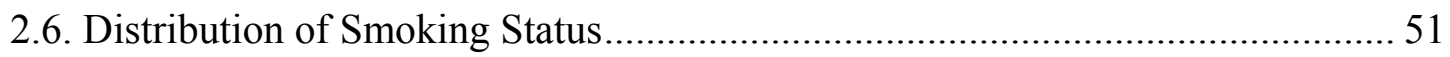

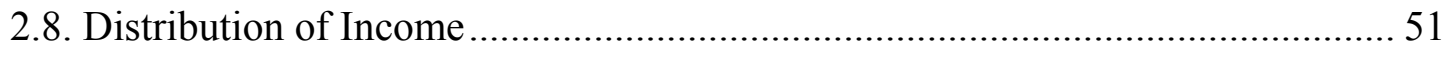

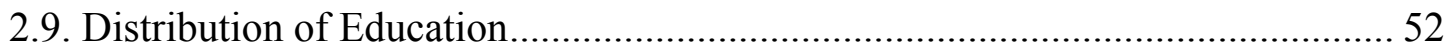

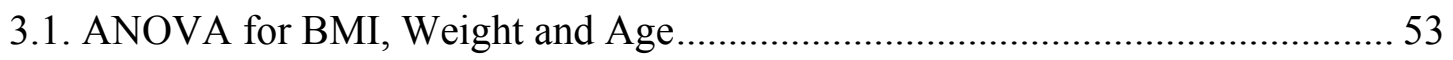

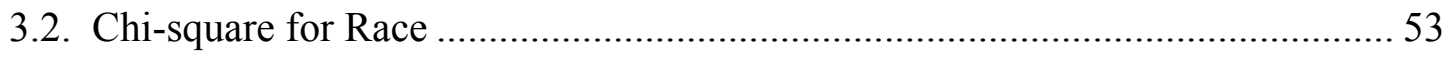

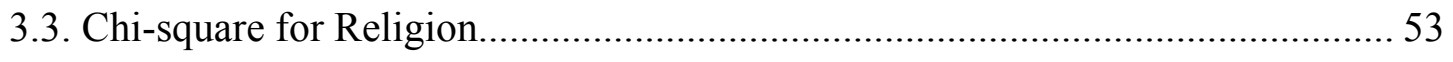

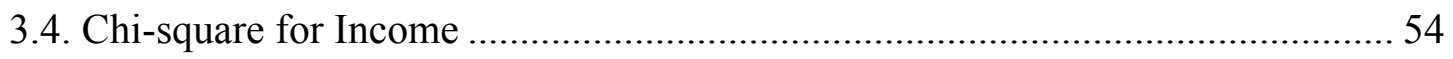

3.5. Chi-square for Education ............................................................................. 54

4.1 IPAQ Questionnaire (Physical Activity) ……………….................................... 54

4.2. Physical Activity Questions in Demographic Questionnaire................................. 55

5.1. Frequencies for Restrained vs. Unrestrained Eaters ........................................... 55

5.2. Frequency of Restrained and Unrestrained Eaters for 3 Groups ......................... 56

5.3. T-tests for Calories Chosen by Restrained/Unrestrained Eaters............................ 56

5.4. T-tests for Calories Consumed by Restrained/Unrestrained Eaters...................... 57

6. Lunch 1 and Lunch 2 Mean Calories and Std. Error of the Mean for Groups........ 58 
7. Descriptive Statistics Restrained and Unrestrained Eaters by Group .................... 60

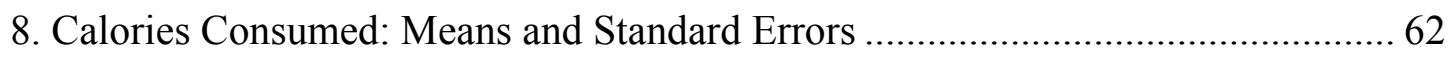

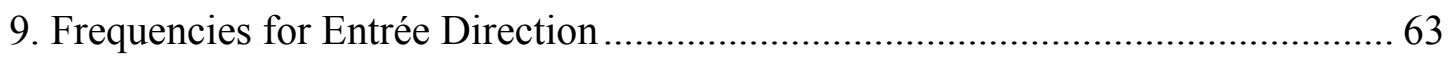

10. Number of Items Chosen from Lunch One and Lunch Two for No Information,

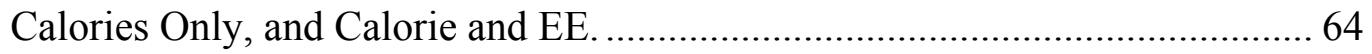

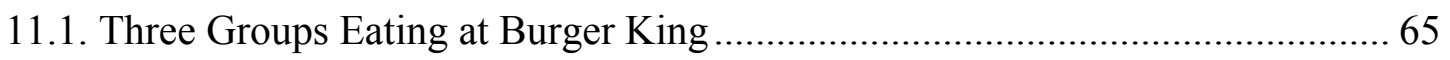

11.2. Three Groups Eating at Fast Food Restaurants.............................................. 65

11.3. Restrained and Unrestrained Eaters Eating at Burger King............................. 66

11.4. Restrained and Unrestrained Eaters Eating Fast Food................................... 66

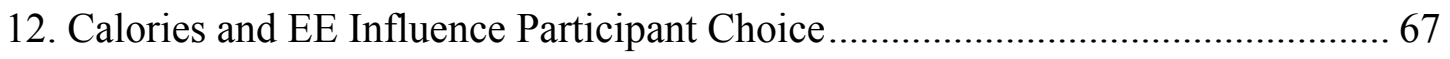




\section{ACRONYMS AND ABBREVIATIONS}

\begin{tabular}{|c|c|}
\hline ANOVA & Analysis of variance \\
\hline $\mathrm{BK}$ & Burger King \\
\hline BMI & Body Mass Index \\
\hline $\mathrm{CDC}$ & Centers for Disease Control and Prevention \\
\hline $\mathrm{EE}$ & Exercise equivalents \\
\hline FDA & Food and Drug Administration \\
\hline FIU & Florida International University \\
\hline IMB & Information Motivation Behavior \\
\hline IPAQ & International Physical Activity Questionnaire \\
\hline IRB & Institutional Review Board \\
\hline LMM & Linear Mixed Model \\
\hline METS & Metabolic equivalents \\
\hline $\mathrm{NCHA}$ & National College Health Assessment \\
\hline NHANES & National Health and Nutrition Examination Survey \\
\hline NLEA & Nutrition Labeling Education Act \\
\hline PASS & Power Analysis and Sample Size \\
\hline RMANCOVA & Repeated measures analysis of covariance \\
\hline RMANOVA & Repeated measures analysis of variance \\
\hline SPSS & Statistical Package for the Social Sciences \\
\hline TFEQ & Three Factor Eating Questionnaire \\
\hline
\end{tabular}




\section{CHAPTER I \\ INTRODUCTION}

Currently, as many $66 \%$ of Americans are considered overweight and 32\% are considered obese (Flegal, Carroll, Ogden, \& Johnson, 2002; Ogden, Carroll, Curtin, McDowell, Tabak, \& Flegal, 2006). According to the World Health Organization (1997), obesity is defined as a body mass index (BMI) above $30\left(30 \mathrm{~kg} / \mathrm{m}^{2}\right)$, while overweight is defined as a BMI above $25\left(25 \mathrm{~kg} / \mathrm{m}^{2}\right)$. Morbid obesity occurs at a BMI above 40 $\left(40 \mathrm{~kg} / \mathrm{m}^{2}\right)$. Obesity is associated with increased risk for cardiovascular disease, diabetes, certain types of cancer, and depression, as well as discrimination and weight-related bias (Katz et al., 2005).

According to the most recent Behavioral Risk Factor Surveillance System, obesity in $18-34$ year olds has increased from a median of $7.4 \%$ in 1990 to $16.5 \%$ in 2002 . This group has seen the largest increase in overweight and obese categories (Centers for Disease Control and Prevention, 2006). Young adults, particularly college students are at risk and represent an important group to study because approximately $70 \%$ of students gain a significant amount of weight between the start of college and the end of sophomore year, which may have an impact on overweight and obesity in adulthood (Racette, Deusinger, Strube, Highstein, \& Deusinger, 2005). However, approximately $58 \%$ of college aged women and $33 \%$ of college aged males are interested in losing weight (National College Health Assessment (ACHA-NCHA), 2007).

A major issue in eating a healthy diet is being able to read a nutrition label and understand its meaning. Past research suggests that although consumers look at labels, the 
actual use of nutrition labels during food purchase is much lower than expected (Cowburn \& Stockley, 2005). A review of more than 103 papers on food labeling found that while consumers are able to find and understand simple information using the nutrition label, label comprehension is reduced as the task becomes more complex (Cowburn \& Stockley, 2005). Some consumers use the nutrition label to make better choices such as decreasing fat or increasing fruit, vegetable and fiber consumption. Kreuter and colleagues (1997) found that those with high blood pressure were more likely to reduce sodium intake, and those with high cholesterol were more likely than those with normal or low cholesterol to look for saturated fat and cholesterol on the label. Also, those with food allergies (e.g., peanuts, milk, eggs, gluten) often use labels to determine the safety of the food before consumption. However, there is a demonstrated need to develop better techniques to assist people in making lower calorie food choices, particularly among the average consumer.

One such technique might be the use of exercise equivalents at the point-ofchoice. For the purposes of this study, exercise equivalents are defined as the amount of activity needed to burn off foods after an individual expends the calories needed for daily subsistence (Trumbo, Schlicker, Yates, \& Poos, 2002). Exercise equivalents are based on metabolic equivalents or METS, which is a commonly used method for demonstrating the energy cost of physical activity (Byrne, Hills, Hunter, Weinsier, \& Schutz, 2005). METS tables for various physical activities were defined and developed by the American College of Sports Medicine (Ainsworth et al., 1993; Ainsworth et al., 2000). Metabolic equivalents are a generalization of calories burned by physical activity. There is only one additional variable needed for its calculation - the weight of the individual (e.g. 150 
pound person burns more calories than a 120 pound person per hour according to METS).

However, METS can vary by as much as 20 percent among individuals of the same weight (Byrne, Hills, Hunter, Weinsier, \& Schutz, 2005).

It has also been reported that METS can vary from the standard for those with coronary heart disease (Kwan, Woo, \& Kwok, 2004) and those who are elderly (Savage, Toth, \& Ades, 2007). However, exercise equivalents could be a useful tool to help people understand what a calorie means in order to be able to decide which calories are "worth it." In fact, the Food and Drug Administration (FDA) Commissioner, when discussing nutrition labels and the health consequences of diet, stated, "People shouldn't need a calculator or an advanced degree in math or nutrition to calculate what makes a healthy diet .... So we have to find a way to make the key information we require to be placed on individual food products easier for consumers to understand and use from the standpoint of what constitutes a healthy meal and a healthy diet" (McClellan, 2003, p. 1). Using exercise equivalents on food labels and food served away from home could provide consumers with a context for the term, "calorie." For instance, here are a few examples of exercise equivalents for an individual who weighs approximately 155 pounds: 1 Double Stuf Oreo cookie $=18$ _minutes of walking; 1 handful of chips $=26$ minutes of dancing; 1 slice of chocolate cake $=88$ minutes of walking; 1 candy bar $=32$ minutes of swimming; 1 soda $=48$ minutes of yoga; 1 tablespoon of butter $=26$ minutes of walking (Ainsworth et al., 2000).

Exercise equivalents could potentially simplify the food and/or restaurant nutrition label, increase understanding of energy imbalance, and facilitate a decrease in overall energy intake. Additionally, it has been well documented and accepted that 
decreasing energy intake by as little as 100 calories per day and increasing physical activity could lead to significant weight loss (Hill, Wyatt, Reed, \& Peters, 2003; Brown, Williams, Ford, Ball, \& Dobson, 2005; Rodearmel, Wyatt, Stroebele, Smith, Ogden, \& Hill, 2007). Exercise equivalents at the point-of-choice with nutritional information could help individuals to achieve this 100 calorie per day differential. For instance, if an individual walked for 15 minutes per day, and reduced their lunch-time consumption by just 50 calories this goal could be achieved. 


\section{CHAPTER II}

\section{LITERATURE REVIEW}

Although genetics contributes to obesity, both weight loss and weight gain are directly related to energy (calorie) intake and expenditure. Weight gain occurs if more calories are consumed than are used, and weight loss occurs if more calories are used than consumed. Energy imbalance sits at the core of the obesity problem (Verduin, Agarwal, \& Waltman, 2005).

Nevertheless, there is still confusion among consumers regarding food messages (Carels, Harper, \& Konrad, 2006). Research shows that consumers are not effectively using the calorie information they are already receiving. As such, providing additional calorie information, regardless of format, may have no impact on the obesity problem (Krukowski, Harvey-Berino, Kolodinsky, Narsana, \& Desisto, 2006). One important step therefore might be to clarify and simplify nutrition information given to consumers.

Currently there is no research that explores the effect of calorie information and exercise equivalent information on food choice. This chapter will review the research literature on food purchase and choice, nutrition labeling and decision making. In addition, the factors that may influence individual choice about food choice and reading labels, such as gender and dieting status, will be covered to set the stage for the research questions that drive this study. 


\section{Food-Away-From-Home and Obesity}

In 1970 , Americans spent $26 \%$ of their food dollars on meals away from the home (Lin, Guthrie, \& Frazao, 1999). Today, however, Americans spend almost half (47.5\%) of their food dollars on foods outside the home (National Restaurant Association, 2007). "Food-away-from-home expenditures as a share of total food spending have risen steadily over the last several decades, whereas the share of food-at-home expenditures has fallen" (Variyam, 2005, p. 6). Americans who consume a "poor" quality diet based on the Healthy Eating Index tend to consume a greater proportion of their daily calories away from home than those with a "good" quality diet (Variyam, 2005).

Foods from restaurants and other food service establishments are generally high in calories and saturated fat and low in fiber and nutrients, such as calcium, as compared to home-prepared foods. Studies also link eating out to higher calorie consumption, overweight, and obesity in both adults and children (Wootan \& Osborne, 2006). In addition, it is not uncommon for restaurant entrees to contain one-half to one entire day's worth of calories, approximately 1100 to 2350 calories (Wootan \& Osborne, 2006). In addition, restaurants often serve large portions, increasing the likelihood that diners will consume more calories than they would at home (Diliberti, Bordi, Conklin, Roe, \& Rolls, 2004). Frequent consumption of restaurant food has also been associated with an increase in body fat in adults (McCrory, Fuss, Hays, Vinken, Greenberg, \& Roberts, 1999). Other research has shown that adolescent girls who eat quick-service food twice a week or more are likely to increase their relative BMI over time (Thompson et al., 2004). Many consumers are unaware of the high levels of calories, fat, saturated fat, and sodium found in many menu items. The provision of nutrition information on restaurant menus 
could potentially have a positive impact on public health by reducing the consumption of less healthy foods (Burton, Creyer, Kees, \& Huggins, 2006).

\section{Fast Food Restaurants}

Fast food restaurants have been positively associated with weight gain (Jeffery, Baxter, McGuire, \& Linde, 2006; Boutelle, Fulkerson, Neumark-Sztainer, Story, \& French, 2007). Additionally, eating at fast food restaurants is associated with higher fat and lower vegetable consumption (Satia, Galanko, \& Siega-Riz, 2004). Fast food consumption is also associated with a diet high in calories and may result in lower intake of healthful and important nutrients (Bowman \& Vinyard, 2004; Paeratakul, Ferdinand, Champagne, Ryan, \& Bray, 2003). Many of the top 10 foods contributing to energy intake in the U.S. population are served at fast food restaurants, including hamburgers, French fries, pizza, and soft drinks (Block, 2004).

As with warning labels on cigarettes, food calories and their exercise equivalents could potentially be important components of a comprehensive obesity control program in the U.S. (O'Hegarty, Pederson, Yenokyan, Nelson, \& Wortley, 2007). Exercise equivalents could create a reference point for consumers in terms of exercise and may help people decide whether they can "afford" to eat a certain food or not.

\section{Effectiveness of Nutrition Labeling}

Although there is no known research regarding the use of exercise equivalents at the point-of-choice, previous research examining the effects of information on food labels may offer some insight on the influence of this information on food choice. The Nutrition 
Labeling Education Act (NLEA) requires nutrition labeling for most foods (except meat and poultry) (Requirements of Laws, 1997). The labels are designed to promote and protect public health by providing nutrition information, thereby allowing consumers to make informed dietary choices (Thompson et al., 2004). However, even with the introduction of food labels, the country's obesity rate has increased significantly (Centers for Disease Control and Prevention, 2005).

Three-quarters of American adults report using food labels (U.S. Department of Health and Human Services, 2001). Ninety-five percent of college students in one study found the label to be useful and $70 \%$ looked at the nutritional label when purchasing a food for the first time (Marietta, Welshimer, \& Anderson, 1999). Kim, Nayga, and Capps (2000) found significant effects for nutrition label use; individuals had lower fat, cholesterol, and sodium intake, and higher intake of fiber. According to the research, the best predictor of food label use among college students was having a positive attitude towards labels and being female (Marietta, Welshimer, \& Anderson, 1999). A major limitation of this study, and many of the studies mentioned above, however, was the lack of a true experimental design.

Consumers may not be effectively utilizing nutrition information that is already available. In one study, for example, researchers reported that very few participants looked at labels for weight control purposes; in a community sample, $31 \%$ of participants looked at caloric information and in the college sample, $56 \%$ looked at caloric information. (Krukowski et al., 2006). As such, additional calorie information, regardless of format, may have no impact on the obesity problem (Krukowski et al., 2006). 
However, other research has shown that there have been some positive effects. Research has demonstrated that nutrition labeling helps reduce certain risk factors associated with disease, including lower intake of total fat, saturated fat and cholesterol (Neuhouser, Kristal, \& Patterson, 1999). Additionally, studies have shown that reading the nutrition label is connected with awareness of overall nutrition and maintaining a healthy weight (Lin, Lee, \& Yen, 2004). Reading labels has also been shown to be helpful for the socio-economically disadvantaged; in one study, minorities who read food labels had higher fruit and vegetable consumption and lower fat intake than those who did not read labels (Satia, Galanko, \& Neuhouser, 2005).

While many consumers do look at labels, the use of nutrition labels during actual food purchase is much lower (Cowburn \& Stockley, 2005). Cowburn and Stockley reviewed more than 103 papers on food labeling and found that labels might be difficult for consumers to use: "Most appear able to retrieve simple information and make simple calculations and comparisons between products using numerical information, but their ability to interpret the nutrition label accurately reduces as the complexity of the task increases" (Cowburn \& Stockley, 2005, p. 26). For instance, a consumer who is comparing the nutrition labels of a bottle of soda and a bottle of juice may note that one serving of soda has 200 calories and one serving of juice has 100 calories. However, the consumer may simultaneously fail to recognize that the juice contains 2.5 servings and the soda only one serving. As a result, the consumer may erroneously choose the bottle of juice as the "lower-calorie" choice when the soda, in fact, has fewer total calories (250 vs. 200 , respectively). 
Another important point to note is that nutrition labels are not read only by those attempting to control their weight. Consumers also use the nutrition label to make better choices when attempting to eat diets lower in fat, and increase fruit, vegetable and fiber consumption. For example, Kreuter and colleagues (1997) found that those with high blood pressure were more likely to reduce sodium intake because they looked at the labels to do so, and those with high cholesterol were more likely than those with normal or low cholesterol to look for saturated fat and cholesterol on the label. Also, those with food allergies (e.g., peanuts, milk, eggs, gluten) often use labels to determine the safety of the food before consumption (Simons, Weiss, Furlong, \& Sicherer, 2005). These data suggest that perhaps those with specific health issues are more likely to read and utilize labels.

Although designed to be helpful, the food label is often the target of criticism. Consumers believe food labels are difficult to read (Cowburn \& Stockley, 2005). Food label comprehension is also problematic; in one study by Rothman and colleagues (2006), participants were asked to examine food labels and asked to interpret and extract information from the labels (e.g., the caloric content of specific items). Other tasks involved asking participants to compare two foods using the food labels and determine which had more or less of a certain nutrient. Approximately $69 \%$ of participants were correctly able to answer these questions relating to food labels. "Common reasons for incorrect responses included misapplication of the serving size, confusion due to extraneous material on the food label, and incorrect calculations" (Rothman et al., 2006, p. 391). Other research has shown a lack of effectiveness where a combination of both education and labeling in supermarkets failed to reduce fat intake (Steenhuis, van 
Assema, van Breukelen, \& Glanz, 2004). Also, it is important to recognize that those who should read labels (e.g., those who are at increased risk for heart disease) often do not (Lin, Lee, \& Yen, 2004). However, “...consumer education can provide educational messages to motivate and to teach label use" (Lin, Lee, \& Yen, 2004, p. 1965).

Additionally, the label can be made simpler to understand and use (Rothman et al., 2006).

Effectiveness of Menu Labeling, Point-of-Sale and Point-Of-Choice Nutritional Information

The Nutrition Labeling and Education Act of 1990 (NLEA) explicitly exempts restaurants from most food labeling requirements (Wootan \& Osborn, 2006). Restaurants, unlike the manufacturers of packaged foods, are not required by the NLEA to provide nutrition information for a menu item or meal unless a nutrient content claim or a health claim is made for the item or meal. When such a claim is made, the restaurant need only provide information on the amount of the nutrient that is the basis of the claim (Menu Education and Labeling Act, 2007). Thus, for example, if a restaurant makes a nutrient content claim with regard to fat, for example that a particular menu item is low in fat, then the NLEA requirement is satisfied by noting, "low fat - provides fewer than 3 grams fat per serving." The restaurant may provide information about the nutrient for which the claim is made in various ways, including in brochures. In other words, restaurants need not provide such information on the menu or menu board (U.S. Food and Drug Administration, 2004).

Currently, most fast food establishments offer nutrition information on menus online but only a few do so with brochures or posters inside the restaurant. However, 
many of the socio-economically disadvantaged, who tend to be more obese (Kersh \& Morone, 2002), do not have Internet access, and thus do not have access to the site or the guidelines (Johnston, 2005; Mitka, 2005). The fact that this information is not available on-site at restaurants may be due to lack of interest in nutrition information, possibly influenced by socio-economic status and education related to food choices. Lack of information may also be due to the type of decision-making that goes into making these food choices. Even though many fast food chains do publish nutrition information, many do not have the information available at the point-of-purchase (Wootan, Osborn, \& Malloy, 2006).

Nutrition information is not readily available at many family-style and casual dining restaurants (e.g., Olive Garden, Red Lobster, Outback). While the number of restaurants providing nutrition information has increased over the last 10 years, making informed and healthful food choices is still hindered by the lack of nutrition information at many restaurants; only $44 \%$ of the largest chain restaurants in the country provide nutrition information for the majority of their menu items (Wootan \& Osborn, 2006). Additionally, at the point-of-purchase only $0.1 \%$ of participants $(\mathrm{n}=4311)$, accessed nutritional information at chain restaurants (Roberto, Agnew, \& Brownell, 2009). Policy makers and health advocates are also discussing the possibility of adding an icon on labels and menu boards that signals more healthful options (Lando \& Labiner-Wolfe, 2007). The addition of icons, however, could create the opposite of the expected reactions, because many consumer relate so-called healthier options with foods that lack taste (Aaron, Evans, \& Mela, 1995). 


\section{Point-of-Purchase, Point-of-Choice and Food-Away-From-Home}

Data gathered after the implementation of the NLEA indicates that menu labeling and point-of-sale nutrition information might be effective at reducing caloric intake and increasing healthy eating behaviors, e.g., lower saturated fat and sodium intake (Variyam, 2005). The city of New York passed a law requiring all restaurants with 15 units or more operating within city limits to post caloric information directly on menu boards or menus. The rationale: "By requiring posting of available information concerning restaurant menu item calorie content, so that such information is accessible at the time of ordering, this Health Code amendment will allow individuals to make more informed choices that can decrease their risk for the negative health effects of overweight and obesity associated with excessive calorie intake" (Department of Health and Mental Hygiene Board of Health, 2008, p. 2). According to a press release accompanying the action, "The Health Department estimates that this regulation could reduce the number of people who suffer from obesity by 150,000 over the next five years, preventing more than 30,000 cases of diabetes" (Department of Health and Mental Hygiene, 2008, p. 1).

New York City was one of the first major urban markets to institute such a law. Recently, however, the state of California (California Health and Safety Code, 2009) as well as the United Kingdom (U.K. Foods Standards Agency, 2009) passed menu labeling laws. These laws are now being considered in several states within the United States (Center for Science in the Public Interest, 2009).

Studies related to point-of-purchase effectiveness at reducing calorie choices are mixed, at best. In one study among United States military personnel, participants were exposed to calorie, fat and cholesterol information on 3" x 5" cards next to 
the foods, along with colored posters promoting healthier choices in the cafeteria. The researchers found no relationship between point-of-purchase nutritional information and healthier eating (Sproul, Canter, \& Schmidt, 2003).

Another study recruited 65 participants for an experimental condition (40 males and 25 females) and 25 controls ( 16 males and 9 females) in a university setting (Aaron, Evans, \& Mela, 1995). The researchers prepared laminated labels (approximately $8 \mathrm{x} 8$ $\mathrm{cm}$ ) for each food item, showing numerical and color graphic information for the calorie content of the food for the experimental condition. The experiment was carried out over a period of two consecutive weeks at the main campus cafeteria. In the first week, a sign was posted that indicated that nutritional information was forthcoming. During the second week, the laminated labels were posted by the foods. The participants were asked to report what they ate, and to rate their feelings of hunger.

The results revealed that the caloric intake of the experimental group increased after the nutritional information was placed on the food items. The authors speculated that this outcome might have been due to a "...belief that such [healthy] foods will be of inferior sensory quality and less satiating, lack of motivation and interest, a poor choice of healthier options, and the negative effect of peer pressure" (Aaron, Evans, \& Mela, 1995, p. 1259). Furthermore, by asking the experimental group specific questions about hunger and food, the researchers hypothesize that the questioning could have created a bias within the group (Aaron, Evans, \& Mela, 1995).

Other studies have also shown that participants chose to eat foods with a greater number of calories after caloric information was provided at the point-of-purchase. For example, Yamamoto and colleagues (2005) evaluated the effect of calorie information on 
restaurant food choices in a sample of adolescents $(n=106)$. Each participant was asked to order a meal from three different restaurant menus, McDonald's, Panda Express, and Denny's. Researchers recorded choices and then showed participants menus with calorie and fat information. After viewing the calorie and fat information, participants were asked if they would like to modify their order. If they wanted to change, the new order was taken. Approximately $17 \%$ of the orders were changed in response to the calorie and fat information. Among the meals that were modified, 20.4\% resulted in an increase in the number of calories.

In another study, 594 adolescents and adults viewed fast food menus to determine if calorie labeling on the menu would have any effect on calorie intake. Researchers created two sets of menus designed to be similar to fast food menu boards - one with calorie information and one without. After participants placed their orders, the researchers drove to a nearby McDonalds, purchased the food, and brought it back for the participants to eat. The researchers did not find significant effect by providing caloric information at point-of-purchase on a fast food menu. The main limitation of this study was that participants were exposed to the experimental condition only once and, as a result, there was no baseline data (Harnack et al., 2008).

However, there are interventions that have demonstrated success in increasing healthier food choices by using point-of-purchase collateral. For instance, researchers were able to increase healthful snack selection in a college food service setting by using point-of-purchase messages placed on 11" x 17" posters located at the cafeteria entrance and two 4" x 2.5" signs placed next to the targeted food item (Buscher, Martin, \& Crocker, 2001). The messages emphasized the "budget-friendly, 
energizing, sensory/taste, time efficient/convenient (best) stimulus properties of [the targeted] food" (p. 909).

A study by Bergen and Yeh (2006) focused on college vending machines and examined the effects of an environmental intervention promoting more non-energycontaining beverage consumption compared to sugar-sweetened soft drink consumption over a period of nine weeks. The researchers labeled eight vending machines with three conditions: a no calorie, no carb label; label plus motivational poster encouraging the purchase of water and no calorie drinks; and a control group. The no calorie, no carb with motivational posters, resulted in fewer sugared beverage sales.

In a study by Edwards and Meiselman (2005), participants were observed in a public university restaurant while they were assisted with their food choice by a server who made a positive, negative or no statement about the popularity of a selected dish. When the meal was completed, the participants were asked to rate the "acceptability" of the dish chosen using a nine-point hedonic scale. The researchers found that only the negative statements made by servers actually influenced food choice; positive statements about the food items did not increase the number of people who chose that food item. However, in all conditions, once participants had chosen a dish, the participants' perception of the "acceptability" of the dish remained unchanged. That is, participants rated their chosen dishes favorably, regardless of what comments had been made about it prior to selection (Edwards \& Meiselman, 2005).

A study at a Dutch worksite that included labeling of high and low fat foods revealed a beneficial and significant intervention effect of the labeling program on total fat intake for respondents who believed they ate a high-fat diet. Sales data revealed a 
significant number chose fewer desserts; there was no effect for the other products. (Steenhuis, Van Assema, Van Breukelen, Glanz, Kok, \& De Vries, 2004).

Additionally, Seymour, Yaroch, Serdula, Blanck, and Khan (2004) completed a review of point-of-purchase interventions and found, "Overall, simply providing information in the restaurant setting appears to be associated with increased purchase of targeted items ..." (Seymour et al., 2004, p. S117). When considering the effectiveness of point-of-sales interventions, it should be noted that taste and cost might be more important components of food choice than nutritional concerns (Glanz, Basil, Maibach, Goldberg, \& Snyder, 1998).

In a point-of-purchase study conducted at a large supermarket in Finland, the researchers grouped the healthier foods together in the shelves under a sign reading, "The Healthier Choice." The study was done over six months and included weekly ads in the local paper; however, baseline data was only recorded for two weeks prior to the start of the study. The program was not successful in increasing the sales of healthier products. This study and some of the others referenced above demonstrate that simply presenting people with more dietary knowledge does not necessarily precipitate a change in behavior (Nayga, 2000).

Researchers at Pennsylvania State University (Cranage, Conklin, \& Lambert, 2005) recruited 150 participants to eat lunch at an on-campus café and offered participants the same menu options over a two-week period. Although there were salads, appetizers and other foods available, the researchers had nutritional information available for the entrees only. The data was collected on the same two days of the week for the control period and the treatment period. The nutrition information was presented in the 
same style as the Food and Drug Administration's Nutrition Facts panel, but printed on a 5" x 8" card. During the control period, 108 higher-fat, higher-calorie entrees were purchased along with, 54 lower-fat, lower-calorie entrees. During the treatment period, when nutrition information was displayed, 72 higher-fat, higher-calorie entrees and 81 lower-fat, lower-calorie entrees were purchased, demonstrating a significant reduction in higher calorie entrees. The study also showed that “...placing this information prominently at places where food choices are made, seems to raise expectations and lower disappointment, resulting in higher satisfaction with food quality, higher intentions to repurchase and selection of healthier foods" (Cranage, Conklin, \& Lambert, 2005, p. 54-55). The researchers concluded that allowing participants to make informed choices, by giving them nutritional information, "provides empowerment" and a way to make autonomous decisions about food choices.

There are several issues with this study. There was a control period but no control group therefore the participants could have been biased. For instance, external factors, such as a university-wide media campaign might have altered food choices. Also, the researchers did not review total calories chosen but instead noted whether lower calorie choices were made compared to higher calorie items. As a result, it is unclear how many calories were actually saved and if those saved calories were substantial and significant enough to improve overall diet and promote participant weight loss. Also, while portion size is a critical factor in controlling weight, many of the lower-calorie entrees were also smaller in size than the higher-calorie entrees. Smaller entrees might have resulted in greater post-meal eating by the participants, thus eliminating any potential gain from posting the nutritional information. 
Several recent studies have examined the impact of calories at the point-ofpurchase using menus. One study recruited 288 college students; some of the students received fast food menus with calorie information for each food item, whereas others received no information at all (Gerend, 2009). The researcher examined the effects of caloric information versus no information. While there were no effects for men, women who received calorie information chose meals that had 146 fewer calories per meal than women who did not receive calorie information.

In a study by Bassett et al (2008), Subway customers (N=1830) in New York City who saw caloric information chose meals with an average of 52 fewer calories (mean calories: 765.5 vs. $713.8, \mathrm{p}<.01$ ) than customers who said they did not see the caloric information. Thirty-seven percent of Subway customers reported seeing caloric information and stated that it affected their purchases; those customers chose 99 fewer calories than those who saw the information and reported it had no impact (mean calories: 647 vs. $746 ; \mathrm{p}<.001)$.

However, the concept of calorie information and perception of "healthier foods" does not always lead to calorie understanding. In a study at Cornell, researchers intercepted 300 customers as they finished their lunches at McDonald's or Subway (Chandon \& Wansink, 2005). The participants were asked to estimate the number of calories that they had just consumed. Customers at McDonald's consumed approximately 710 calories and estimated an intake of 670 calories, whereas those at Subway ate 560 calories but estimated 335 calories. In this case, individuals who ate at Subway assumed they had a larger "calorie budget" (i.e., they assumed they could eat more) because foods at Subway were promoted as "healthier" and no point-of-sale nutritional information was 
provided (Chandon \& Wansink, 2005). If individuals eat more of a food choice because it is perceived to be healthy, it could potentially counteract the intended benefits of promoting healthier food choices (Chandon \& Wansink, 2005).

Research on calorie information at the point-of-purchase in restaurants has shown mixed results in terms of effectiveness (Harnack et al., 2009); one possible reason for this lack of effectiveness could be the lack of understanding of a value of a calorie or the lack of a reference amount for a calorie (Lichtman et al., 1992; Wansink \& Chandon, 2006). The Obesity Working Group commissioned by the Food and Drug Administration recommended that point-of-sale calorie information on menus for food-away-from-home would be the most helpful to consumers and could have a potentially positive effect on obesity (U.S. Food and Drug Administration, 2004). In addition, exercise equivalents could create a reference point for consumers. Knowing what a calorie means in terms of exercise may help people to understand whether they can "afford" to eat a certain food.

\section{Exercise Equivalents and Calories at Point-of-Purchase}

Providing exercise equivalents on food labels and menus could create an easilyunderstandable reference point for consumers with regard to the calorie (energy) content of foods. Anecdotal evidence from informal interviews with members of the news media and discussions conducted with website and column readers and informal polls indicate that consumers are surprised to learn the exercise equivalents of common foods, even though they might have a general idea of the number of calories in those particular foods. When a consumer visualizes that it takes three hours to walk off an ice cream cone and only 30 minutes to burn off a piece of fruit (Ainsworth et al., 2000), this theoretically 
creates a level of awareness of the "cost" of a food item. Sometimes the perceived benefits of the food item (such as taste, or social context) may still outweigh the negatives. At the very least, however, knowing the exercise equivalents of various foods may create an opportunity for the consumer to make an informed decision. Ultimately, knowledge of exercise equivalents could lead to lower calorie food choices.

Exercise equivalents may also help consumers understand the value and importance of calories. For example, knowing that one apple provides enough energy to keep walking for about 19 minutes (Ainsworth et al., 2000) can demonstrate to consumers that a calorie can be "friend or foe," depending on the circumstances and an individual's daily caloric budget (Trumbo et al., 2002). In fact, the FDA's Obesity Working Group reported a need for additional work on the current food label (U.S. Food and Drug Administration, 1999). The report made reference to suggestions from food manufacturers including the need for “...consumers be educated about calorie balance, possibly illustrated by pictorials on packages to correspond to energy expenditure activity equivalent to the calorie content of the food" (U.S. Food and Drug Administration, 1999, "Dietary and Health Context," para. 3).

While there is no research specifically discussing exercise equivalents and the impact of point-of-food choice, research suggesting that consumers often underestimate their energy consumption has been conducted (Lichtman et al., 1992; Wansink \& Chandon, 2006). A large body of research demonstrates the underreporting of food intake, which can range from 10 to $45 \%$ depending on the age, gender, and body composition of individuals in the sample population (Trumbo et al., 2002). Briefel, Sempos, McDowell, Chien, and Alaimo (1997) found that approximately $18 \%$ of men 
and $28 \%$ of women in their sample were under-reporters. Young adults are no exception; they also exhibit insufficient knowledge about the value of a calorie and have difficulty determining estimates (Schwartz \& Byrd-Bredbenner, 2006). In one study, for example, researchers recruited college undergraduates (60\% female), and showed these participants nine restaurant entrees. They gave participants serving size information, and brief descriptions. For each of the entrees the participants were asked to estimate calories and nutrient levels. The researchers classified the items from "very unhealthful" to "more-healthful." The accuracy of estimating the correct number of calories worsened as the entrees became increasingly more "unhealthful." On average, less healthful items were underestimated by more than 600 calories (Burton, Creyer, Kees, \& Huggins, 2006). However, the study did not look at the BMI, gender or dieting status of participants - all which could have an impact on these results.

Even among those who should have more knowledge about food values, errors of judgment are not uncommon. For example, in one study, registered dietitians underestimated their caloric consumption by $16 \%$ (Goris \& Westerterp, 1999). Another study testing the ability of registered dietitians to estimate calories found underestimates of calorie values by 200 to 600 calories (Backstrand et al., 1997). Other health professionals, including physicians and nurses, are not significantly better at making these estimates. In one study, $70 \%$ of the participants incorrectly estimated patients' calorie needs by more or less than 13\% (Ashley, Davidson, Wilkins, \& Thompson, 2004). However, the common assumption that heavier individuals are more likely to underestimate calories does not necessarily hold up under scrutiny. One study, for example, demonstrated that caloric underestimation is more related to meal size than 
body size. In fact, the larger the meal size, the more the participants underestimated the calories they consumed (Wansink \& Chandon, 2006).

It has been well documented and accepted that decreasing energy intake and increasing physical activity by as little as 100 calories per day could cause significant weight loss (Hill, Wyatt, Reed, \& Peters, 2003; Brown, Williams, Ford, Ball, \& Dobson, 2005; Rodearmel, Wyatt, Stroebele, Smith, Ogden, \& Hill, 2007). In fact, making small daily behavioral changes has a tremendous impact on reducing disease related to obesity (Hill, 2009). In one study of 8071 Australian women aged 45-55 years old who gained approximately $0.5 \mathrm{~kg}$ per year, researchers found that the energy imbalance, i.e., calories consumed compared to calories expended, was only 10 calories per day (Brown et al., 2005). Another study in China estimated the energy gap to be 45 calories per day (Zhai et al., 2008). Exercise equivalents at the point of choice with caloric information could help individuals to achieve the 100 calorie per day differential proposed by Hill and colleagues (2003). For instance, if an individual walked for 15 minutes per day, and reduced their lunch time consumption by 50 calories this goal could be achieved.

\section{Gender}

Research has determined that there are several factors that influence an individual's decision to engage in healthy eating behaviors. The remaining sections of this chapter will cover several of these, including gender, body mass index (BMI), whether an individual exhibits restrained or unrestrained eating behaviors, dieting status and activity level. These variables have been shown in the literature to have an impact on food choice and reading nutrition labels. 
A majority of studies have found that females are, in general, more likely than men to use nutritional labels (Drichoutis, Laziridis, \& Nayga, 2006). Additionally, females tend to take nutrition into consideration more frequently than males when making food choices. This discrepancy may be the result of a range of reasons, for instance, females are often the main meal planners, making more food decisions for the household (He, Fletcher, \& Rimal, 2004). Females may also be more likely to take nutrition into consideration because they are often more concerned about their weight than men. For example, in a study surveying the dieting practices of 185 female college students aged 18 to 24 , "the majority of participants (83\%) used dieting for weight loss and believed they would be $2 \%$ to $6 \%$ greater than current weight if they did not diet; normal weight, overweight, and obese groups perceived attractive weight to be $94 \%$, $85 \%$, and $74 \%$, respectively, of current weight" (Malinauskas, Raedeke, Aeby, Smith, \& Dallas, 2006, p. 1).

Nayga (2000) surveyed individuals at a supermarket in New Jersey using questions to determine nutrition knowledge and food label usage. For example, participants were asked which of two items contained more fat (e.g., sour cream versus yogurt; roast chicken leg versus fried chicken leg). Results suggested that, on average, males possessed less nutrition knowledge than females. However, this study also found that male and female consumers who possess the same level of nutrition knowledge do not differ significantly in their likelihood of food label use.

This study had several limitations. It was completed among supermarket shoppers, which may have skewed the sample. It did not discuss the time frame used to gather the information from recipients. Depending on the time of day of the observations, 
the type of the shopper could have been skewed, i.e., shoppers who were approached during the workday might have been disproportionately married female shoppers who were purchasing for their families. Indeed, one study reported that $67.2 \%$ of the women do the family shopping versus only $18.1 \%$ of the men (Beardsworth et al., 2002). Additionally, the males in this sample who were grocery shopping may potentially have more nutrition knowledge than other males who may have been approached at a different study location.

According to Beardsworth, Bryman, Keil, Goode, Haslam, and Lancashire (2002), women seem to be more engaged in efforts to lose weight and are more dissatisfied with their body weight, even though they have similar overweight and obesity rates compared to men. In this study, the researchers administered a survey at the person's home and found several key differences in gender attitudes towards food. For instance, women reported eating more fresh fruit and vegetables. Also, whereas $76.6 \%$ of the women indicated that they decided what foods to purchase for the household, only $15.3 \%$ of the men did so. When women and men were asked if they knew what foods they should eat to follow official recommended dietary guidelines, approximately $60 \%$ of the women said yes compared with $39 \%$ of the men. In terms of dissatisfaction with body shape, approximately $40 \%$ of the women were dissatisfied compared to only $23.9 \%$ of the men. Additionally, women were more likely to feel guilty than men about overeating (Beardsworth et al., 2002). 


\section{Body Mass Index (BMI)}

Individuals with a BMI equal to or greater than 25 and less than 40, indicating overweight and obese status, are of particular concern from a public health perspective because they are at increased risk for "cardiovascular disease, diabetes, certain forms of cancer, depression, discrimination and weight-related bias, and various other physical, psychological, and social morbidities" (Katz et al., 2005, p. 1).

Obese individuals tend to like more palpable and tasty foods, which are typically high-fat, high-sugar foods, compared with non-obese individuals (Salbe, DelParigi, Pratley, Drewnowski, \& Tataranni, 2004) and tend to choose more energy-dense meals (Cox, Perry, Moore, Vallis, \& Mela, 1999). These factors lead to a situation in which those who may already be obese continue on a cycle of high-calorie food choice, possibly due to lack of awareness or insufficient information regarding their choices.

\section{Restrained and Unrestrained Eaters}

The term dietary restraint is most often associated with calorie restriction, and has been defined as a voluntary and continuous effort to restrict calorie intake or to avoid high calorie foods or to exert cognitive control over eating (Sysko, Walsh, \& Wilson, 2007). Dietary restraint is generally defined as the conscious effort to limit and control dietary intake, typically for the purpose of reducing or maintaining body weight (Stunkard, 1981).

Short-term dieting is often referred to or confused with dietary restraint. However, dieting and restrained eating are not necessarily the same terms (Hawks et al., 2008; Lowe \& Timko, 2004). While restrained eating and dieting are certainly connected - 
they are not the completely interchangeable (French et al., 1997; Hawks et al., 2008). The weight of restrained dieters cycles more often than that of restrained non-dieters (Lowe \& Timko 2004). Moreover, restrained eaters who are dieting are more focused on weight control than restrained eaters who are not dieting (Boon et al., 1998). Additionally restrained dieters tend to be stable over time, meaning they are constant restrictors, whereas those who diet, tend to implement more short-term strategies and follow a more “structured regimen" (Hawks et al. 2008; French et al., 1999). And finally, restrained eaters tend to rely on external or environmental signals, and are less responsive to hunger cues (Fedoroff et al., 2003; Rotenberg et al., 2000).

Women are generally more restrained than men (Drapeau et al., 2004; Moreira et al., 2005). In order to reduce energy consumption, restrained women use strategic dieting behaviors and avoid more energy dense foods. When restrained eaters are faced with high calorie foods, internally their reaction is positive, but externally negative, meaning that while they have a high desire for the high calorie foods, they may not satisfy their desires. On the other hand, unrestrained eaters do not have as much of a desire to eat high calorie foods (Hoefling \& Strack, 2008).

In a cafeteria experiment, restrained eaters with calorie information (three lower calorie foods were identified with labels) were more likely to choose lower calorie foods compared to non-restrained eaters (Johnson et al., 1990). In another study, when restrained eaters were given what they thought was a "high-calorie" milk shake or a "low-calorie" milk shake (both milk shakes had the same number of calories) under both pre-load conditions, restrained eaters ate more cookies ad libitum than unrestrained eaters, and ate more when there was no pre-load (control). (Mills \& Palandra, 2008). 
Here, when restrained eaters were presented with low or high calorie forbidden foods, restrained eaters demonstrated disinhibited eating behavior.

It is possible that restrained dieters will eat more calories when they have calorie information and/or calorie plus exercise equivalents because they perceive the foods to be lower calorie than originally thought. For instance, when female restrained eaters were given information about fat-free chips versus regular chips, they ended up eating more of the fat-free chips than regular chips (but fewer overall calories). Female restrained eaters ate fewer chips, overall, when presented with no information (whether fat-free or regular) versus with information, although this was not statically significant (Miller et al., 1998). However, restrained eaters are more conscious and aware of food choices and will typically choose foods that are lower in calories in order to lose or maintain weight (Rideout, McLean, \& Barr, 2004). While there is some data to suggest that restrained eaters will have lower intake (Rideout, McLean \& Barr, 2004), there is also data which suggests that restrained eaters might eat more under certain circumstances (Miller et al., 1998). That said, under these particular conditions - calorie information and exercise equivalents at the point-of-choice of fast food during one meal-restrained eaters will likely choose fewer calories than those who are unrestrained. Thus, the influence of calorie information and exercise equivalents at the point-of-choice of fast food could influence these participants to choose fewer calories than those who are unrestrained eaters. 


\section{Dieting Status}

People who are dieting are often more sensitive to nutrition information than those who are not. They typically look for lower calorie foods such as low-fat cheese, low-fat margarine, vegetables and high-fiber bread while avoiding foods with high levels of sugar and fat (Borg, Fogelholm, \& Kukkonen-Harjula, 2004). However, many who anticipate restricting their dietary intake can end up actually over-eating. In a study by Urbsxat, Herman and Polivy (2002), two groups were assigned to a diet condition for one week and another group to a non-dieting condition for one week. Eating behaviors were then observed after one week. Those who were in the restricted diet condition ate significantly more cookies than those who were not dieting. The research suggests that simply thinking about going on a diet can trigger overeating in restrained eaters (Urbszat, Herman, \& Polivy, 2002). Given these findings, it is possible that presenting calorie information or calorie information with exercise equivalents may have the unintended effect of making those that are dieting eat more instead of less.

\section{Activity Level}

Exercise has been shown to have an impact on eating behavior. In one study examining the effects of exercise and dieting on eating behavior, 36 overweight women, were divided into two group conditions, exercise and no exercise, using a crossover design on two different days (Visona \& George, 2002). On the exercise day, the participants walked on a treadmill for 60 minutes. On both days the participants went to lunch and information on eating behavior was recorded. The dieting group and the non- 
dieting group consumed an additional 165 and 203 calories on the exercise day than on the no-exercise day, respectively.

Other studies have also examined the relationship between food and exercise. For example, in a study of university students, those who reported using exercise to lose weight or to keep from gaining weight were more likely than those who did not to eat more than five servings of fruits and vegetables per day and less than two servings per day of high-fat foods (Lowry, Galuska, Fulton, Wechsler, Kann, \& Collins, 2000). In another study, 12 participants were asked to exercise and the level of energy intake assessed; the results showed no overall change (Lluch, King, \& Blundell, 1997). Additionally, Koulouri, Tigbge, and Lean (2006) demonstrated that a simple increase in physical activity, such as an additional 2000 steps per day, did not result in an increase in food consumption.

King, Tremblay, and Blundell (1997) reported that there appears to be only "a weak short-term coupling between energy expenditure and energy intake" (p. 1076). In terms of food selection and the effects of physical activity, the researchers did not find any clear or reliable confirmation to indicate that bouts of exercise induced changes in preferences for food or nutrients in the short-term. However, they did find that with long-term exercise there was some increase in carbohydrate intake.

Given the contradictory findings, there is no clear inference that can be made regarding physical activity and food choice (Blundell et al., 2003). More specifically, there has not been any research on an individual's response to exercise equivalents in relation to their physical activity level. 
The Information-Motivation Behavioral Skills Conceptual Framework

The Information Motivation Behavioral Skills (IMB; see Appendix A) model has been used in various health promotion studies and interventions aimed at influencing lifestyle changes. For example, influencing lower calorie food choices must incorporate the ideas of information, motivation, and behavioral skills in order to effectively alter eating behaviors. The concepts pertaining to the IMB model are easily understood and are well supported by research in the area of risky sexual behaviors (Fisher, Fisher, \& Harman, 2003). However, It should be noted that, as applied to high risk sexual behaviors, the IMB model's effectiveness in reducing such behaviors has been limited and can only been interpreted within the context of a controlled trial (Fisher, Fisher, Misovich, Kimble, Malloy, 1996).

The framework behind this theory revolves around three concepts found in the title: information, motivation, and behavioral skills. With reference to eating behaviors, the information component helps individuals make lower calorie food choices when dining at a fast food restaurant. Choosing lower calorie foods at fast food meals may reduce the individual's likelihood of being overweight or obese, and thus reduce the risk of certain chronic diseases. This information must be relayed to the individual in an easy to translate, practical manner that is conducive and adaptable to their environment, and that takes their ethnic, religious, and cultural background into account.

The next concept to be addressed in this theory is the motivation factor. Motivation refers to the person's emotional response to the risky health behavior; in this case, eating foods that are high in calories. Personal motivation pertains to the individual's attitude and perception to make lower calorie food choices because of the 
individual's already existing desire to lose and control his or her weight (e.g., restrained eaters). However, motivation does not solely refer to restrained eaters; it may be important for any individual interested in looking better and/or feeling healthier (i.e., eating fewer calories and losing weight). Those individuals who are restrained eaters, however, will have increased motivation to choose fewer calories when presented with caloric information and exercise equivalents, compared to unrestrained eaters.

The final concept in the IMB theory is behavioral skills. Behavioral skills include being able choose lower calorie versus a higher calorie food items. For this study, behavior relates to the skills needed to choose meals that are fewer in overall calories.

This 3-group experimental research design was created by utilizing the framework of the IMB model. The information, motivation, and behavioral skills may lead to improved health outcomes which, in this study, translate to lower calorie food choices at fast food establishments. 


\section{Research Questions and Hypothesis}

Question \# 1: When presented with caloric information and exercise equivalents of fast food, at the point-of-choice, will overweight and obese women, ages 18-34, make lower calorie food choices compared to when only caloric information is provided or when no information is provided?

Question \# 2: When presented with caloric information of fast food and exercise equivalents, will this information have a greater impact on the food choices of 1834 year old, restrained overweight and obese women than on unrestrained overweight and obese women?

Hypothesis 1: When presented with caloric information and exercise equivalents of fast food, at the point-of-choice, overweight and obese women, ages 18-34, will make lower calorie food choices compared to when only caloric information is provided or when no information is provided.

Hypothesis 2: Presentation of caloric information of fast food, translated into exercise equivalents, will have a greater impact on the food choices of 18-34 year old, restrained overweight and obese women than on unrestrained overweight and obese women. 


\section{CHAPTER III}

\section{METHODS}

\section{Study Design}

The goal of this 3-group experimental study was to determine if calorie information and exercise equivalents, at the point-of-choice, would decrease calorie consumption of a fast food meal, among overweight and obese (Body Mass Index (BMI) equal to or greater than 25 and less than 40) 18-34 year old women recruited from a south Florida university campus. The Institutional Review Board of Florida International University approved this study. The study was conducted on the F.I.U. campus at the Graham Center from May 19, 2009 through May 29, 2009.

\section{Participants}

For this study, a total of 62 overweight or obese female participants, aged 18 to 34, were recruited. Participants were paid $\$ 5$ during the prescreening process to fill out questionnaires and to allow the researcher to weigh and get height data to establish BMI. Assuming an attrition rate of $10 \%$, this resulted in a minimum sample size of 48 participants. The statistical package PASS (Power Analysis and Sample Size) was used for power and sample size analysis. A priori power analysis indicated that a sample of size of 42 provided high power (greater than 90\%) for the treatment by time interaction under a variety of scenarios with a significance level of 0.05 . 
A random number generator was utilized to divide the three groups. Completed cases were defined as participants present at the two sessions in which the study is conducted; participants could not miss any of the sessions.

Attrition of participants was minimized mainly due to the short duration of the project, but a number of strategies were employed to ensure maximum participation. Several retention strategies included: a) Reminders: Participants' emails and cell phone numbers were taken, and they were reminded of the intervention dates so that they remembered to show up at the specified setting; and b) Incentives: Each participant had access to free lunch on the days of the intervention. In addition, a \$20 Target gift card was given as an incentive for each lunch they attend.

\section{Sample Selection Criteria}

Inclusion Criteria:

1. Must be able to read and speak English (to be able to fill out questionnaire, and read placards)

2. Age 18-34 years

3. Overweight or obese, Body Mass Index (BMI) equal to or greater than 25 and less than 40

4. Must have a signed consent form

5. Female

6. If students, not health majors

7. Agree to no cell phone, no reading, and no talking during meals

8. Must be available at designated times to eat lunch

9. Willingness to consent to the conditions of study participation

10. Must be willing to eat their typical breakfast and refrain from eating 2 hours before lunch.

11. Food may not be removed from study area

12. Occasionally eat fast food

Exclusion Criteria:

1. Participation in previous food-related study

2. Pregnant or having given birth within one year 
3. Anyone who needs to follow a special diet, as this may bias the results. (e.g., food allergies, Kosher diet, etc.)

4. Chronic diseases (e.g., heart disease, diabetes or having other dietary restrictions related to health)

5. Vegetarian

6. Self-reported depression

7. Self-reported chemical dependency

8. Self-reported and/or diagnosed eating disorder (i.e., anorexia, bulimia)

9. Dieting, currently or within the last three months

10. Those who do not typically eat lunch

\section{Recruitment and Randomization}

To generate interest, flyers and other promotional material were posted on electronic bulletin boards around the university, an electronic announcement was sent out, and researchers recruited individuals in person on the university campus. Professors from various classes (using researcher relationships) were also asked to make announcements regarding the study and its purpose. The recruitment process followed the following steps:

1. Participants were solicited from the university campus and told that the study being conducted would assess factors influencing eating habits at fast food restaurants.

2. Potential participants were asked to call a telephone number designated for study recruitment.

3. Initial telephone screening took place in order to determine inclusion and exclusion criteria. Potential participants' names were not asked, and as a result informed consent was not necessary. Using a recruitment script (e.g., age, height, weight, availability, do they typically eat lunch, occasionally eat fast food, plus all the exclusion questions), potential participants were screened.

4. Following the initial phone or in person screening, participants selected were asked to a research table. At this time consent forms were given to all potential participants to inform them of the study's purpose and objectives.

5. Participants with signed consent forms received a questionnaire packet including: Three Factor Eating Questionnaire (TFEQ; Stunkard \& Messick, 1988), International Physical Activity Questionnaire, and the 
6. Additional screening was reviewed based on information gathered.

7. A total of 62 participants were recruited to ensure a minimum of 42 total participants. During the recruitment process, the researcher tracked the control variable (Dietary Restraint). Sufficient numbers were interviewed to recruit 24 participants in the restrained group and 38 in the unrestrained group; these were then randomly assigned to Group A / Control, Group B / Intervention 1 or Group C / Intervention 2.

\section{Procedure}

\section{Overview}

- Recruitment (women, equal to or greater than 25 and less than 40 BMI, 18-34 years old)

- Participants enroll (BMI, 3-Factor, IPAQ, Demographics)

- Criteria met - 62 participants

- Block by restrained and unrestrained eaters -- Randomly assign to three groups (See Table 1)

- Group A / Control - No Information ( 9 restrained, 11 unrestrained)

- Group B / Intervention 1 - Calorie Information Alone ( 7 restrained, 15 unrestrained)

- Group C / Intervention 2 - Calorie Information plus Exercise Equivalents ( 9 restrained, 11 unrestrained)

- Week 1 -- Lunch 1

O Participants set appointments between 11:30 a.m. and 3:00 p.m.

- Participants from any group can eat any time -- (on the half hour)

- All participants receive only name of food items on menus

- Participants order food from menus

- Researcher gets food for participants

- Participants receive individual bags of food and eat food

○ Researcher weighs and measures leftover food and drink

- Week 2 -- Lunch 2

○ Participants set appointments between 11:30 a.m. and 3:00 p.m. 
- Participants eat at same time as chosen for Week 1 -- (on the half hour)

- Participants choose foods from menu -- Three menus

- Menu given to participant based on group assignment

- Group A / Control - Menus with No Information ( 9 restrained, 11 unrestrained)

- Group B / Intervention 1 - Menus with Calorie Information Only (7 restrained, 15 unrestrained)

- Group C / Intervention 2 - Menus with Calorie Information plus Exercise Equivalents ( 9 restrained, 11 unrestrained)

- Researcher gets food for participants based on menu choices

- Participants receive individual bags of food and eat food

- $\quad$ Researcher weighs and measures leftover food and drink

- Analyze data to assess if fewer calories chosen or eaten with Calorie Information vs. Calorie Information and Exercise Equivalents vs. No Information on menus

Table 1. Group Assignment

\begin{tabular}{|c|c|c|c|}
\hline & Lunch 1 & Lunch 2 & Outcome \\
\hline Group A & No Information & No Information & Difference \\
\hline Group B & No Information & Calorie Information & Difference \\
\hline Group C & No Information & $\begin{array}{c}\text { Calorie Information }+ \\
\text { Exercise Equivalents }\end{array}$ & Difference \\
\hline
\end{tabular}

All participants were asked to eat a total of two lunches at two sessions during a two-week period. (The first lunch / phase 1 recorded baseline data; the second lunch/ phase 2 measured change.)

The study controlled for dietary restraint using the Three Factor Eating Questionnaire (TFEQ; Stunkard \& Messick, 1988). Dietary restraint is generally defined as the conscious effort to limit and control dietary intake, typically for the purpose of reducing or maintaining body weight (Stunkard, 1981). Restraint scores (sub-scale) can range from 0 to 21 , with high scores indicating high dietary restraint. Restrained eaters 
are defined as those participants who have a score of 13 or above on the subscale related to retrained eating on the TFEQ (1988). In the current study, 24 restrained eaters and 38 unrestrained eaters were identified; participants were blocked by restraint and then randomly assigned to Group A / Control, Group B / Intervention 1 or Group C / Intervention 2.

After the participants were randomly assigned to two intervention and one control group (Calorie Information Only, Calorie Information Plus Exercise Equivalents and Control), baseline data were collected during the first lunch session.

Participants were asked to eat a typical breakfast and refrain from eating for two hours prior to the lunch session. Additionally, participants were asked to not use cell phones, talk or read during consumption. The participants had free choice of all menu items. The food choices were from Burger King located on the F.I.U. campus at Graham Center. The foods were in their original portion-controlled wrappers or packaging, which allowed the researcher to easily record choices made by participants. In order to blind participants to the menu manipulation aspect of the study, participants were told that the purpose of the study was to "better understand fast food meal choices."

During the baseline meal, participants were given a menu. The paper menus were in a similar format to menu boards at fast food restaurants. The food items were those available for lunch at Burger King on the dates of the experiment. The participants were able to choose entrées (e.g. Hamburger, Whopper, TenderGrill, BK Veggie Burger or TenderGrill), a garden salad, side dishes (i.e., fries, onion rings), condiments (ketchup, mayonnaise, fat free ranch dressing, or honey mustard dressing) and a drink (i.e., water, Coca-Cola, diet Coca-Cola, or apple juice). 
There was no additional information on the menu other than the names of food. That is, calorie information and exercise equivalents were not posted with the foods for the first baseline lunch. Lunches were served from 11:30 a.m. until 3:00 p.m. Participants made appointments based on their individual schedules at 30-minute increments. Upon arrival to the study location, participants were given a tag to wear with their individuallyassigned study number. The menus given to the participants were also marked with the participant's study number as well as their name. After participant orders were taken, a research assistant took the orders to the fast food restaurant, gathered the items, and within a 15-minute time frame, delivered the individually-wrapped meals, in bags, to participants for consumption. This procedure allowed participants from all three groups to come at various times during the study period, thus avoiding a system-time bias. All bags, as well as food and drink, were marked with the participant's assigned study numbered to easily identify the food and drinks they had ordered.

Participant seating was staggered (e.g., every other seat) in order to ensure privacy as each participant made her food choices. The participants ate their lunches at the study site. Each participant was asked to eat her food at a separate desk so she would not influence others' food consumption. All participants were told in advance that they would not be able to leave the study site with any left over food - this was to limit the possibility of participants ordering more food then they intended to consume.

During the next phase of the study, the three experimental groups received different information on their menus according to their randomized group assignment. In the second set of lunches (Lunch 2), the three groups received varying information. Group A / Control (No Information) was exposed to no information other than the food 
names on the fast food menu. Group B/ Intervention 1 (Calorie Information Only) was exposed to the calories on the fast food menu. Group C / Intervention 2 (Calorie Information plus Exercise Equivalents) was exposed to both Calorie Information and Exercise Equivalents on the fast food menu. Upon arrival to the study location, participants were given a tag to wear with their individually assigned study number. Participants made their menu selections and all food and drink choices were recorded on two menus. Duplicate menus were used to ensure that a copy could be kept by the researcher - each copy was reviewed by a second researcher to ensure they matched; the copy menu was used to order foods at Burger King. Lunches were served from 11:30 a.m. until 3:00 p.m. All procedures thereafter followed those of Lunch 1, other than the menu manipulation.

Although the researcher was primarily interested in the food choices, as part of an additional analysis, the researcher checked the waste on the trays to determine the level of consumption. The observer recorded the quantity of the food ordered and eaten by using a digital food scale, weighing the remaining portions and using a measuring cup for the liquids. The researcher ensured that all participants had finished eating and had left the study site prior to weighing and measuring left-over foods and drinks. Additionally, the researcher recorded items chosen by participants, and designated items as either low calorie or high calorie. The researcher then examined the total number of items chosen by each group to assess if there was a difference across time periods, as well as whether there was an increase in lower calorie foods chosen versus higher calories foods. Lower calorie foods were considered foods that are 360 calories or fewer -360 calories is the median (mean=376) of all Burger King foods (the foods used for this study). 


\section{Confounding Variables}

The intent of a randomized design is to produce group equivalence on potential confounding variables. However, because between-group equivalency may be critical to generalizing the results, selected variables described below were analyzed as possible confounds, as their covariance may influence the appropriate interpretation of intervention effects. If confounding variables were identified, they were included as covariates in the statistical models.

Socioeconomic status and education associated with food choice and the process of decision making are among many potential confounders to the study. 


\section{Study Setting}

The setting for the study was a college campus. A college campus was chosen because this group has seen the largest increase in overweight and obese categories (Centers for Disease Control and Prevention, 2006), and young people are at higher risk of becoming overweight or obese adults, (Racette, Deusinger, Strube, Highstein, \& Deusinger, 2005). The study took place in a controlled setting within the university, at a private conference room in the University's Graham Center. There was no cell phone use, talking, or reading during the observational period to limit distractions from the actual intervention tools.

\section{Training of Project Staff}

Four research assistants trained in the study protocol were involved in the development, implementation, and data collection procedures. To ensure that the project was implemented as planned, and to enhance the quality of the data collected, the research team underwent a training session prior to the implementation of the project. A meeting among research team members was held prior to the study to review (a) the study's conceptual framework and methodology, (b) the roles of the project team and project procedures, (c) observational techniques, (d) retention procedures, (e) responses to questions from participants, (f) general and project-specific ethical issues in conducting research, $(\mathrm{g})$ entering and recording qualitative data, and $(\mathrm{h})$ coding observational data for data analysis. A written protocol and standard operating procedure guide were used in this training, better ensuring standardization among the research 
assistants. The procedures and forms reduced bias among the researchers. Additionally, a pilot study was conducted prior to the actual experiment. A one day practice run was planned and executed where friends were used as participants. A total of eight participants were recruited. The pilot was scheduled for two hours during lunch time from $12-2$ PM. The room designated for the actual study was used. Pilot study participants were given one of three menus that varied: no information, calorie information, or calorie information and EE. From the pilot we were able to ensure the proper timing and coordination with the Burger King in the Graham Center at FIU. This also allowed the researcher to see if participants were able to read and understand the menus, create a series of rules that were specific to this particular study room, and facilitate the flow of food delivery to participant. The pilot also helped to facilitate the development of a number identification system for each participant as well as a system for monitoring food waste.

\section{Data Collection}

After informed consent was received from study participants, and before the first lunch session, the researcher explained the purpose, duration, and procedure of the study; participants had the opportunity to ask questions. Afterwards, they were given menus and asked to circle their food choices. The foods were the same at each weekly session. Each participant was asked to come back to the second lunch at the same period of time as her first session. The lunch sessions were administered over a two-week period; there were two lunch sessions. 
There were two intervention groups and a control group. Group A was the control group at the point-of-choice. Group B / Intervention 1 was exposed to displays of the calories at the point-of-choice. Group C / Intervention 2 was exposed to both calories and exercise equivalents at the point-of-choice. The participants' choices were observed by the principal investigator with the help of trained research assistants; the total caloric information was reviewed and analyzed for all sessions for all participants.

\section{Assessments}

Food choices for participants for the two lunch sessions were analyzed and total calories of the foods chosen were tallied by the researcher for each session, for each participant. The caloric information was taken from existing nutritional information provided on the fast food establishment's website (Burger King USA, 2009).

\section{Instruments and Measurements}

Dietary restraint was measured by Three-Factor Eating Questionnaire (TFEQ) which is a 51-question instrument designed to measure restrained eating (Stunkard \& Messick, 1988). Restraint scores (sub-scale) can range from 0 to 21, with high scores indicating high dietary restraint. Restrained eaters are defined as those participants who have a score of 13 or above on the subscale related to retrained eating on the TFEQ (1988).

Physical activity was assessed using the International Physical Activity Questionnaire (IPAQ) short form. The International Physical Activity Questionnaire (IPAQ) was developed as an instrument to assess physical activity and inactivity (Craig 
et al., 2003; Brown et al., 2004). The IPAQ was scored using total METS for activities recorded.

Body Mass index was assessed using a standardized height and weight measurement procedure as outlined in Third National Health and Nutrition Examination Survey (NHANES III) Anthropometric Procedures Manual. The manual contains the standardized anthropometric procedures used throughout NHANES III for the body measurement component of the survey. All researchers followed this procedure as outlined.

\section{Data Analysis}

Data were analyzed using a repeated measure linear mixed model (LMM) in SPSS. For the mixed model, the response variable was calories chosen. The predictors were: Intervention (3 levels), Restraint (2 levels), Time (2 levels) and their interactions. The mixed model included a random effect for subject. Intervention and Restraint were between subjects effects (can change only between subjects) and Time was a within subjects effect. Assumptions of the model were: (1) the response variable was continuous, (2) the residuals were normally distributed and (3) the subjects were independent. The total calories for food choices were determined for each meal at each lunch and compared to see if there was a difference in outcome. Frequencies, means and standard deviations were used to describe the data. ANOVA and Chi square tests were conducted with the demographic information to study relationships between potential covariates and the main outcome variable, calories chosen. Data for the three groups were compared at pre-assessment and one week later at post-assessment using a repeated 
measures analysis of covariance (RMANCOVA). Hypothesis 2 does not have a covariate (Hypothesis 1 has the covariate of restrained and unrestrained eaters) and will use a repeated measures analysis of variance (RMANOVA) (in hypothesis two restrained and unrestrained eating is not a covariate). 


\section{CHAPTER IV}

\section{RESULTS}

\section{Participant Characteristics}

$\underline{\text { Age }}$

Descriptive characteristics of the participants are displayed in Tables 2.1-2.9.

Sixty-two females, with a mean age of 21.87 years $(S D=3.03)$, and a range of 18 to 33 , completed the study. Approximately $78 \%$ of the participants were between the ages of 18 to 23 , and approximately $23 \%$ were between the ages of 24 to 33 .

Table 2.1. Distribution of Age

\begin{tabular}{|l|c|c|}
\hline \multicolumn{1}{|c|}{ Age } & Frequency & Percent \\
\hline $\mathbf{1 8 - 2 0}$ & 27 & $43.55 \%$ \\
\hline $\mathbf{2 1 - 2 3}$ & 21 & $33.87 \%$ \\
\hline $\mathbf{2 4 - 2 6}$ & 8 & $12.90 \%$ \\
\hline $\mathbf{2 7 - 2 9}$ & 5 & $8.06 \%$ \\
\hline $\mathbf{3 3}$ & 1 & $1.61 \%$ \\
\hline
\end{tabular}

Note: $N=62$

\section{$\underline{\text { Weight and BMI }}$}

Overall, the mean weight of participants was 168.19 pounds $(\mathrm{SD}=25.77)$ with a range of 128 to 234 pounds. Participants had a mean BMI of $28.42(\mathrm{SD}=3.10)$. Approximately $72 \%$ of all participants had a BMI of between 25 and 28.9 , which is 
considered overweight. Approximately $21 \%$ of the sample was obese; none of the participants in this sample were morbidly obese.

Table 2.2 Distribution of Weight

\begin{tabular}{|l|c|c|}
\hline Weight & Frequency & Percent \\
\hline $\mathbf{1 2 8 - 1 4 3}$ & 10 & $16.13 \%$ \\
\hline $\mathbf{1 4 4 - 1 5 9}$ & 20 & $32.26 \%$ \\
\hline $\mathbf{1 6 0 - 1 7 5}$ & 8 & $12.90 \%$ \\
\hline $\mathbf{1 7 5 - 1 9 0}$ & 13 & $20.97 \%$ \\
\hline $\mathbf{1 9 1 - 2 0 6}$ & 6 & $9.68 \%$ \\
\hline $\mathbf{2 0 7 - 2 2 2}$ & 2 & $3.23 \%$ \\
\hline $\mathbf{2 2 3 - 2 3 4}$ & 3 & $4.84 \%$ \\
\hline
\end{tabular}

Note: $N=62$

Table 2.3. Distribution of BMI

\begin{tabular}{|l|c|c|}
\hline \multicolumn{1}{|c|}{ BMI } & Frequency & Percent \\
\hline $\mathbf{2 5 - 2 6 . 9}$ & 22 & $35.48 \%$ \\
\hline $\mathbf{2 7 - 2 8 . 9}$ & 23 & $37.10 \%$ \\
\hline $\mathbf{2 9 - 3 0 . 9}$ & 9 & $14.52 \%$ \\
\hline $\mathbf{3 2 - 3 3 . 9}$ & 3 & $4.84 \%$ \\
\hline $\mathbf{3 4}$ & 2 & $3.23 \%$ \\
\hline $\mathbf{3 6}$ & 2 & $3.23 \%$ \\
\hline $\mathbf{3 8}$ & 1 & $1.61 \%$ \\
\hline
\end{tabular}

Note: $N=62$

$\underline{\text { Race }}$

In terms of race, $45.16 \%$ of the participants self-reported Hispanic or Latino background, and $27.42 \%$ endorsed Black/African American for a total of $72.6 \%$ of all participants. Caribbean non-Hispanics accounted for $4.84 \%$ of the sample, Asian/Pacific Islander for $8.06 \%$, White Non-Hispanic for 3.23\%, Mixed Race for $9.68 \%$ and lastly, $1.61 \%$ chose Don't Know/Not Sure. 
Table 2.4. Distribution of Race

\begin{tabular}{|l|c|c|}
\hline \multicolumn{1}{|c|}{ Race } & Frequency & Percent \\
\hline White Non Hispanic & 2 & $3.23 \%$ \\
\hline Black/African American & 17 & $27.42 \%$ \\
\hline Caribbean Non-Hispanic & 3 & $4.84 \%$ \\
\hline Hispanic/Latino & 28 & $45.16 \%$ \\
\hline Asian/Pacific Islander & 5 & $8.06 \%$ \\
\hline Don't Know/Not Sure & 1 & $1.61 \%$ \\
\hline Mixed Race & 6 & $9.68 \%$ \\
\hline
\end{tabular}

Note: $N=62$

Marital Status, Smoking and Religious Background

Participants were asked to report their marital status. Approximately $85 \%$ of the participants were single, $3.23 \%$ married, and $9.68 \%$ were members of an unmarried couple. Eighty-two percent of the participants were non-smokers, $14.52 \%$ were occasional smokers, and 3.23\% reported they were former smokers. Approximately 67\% percent of participants were either Catholic or Christian, 25.8\% selected "other." Jewish participants comprised $1.61 \%$ percent of the sample, $3.23 \%$ were Hindu and $1.61 \%$ were Buddhist.

Table 2.5. Distribution of Marital Status

\begin{tabular}{|l|c|c|}
\hline \multicolumn{1}{|c|}{ Marital Status } & Frequency & Percent \\
\hline Single & 53 & $85.48 \%$ \\
\hline Married & 2 & $3.23 \%$ \\
\hline Divorced & 1 & $1.61 \%$ \\
\hline Member Of An Unmarried Couple & 6 & $9.68 \%$ \\
\hline
\end{tabular}

Note: $N=62$ 
Table 2.6. Distribution of Smoking Status

\begin{tabular}{|l|c|c|}
\hline \multicolumn{1}{|c|}{ Smoking Status } & Frequency & Percent \\
\hline Non-Smoker & 51 & $82.26 \%$ \\
\hline Occasional Smoker & 9 & $14.52 \%$ \\
\hline Former Smoker & 2 & $3.23 \%$ \\
\hline
\end{tabular}

Note: $N=62$

Table 2.7. Distribution of Religion

\begin{tabular}{|l|c|c|}
\hline \multicolumn{1}{|c|}{ Religion } & Frequency & Percent \\
\hline Christian & 23 & $37.10 \%$ \\
\hline Catholic & 19 & $30.65 \%$ \\
\hline Jewish & 1 & $1.61 \%$ \\
\hline Hindu & 2 & $3.23 \%$ \\
\hline Buddhist & 1 & $1.61 \%$ \\
\hline Other & 16 & $25.81 \%$ \\
\hline
\end{tabular}

Note: $N=62$

$\underline{\text { Income }}$

Approximately $63 \%$ percent of the participants earned $\$ 50,000$ or less per year, and $40.3 \%$ earned less than 30,000 per year.

Table 2.8. Distribution of Income

\begin{tabular}{|l|c|c|}
\hline \multicolumn{1}{|c|}{ Income } & Frequency & Percent \\
\hline Less Than Ten Thousand & 11 & $17.7 \%$ \\
\hline $\mathbf{1 0 , 0 0 0 - 2 9 , 9 9 9}$ & 14 & $22.6 \%$ \\
\hline $\mathbf{3 0 , 0 0 0 - 4 9 , 9 9 9}$ & 14 & $22.6 \%$ \\
\hline $\mathbf{5 0 , 0 0 0}$ to $\mathbf{6 9 , 9 9 9}$ & 5 & $8.1 \%$ \\
\hline $\mathbf{7 0 , 0 0 0}$ to $\mathbf{8 9 , 9 9 9}$ & 3 & $4.8 \%$ \\
\hline $\mathbf{9 0 , 0 0 0}$ to $\mathbf{1 1 9 , 9 9 9}$ & 3 & $4.8 \%$ \\
\hline $\mathbf{1 2 0 , 0 0 0}$ to $\mathbf{1 4 9 , 9 9 9}$ & 1 & $1.6 \%$ \\
\hline Don't Know/Not Sure & 11 & $17.7 \%$ \\
\hline
\end{tabular}

Note: $N=62$ 


\section{$\underline{\text { Education }}$}

In terms of education, $51.6 \%$ of the participants finished high school and had some college experience, $48.3 \%$ had a 2 -year degree or more of schooling; $82.2 \%$ of all participants had a high school degree/GED, some college or a 2 year college degree.

Table 2.9. Distribution of Education

\begin{tabular}{|l|c|c|}
\hline \multicolumn{1}{|c|}{ Education } & Frequency & Percent \\
\hline High School/GED & 3 & $4.80 \%$ \\
\hline Some College & 29 & $46.80 \%$ \\
\hline 2 Year College Degree & 19 & $30.60 \%$ \\
\hline 4 Year College Degree & 8 & $12.90 \%$ \\
\hline Master's & 2 & $3.20 \%$ \\
\hline Professional Degree & 1 & $1.60 \%$ \\
\hline
\end{tabular}

Note: $N=62$

Covariate Analyses

ANOVA and chi-square tests were conducted with the demographic information collected to examine relationships between potential covariates and the main outcome variable, calories chosen. The purpose of these analyses was to examine whether group differences (No Information, Calories Only, and Calories and Exercise Equivalents) were significant enough to potentially influence the outcome of these analyses. ANOVAs were conducted (Table 2.1) for BMI $(\mathrm{F}(2,59)=.45, \mathrm{p}=.641)$, weight $(\mathrm{F}(2,59)=.23$, $\mathrm{p}=.793)$, and age $(\mathrm{F}(2,59)=.194, \mathrm{p}=.824)$. Chi-square analyses were conducted for race (Table 2.2; $\mathrm{F}(4)=1.066, \mathrm{p}=.900)$, religion (Table $2.3 ; \mathrm{F}(4)=2.33, \mathrm{p}=.675)$, income (Table 2.4; $\mathrm{F}(4)=5.74, \mathrm{p}=.220)$, and education (Table 2.5; $\mathrm{F}(2)=.864, \mathrm{p}=.649)$. No covariates emerged as being significantly related to calories chosen by study participants (all p's 
$>.05)$. Results indicated that the groups did not differ significantly on demographic variables. Covariate analyses were not conducted for smoking or marital status because of lack of variability on these demographics $(85.48 \%$ of all study participants were single, and $82.26 \%$ of the study sample were non-smokers).

Table 3.1. ANOVA for BMI, Weight and Age

\begin{tabular}{|l|c|c|c|}
\hline Variable & $\begin{array}{c}\text { No Information } \\
(\mathbf{n = 2 2}) \\
\text { Mean } \\
\text { (SD) }\end{array}$ & $\begin{array}{c}\text { Calories Only } \\
(\mathbf{n = 2 0}) \\
\text { Mean } \\
\text { (SD) }\end{array}$ & $\begin{array}{c}\text { Calories and EE } \\
(\mathbf{n = 2 0} \\
\text { Mean } \\
(\text { SD) }\end{array}$ \\
\hline \multirow{2}{*}{ BMI } & 27.91 & 28.70 & 28.70 \\
& $(3.11)$ & $(2.95)$ & $(3.30)$ \\
\hline \multirow{2}{*}{ Weight } & 167.85 & 171.17 & 165.57 \\
& $(26.49)$ & $(26.62)$ & $(25.77)$ \\
\hline \multirow{2}{*}{ Age } & 21.91 & 21.55 & 22.15 \\
& $(3.53)$ & $(2.28)$ & $(3.20)$ \\
\hline
\end{tabular}

Note: $N=62$

Table 3.2. Chi-square for Race

\begin{tabular}{|l|c|c|c|}
\hline \multicolumn{1}{|c|}{ Variable } & $\begin{array}{c}\text { African } \\
\text { American }\end{array}$ & Hispanic & Other \\
\hline No Information & 7 & 8 & 7 \\
\hline Calorie Only & 5 & 10 & 5 \\
\hline Calories and EE & 5 & 10 & 5 \\
\hline Total & 17 & 28 & 17 \\
\hline Percent & $27.42 \%$ & $45.16 \%$ & $27.42 \%$ \\
\hline
\end{tabular}

Table 3.3. Chi-square for Religion

\begin{tabular}{|l|c|c|c|c|}
\hline \multicolumn{1}{|c|}{ Variable } & Christian & Catholic & Other & Total \\
\hline No Information & 7 & 7 & 8 & 22 \\
\hline Calories Only & 7 & 8 & 5 & 20 \\
\hline Calories and EE & 9 & 4 & 7 & 20 \\
\hline Total & 23 & 19 & 20 & 62 \\
\hline Percent & $37.10 \%$ & $30.65 \%$ & $32.26 \%$ & \\
\hline
\end{tabular}


Table 3.4. Chi-square for Income

\begin{tabular}{|l|c|c|c|c|}
\hline \multicolumn{1}{|c|}{ Variable } & $\mathbf{\$ \$ 3 0 , 0 0 0}$ & $\mathbf{\$ \$ 3 0 , 0 0 0}$ & Don't Know & Total \\
\hline No Information & 11 & 5 & 6 & 22 \\
\hline Calorie Only & 7 & 10 & 3 & 20 \\
\hline Calories and EE & 7 & 11 & 2 & 20 \\
\hline Total & 25 & 26 & 11 & 62 \\
\hline Percent & $40.32 \%$ & $41.94 \%$ & $17.74 \%$ & \\
\hline
\end{tabular}

Table 3.5. Chi-square for Education

\begin{tabular}{|l|c|c|c|}
\hline \multicolumn{1}{|c|}{ Variable } & $\begin{array}{c}\text { High School or } \\
\text { Some College }\end{array}$ & $\begin{array}{c}\text { 2 Year Degree or } \\
\text { More Schooling }\end{array}$ & Total \\
\hline No Information & 13 & 9 & 22 \\
\hline Calorie Only & 9 & 11 & 20 \\
\hline Calories and EE & 10 & 10 & 20 \\
\hline Total & 32 & 30 & 62 \\
\hline Percent & $51.61 \%$ & $48.39 \%$ & \\
\hline
\end{tabular}

Physical Activity Reporting

The IPAQ (see Table 4.1) self report data showed $87.10 \%$ of participants classifying themselves as having high physical activity, $3.23 \%$ moderate, and $9.68 \%$ low. Contrasting this with a specific question in the demographic questionnaire (see Table 4.2), self-reports showed $3.23 \%$ as extremely active, $14.52 \%$ very active, $29.03 \%$ moderately active, $41.94 \%$ lightly active, and $9.68 \%$ sedentary.

Table 4.1 IPAQ Questionnaire (Physical Activity)

\begin{tabular}{|l|c|c|}
\hline \multicolumn{1}{|c|}{ Physical Activity } & Frequency & Percent \\
\hline Low & 6 & $9.68 \%$ \\
\hline Moderate & 2 & $3.23 \%$ \\
\hline High & 54 & $87.10 \%$ \\
\hline Total & 62 & $100.00 \%$ \\
\hline
\end{tabular}


Table 4.2. Physical Activity Questions in Demographic Questionnaire

\begin{tabular}{|l|c|c|}
\hline & Frequency & Percent \\
\hline Sedentary & 6 & $9.68 \%$ \\
\hline Lightly Active & 26 & $41.94 \%$ \\
\hline Moderately Active & 18 & $29.03 \%$ \\
\hline Very Active & 9 & $14.52 \%$ \\
\hline Extremely Active & 2 & $3.23 \%$ \\
\hline Total & 59 & $95.16 \%$ \\
\hline Not Answered & 1 & $1.61 \%$ \\
\hline & 62 & $100.00 \%$ \\
\hline
\end{tabular}

Restrained and Unrestrained Eaters as Covariates

The proposed minimum numbers of restrained eaters were recruited per the power analysis for each cell in the block design. Restrained Eaters (R) composed $37.1 \%(n=23)$ of the sample, compared to Unrestrained Eaters $(U)$, who represented $62.9 \%(n=39)$ of the sample (See Table 5.1).

Table 5.1. Frequencies for Restrained vs. Unrestrained Eaters

\begin{tabular}{|l|c|c|}
\hline & Frequency & Percent \\
\hline Restrained & 23 & $37.1 \%$ \\
\hline Unrestrained & 39 & $62.9 \%$ \\
\hline Total & 62 & $100 \%$ \\
\hline
\end{tabular}

A chi-square test was performed for restrained vs. unrestrained eaters by group, No Information, Calories Only and Calories and Exercise Equivalents, to determine if restrained and unrestrained eaters were evenly distributed across experimental groups. The chi-square test revealed no differences among the groups on this variable $\left(X^{2}=(2\right.$, $\mathrm{N}=62) .836, \mathrm{p}=.658$; See Table 5.2). 
Table 5.2. Frequency of Restrained and Unrestrained Eaters for 3 Groups

\begin{tabular}{|l|c|c|c|c|}
\hline \multicolumn{1}{|c|}{ Variable } & Restrained & Unrestrained & Total & Percent \\
\hline $\begin{array}{l}\text { No Information } \\
\text { (control) }\end{array}$ & 7 & 15 & 22 & $35.48 \%$ \\
\hline Calories only & 7 & 13 & 20 & $32.26 \%$ \\
\hline EE & 9 & 11 & 20 & $32.26 \%$ \\
\hline Total & 23 & 39 & 62 & \\
\hline
\end{tabular}

A t-test was conducted to determine the relationship between restrained and unrestrained eaters and the main outcome variable, calories chosen. For Lunch 1 total calories chosen, there was a significant difference between restrained and unrestrained eaters with restrained eaters averaging 983.91(SD=446.09) calories and unrestrained eaters averaging $1351.54(\mathrm{SD}=488.06)$ calories $(\mathrm{t}=-2.96(60), \mathrm{p}=.004$; See Table 5.3).

Table 5.3. T-tests for Calories Chosen by Restrained/Unrestrained Eaters

\begin{tabular}{|c|c|c|}
\hline Variable & $\begin{array}{c}\text { Restrained } \\
(\mathbf{n}=\mathbf{2 3}) \\
\text { Mean } \\
(\mathrm{SE})\end{array}$ & $\begin{array}{c}\begin{array}{c}\text { Unrestrained } \\
(\mathbf{n}=39)\end{array} \\
\text { Mean } \\
\text { (SE) }\end{array}$ \\
\hline Lunch 1 Total Calories Chosen & $\begin{array}{r}983.91 \\
(93.02) \\
\end{array}$ & $\begin{array}{c}1351.54 \\
(78.15) \\
\end{array}$ \\
\hline Lunch 2 Total Calories Chosen & $\begin{array}{l}922.39 \\
(85.80)\end{array}$ & $\begin{array}{l}1184.87 \\
(76.90)\end{array}$ \\
\hline Difference In Calories Chosen & $\begin{array}{c}-61.52 \\
(93.27)\end{array}$ & $\begin{array}{r}-166.67 \\
(87.37)\end{array}$ \\
\hline
\end{tabular}

For Lunch 2 total calories chosen, there was a significant difference between restrained and unrestrained eaters with restrained eaters averaging $922.39(\mathrm{SD}=411.47)$ calories and unrestrained eaters averaging $1184.87(\mathrm{SD}=480.21)$ calories $(\mathrm{t}=-2.19(60)$, $\mathrm{p}=.033$; See Table 5.4) 
For Lunch 1 total calories consumed, there was a significant difference between restrained and unrestrained eaters with restrained eaters averaging $792.57(\mathrm{SD}=347.79)$ calories and unrestrained eaters averaging $1063.68(\mathrm{SD}=363.78)$ calories $(\mathrm{t}=-2.88(60)$, $\mathrm{p}=.006)$.

For Lunch 2 total calories consumed, there was not a significant difference between restrained and unrestrained eaters, with restrained eaters averaging 798.57 $(\mathrm{SD}=149.02)$ calories and unrestrained eaters averaging $982.93(\mathrm{SD}=411.32)$ calories $(\mathrm{t}=-$ 1.80(60), $\mathrm{p}=.077$; See Table 5.4).

Table 5.4. T-tests for Calories Consumed by Restrained/Unrestrained Eaters

\begin{tabular}{|l|c|c|}
\hline & $\begin{array}{c}\text { Restrained } \\
(\mathbf{n = 2 3 )} \\
\text { Mean } \\
(\mathbf{S E})\end{array}$ & $\begin{array}{c}\text { Unrestrained } \\
(\mathbf{n = 3 9 )} \\
\text { Mean } \\
\text { (SE) }\end{array}$ \\
\hline Lunch 1 Total & 792.57 & 1063.68 \\
Calories Consumed & $(72.55)$ & $(58.25)$ \\
\hline Lunch 2 Total & 798.57 & 982.93 \\
Calories Consumed & $(72.78)$ & $(65.86)$ \\
\hline Difference In Calories & -6 & 80.75 \\
Consumed & $(69.60)$ & $(71.63)$ \\
\hline
\end{tabular}

Hypothesis Testing

Hypothesis 1: When presented with caloric information and exercise equivalents of fast food at the point-of-choice, overweight and obese women, ages 18-34, will make lower calorie food choices compared to when only caloric information is provided or when no information is provided. 
This hypothesis was not supported. After controlling for restrained/unrestrained eating habits, the analysis showed no significant group, time or group by time effects. Using $\mathrm{p}<0.05$ to show significance, the $\mathrm{p}$-values in this analysis range from 0.395 to 0.801 and do not provide evidence to reject the null hypothesis.

Data for the three groups were compared at pre-assessment and one week later at post-assessment using a repeated measures analysis of covariance (RMANCOVA) for calories chosen for fast food (see Table 6). The RMANCOVA analysis revealed no significant group by time interaction effects for calories chosen from Lunch 1 to Lunch 2 $(\mathrm{F}(2)=.777, \mathrm{p}=.464)$.

Table 6. Lunch 1 and Lunch 2 Mean Calories and Std. Error of the Mean for Groups

\begin{tabular}{|l|c|c|c|}
\hline \multicolumn{1}{|c|}{ Variable } & $\begin{array}{c}\text { No Information } \\
(\mathbf{n}=\mathbf{2 2}) \\
\text { Mean } \\
(\text { SE) }\end{array}$ & $\begin{array}{c}\text { Calories Only } \\
(\mathbf{n = 2 0}) \\
\text { Mean } \\
(\text { SE) }\end{array}$ & $\begin{array}{c}\text { Calories and EE } \\
(\mathbf{n = 2 0}) \\
\text { Mean } \\
(\text { SE) }\end{array}$ \\
\hline $\begin{array}{l}\text { Lunch 1 Total } \\
\text { Calories } \\
\text { Chosen }\end{array}$ & $\begin{array}{c}1201.36 \\
(100.00)\end{array}$ & $\begin{array}{c}1282.75 \\
(89.74)\end{array}$ & $\begin{array}{c}1162.75 \\
(141.07)\end{array}$ \\
\hline $\begin{array}{l}\text { Lunch 2 Total } \\
\text { Calories } \\
\text { Chosen }\end{array}$ & 1176.14 & 1077 & 1000.50 \\
\hline $\begin{array}{l}\text { Difference } \\
\text { Between }\end{array}$ & $(99.5)$ & $(113.97)$ & $(98.12)$ \\
$\begin{array}{l}\text { Lunch 1 and } \\
\text { Lunch 2 }\end{array}$ & 25.22 & 205.75 & 162.25 \\
\hline
\end{tabular}

RMANCOVA analysis examination of the main time effects, irrespective of group assignment or covariates; Lunch 1 (baseline) to Lunch 2 (follow-up) for total calories chosen, across all groups ( No Information, Calories Only, Calories and Exercise 
Equivalent groups) was significant with a reduction in percentage in total calories chosen at Lunch $2(\mathrm{~F}(1)=4.04, \mathrm{p}=.049)$.

\section{Hypothesis 2: Presentation of caloric information of fast food translated into exercise equivalents will have a greater impact on the food choices of 18-34 year old, restrained overweight and obese women than on unrestrained overweight and obese women.}

This hypothesis is not supported. RMANOVA did not reveal a significant group by time interaction between restrained and unrestrained eaters, with calories chosen from Lunch 1 to Lunch $2(\mathrm{~F}(1)=.873, \mathrm{p}=.363)$ among those in the Exercise Equivalent group. In addition, the examination of time effects for Lunch 1 (baseline) to Lunch 2 (followup) for total calories chosen, across all groups (restrained and unrestrained eaters) was not significant $(\mathrm{F}(1)=1.26, \mathrm{p}=.277)$. However, the analysis of group effects irrespective of time showed a significant difference between restrained and unrestrained eaters $\mathrm{F}(1)=4.84, \mathrm{p}=.041$ with restrained eaters choosing fewer calories (see Table 7, Graph 1 and Graph 1.2). 
Table 7. Descriptive Statistics Restrained and Unrestrained Eaters by Group -- Block Design.

\begin{tabular}{|c|c|c|c|c|c|c|}
\hline Variable & $\begin{array}{c}\text { R-No } \\
\text { Info } \\
(n=7) \\
\text { Mean } \\
\text { (SE) }\end{array}$ & $\begin{array}{c}\text { UR-No } \\
\text { Info } \\
(n=15) \\
\text { Mean } \\
\text { (SE) }\end{array}$ & $\begin{array}{c}\text { R-Cal } \\
\text { Only } \\
(n=7) \\
\text { Mean } \\
\text { (SE) }\end{array}$ & $\begin{array}{c}\text { UR- Cal } \\
\text { Only } \\
(\mathrm{n}=13) \\
\text { Mean } \\
\text { (SE) }\end{array}$ & $\begin{array}{c}\text { R- Cal \& } \\
\text { EE } \\
(\mathrm{n}=9) \\
\text { Mean } \\
\text { (SE) }\end{array}$ & $\begin{array}{c}\text { UR-Cal } \\
\& \text { EE } \\
(n=11) \\
\text { Mean } \\
\text { (SE) }\end{array}$ \\
\hline $\begin{array}{l}\text { Lunch } 1 \\
\text { Total } \\
\text { Calories } \\
\text { Chosen }\end{array}$ & $\begin{array}{c}958.57 \\
(138.88)\end{array}$ & $\begin{array}{l}1314.67 \\
(123.62)\end{array}$ & $\begin{array}{c}1157.86 \\
(88.83)\end{array}$ & $\begin{array}{c}1350 \\
(128.22)\end{array}$ & $\begin{array}{c}868.33 \\
(200.57)\end{array}$ & $\begin{array}{l}1403.64 \\
(171.45)\end{array}$ \\
\hline $\begin{array}{l}\text { Lunch } 2 \\
\text { Total } \\
\text { Calories } \\
\text { Chosen }\end{array}$ & $\begin{array}{l}1075.71 \\
(183.54)\end{array}$ & $\begin{array}{c}1223 \\
(120.60)\end{array}$ & $\begin{array}{c}870.71 \\
(146.37)\end{array}$ & $\begin{array}{l}1188.08 \\
(151.51)\end{array}$ & $\begin{array}{c}843.33 \\
(127.10)\end{array}$ & $\begin{array}{l}1129.09 \\
(137.61)\end{array}$ \\
\hline $\begin{array}{l}\text { Difference } \\
\text { Between } \\
\text { Lunch 1 } \\
\text { and } \\
\text { Lunch 2 } \\
\end{array}$ & $\begin{array}{l}-117.14 \\
(137.42)\end{array}$ & $\begin{array}{c}91.67 \\
(123.15\end{array}$ & $\begin{array}{c}287.15 \\
(127.93)\end{array}$ & $\begin{array}{c}161.92 \\
(157.85)\end{array}$ & $\begin{array}{c}25 \\
(179.88)\end{array}$ & $\begin{array}{c}274.55 \\
(191.39)\end{array}$ \\
\hline
\end{tabular}

Graph 1. Restrained Eaters: Lunch 1 to Lunch 2 Comparison by Group

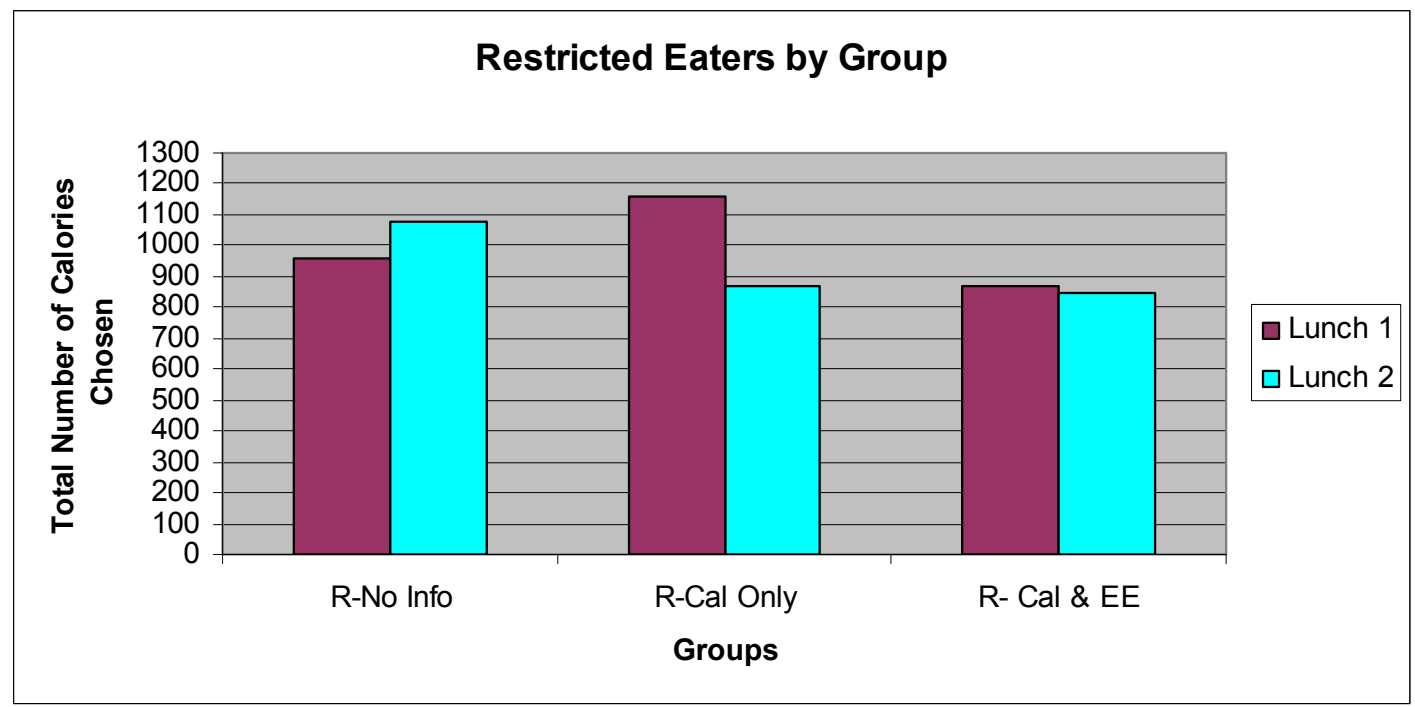


Graph 1.2. Unrestrained Eaters: Lunch 1 to Lunch 2 Comparison by Group

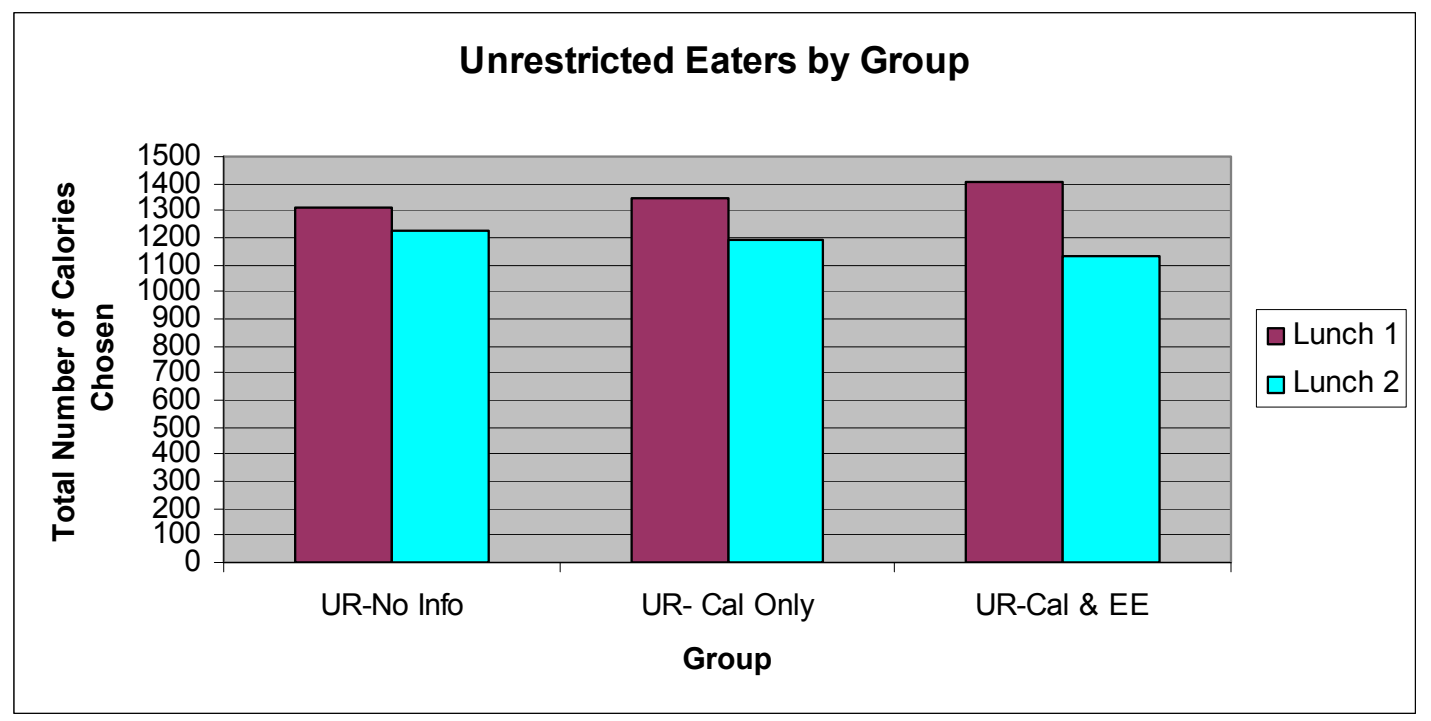

Additional Analysis: Calories Consumed

While not the main purpose of the study, the number of calories consumed was analyzed. Calories consumed reflected the amount of food the participant actually ate as compared to calories chosen, which was the amount of calories selected on the menus. Calories consumed was derived by taking food waste and weighing on a digital scale and calculating total calories eaten by the following formula: Total Calories For Food Item Chosen - Food Waste $=$ Calories Consumed. Data for the three groups were compared at pre-assessment and one week later at post-assessment using repeated measures analysis of covariance (RMANCOVA) for calories consumed. The analysis did not reveal a significant group by time interaction for calories chosen from Lunch 1 to Lunch 2 $(\mathrm{F}(2)=1.09, \mathrm{p}=.344)($ see Table 8$)$ 
Table 8. Calories Consumed: Means and Standard Errors

\begin{tabular}{|l|c|c|c|}
\hline \multicolumn{1}{|c|}{ Variable } & $\begin{array}{c}\text { No Information } \\
(\mathbf{n = 2 2}) \\
\text { Mean } \\
(\text { SE) }\end{array}$ & $\begin{array}{c}\text { Calories Only } \\
(\mathbf{n = 2 0 )} \\
\text { Mean } \\
\mathbf{( S E )}\end{array}$ & $\begin{array}{c}\text { Calories and EE } \\
(\mathbf{n = 2 0}) \\
\text { Mean } \\
\mathbf{( S E )}\end{array}$ \\
\hline $\begin{array}{l}\text { Lunch 1 Total } \\
\text { Calories } \\
\text { Consumed }\end{array}$ & $\begin{array}{c}986.62 \\
(83.87)\end{array}$ & $\begin{array}{c}1059.57 \\
(72.74)\end{array}$ & $\begin{array}{c}840.79 \\
(88.66)\end{array}$ \\
\hline $\begin{array}{l}\text { Lunch 2 Total } \\
\text { Calories } \\
\text { Consumed }\end{array}$ & 995.40 & 898.82 & 841.31 \\
\hline $\begin{array}{l}\text { Difference } \\
\text { Between } \\
\text { Lunch 1 and }\end{array}$ & $(91.54)$ & $(87.66)$ & $(82.07)$ \\
Lunch 2 & $(83.89)$ & 160.75 & .52 \\
\hline
\end{tabular}

RMANCOVA analysis of the time effects, Lunch 1 (baseline) to Lunch 2 (followup) for total calories chosen, across all groups ( No Information, Calories Only, Calories and Exercise Equivalent groups) was not significant for percentage of total calories consumed at Lunch $2(\mathrm{~F}(1)=.949, \mathrm{p}=.334)$.

An ANOVA analysis examining group effects only, without respect to time, evaluating restrained and unrestrained eaters, revealed no significant findings for the No Information group, Calorie Only Information group, or Calories and Exercise Equivalents $\operatorname{group}(\mathrm{F}(2)=.970, \mathrm{p}=.385)$.

Additional Analysis: High to Low, Low to High, Same Foods Chosen Chi-square analyses were conducted assessing whether there was an increase in lower calorie foods chosen versus higher calories foods or if food choices stayed the same at 
Lunch 2. Lower calorie foods are considered foods that are 360 calories or fewer -360 calories is the median (mean=376) of all Burger King foods (the foods used for this study). High to Low, Low to High and Same groups showed no differences for sides, desserts, condiments or drinks (all p's $>.05$ ). There was a significant finding for entrées chosen from Lunch 1 to Lunch 2, $\left(\mathrm{X}^{2}(4,62)=13.767, \mathrm{p}=.008\right)$. The Calories Only group was more likely to go from Low to High calorie food choices. (See Table 9).

Table 9. Frequencies for Entrée Direction

\begin{tabular}{|l|c|c|c|c|c|}
\hline \multicolumn{1}{|c|}{ Variable } & $\begin{array}{c}\text { High to } \\
\text { Low }\end{array}$ & $\begin{array}{c}\text { Low to } \\
\text { High }\end{array}$ & Same & Total & Percent \\
\hline $\begin{array}{l}\text { No } \\
\text { Information }\end{array}$ & 8 & 7 & 7 & 22 & $35.48 \%$ \\
\hline Calories Only & 3 & 16 & 1 & 20 & $32.26 \%$ \\
\hline EE & 9 & 6 & 5 & 20 & $32.26 \%$ \\
\hline
\end{tabular}

Additional Analysis: Number of Items Chosen

A RMANCOVA was conducted examining the number of items chosen. Time effects $(\mathrm{F}=(1) .765, \mathrm{p}=.385)$, group effects $(\mathrm{F}=(2) .037, \mathrm{p}=.964)$, and group by time effects $(\mathrm{F}=(1) 1.159, \mathrm{p}=.321)$ showed no significant differences (See Table 10). 
Table 10. Number of Items Chosen from Lunch One and Lunch Two for No Information, Calories Only, and Calorie and EE.

\begin{tabular}{|l|c|c|c|}
\hline & $\begin{array}{c}\text { Group A } \\
(\mathbf{n = 2 2}) \\
\text { Mean } \\
\text { (SE) }\end{array}$ & $\begin{array}{c}\text { Group B } \\
(\mathbf{n = 2 0}) \\
\text { Mean } \\
\text { (SE) }\end{array}$ & $\begin{array}{c}\text { Group C } \\
(\mathbf{n}=\mathbf{2 0}) \\
\text { Mean } \\
\text { (SE) }\end{array}$ \\
\hline Lunch 1 Total Items & 3.82 & 3.75 & 4 \\
Chosen & $(0.23)$ & $(0.31)$ & $(0.37)$ \\
\hline Lunch 2 Total Items & 3.95 & 4.20 & 3.80 \\
Chosen & $(0.24)$ & $(0.37)$ & $(0.28)$ \\
\hline Difference Between & & & -.2 \\
Lunch 1 and Lunch & 0.14 & 0.55 & $(0.32)$ \\
$\mathbf{2}$ & $(.24)$ & $(.38)$ & \\
\hline
\end{tabular}

Post-Hoc Analysis of Fast Food and Burger King Frequency

Several questions were asked of participants upon exiting, specifically about their eating behavior in relation to Burger King as well as fast food in general. A chi-square test was conducted for all three groups (No Information, Calorie Information Only, and Calories and EE) by how often participants eat at Burger $\operatorname{King}\left(\mathrm{X}^{2}(12,62)=9.58\right.$, $\mathrm{p}=.652$ ). There were no significant differences between restrained and unrestrained eaters (See Tables 11.1 and 11.2). Similarly, a chi-square test was conducted for all three groups by how often participants frequent fast food restaurants in general $\left(X^{2}(12,62)=\right.$ 13.30, $\mathrm{p}=.347$ ) with no significant differences emerging (See Tables 11.1 and 11.2). 
Table 11.1. Three Groups Eating at Burger King

\begin{tabular}{|l|c|c|c|c|c|}
\hline & $\begin{array}{c}\text { No } \\
\text { Information }\end{array}$ & $\begin{array}{c}\text { Calories } \\
\text { Only }\end{array}$ & $\begin{array}{c}\text { Calories } \\
\text { and EE }\end{array}$ & Total & Percent \\
\hline Never & 4 & 4 & 2 & 10 & $16.13 \%$ \\
\hline $\begin{array}{l}\text { 1-2 times Per } \\
\text { Year }\end{array}$ & 5 & 4 & 8 & 17 & $27.42 \%$ \\
\hline 1x Per Month & 7 & 6 & 4 & 17 & $27.42 \%$ \\
\hline 2x Per Month & 6 & 5 & 4 & 15 & $24.19 \%$ \\
\hline 1x Per Week & 0 & 0 & 1 & 1 & $1.61 \%$ \\
\hline 2x Per Week & 0 & 0 & 1 & 1 & $1.61 \%$ \\
\hline $\begin{array}{l}\text { More than 3x } \\
\text { Per Week }\end{array}$ & 0 & 1 & 0 & 1 & $1.61 \%$ \\
\hline Total & 22 & 20 & 20 & 62 & $100.00 \%$ \\
\hline
\end{tabular}

Table 11.2. Three Groups Eating at Fast Food Restaurants

\begin{tabular}{|l|c|c|c|c|c|}
\hline & $\begin{array}{c}\text { No } \\
\text { Information }\end{array}$ & $\begin{array}{c}\text { Calories } \\
\text { Only }\end{array}$ & $\begin{array}{c}\text { Calories } \\
\text { and EE }\end{array}$ & Total & Percent \\
\hline Never & 1 & 0 & 1 & 2 & $3.23 \%$ \\
\hline $\begin{array}{l}\text { 1-2 times Per } \\
\text { Year }\end{array}$ & 1 & 0 & 4 & 5 & $8.06 \%$ \\
\hline 1x Per Month & 2 & 2 & 3 & 7 & $11.29 \%$ \\
\hline 2x Per Month & 5 & 8 & 5 & 18 & $29.03 \%$ \\
\hline 1x Per Week & 8 & 5 & 4 & 17 & $27.42 \%$ \\
\hline 2x Per Week & 4 & 2 & 3 & 9 & $14.52 \%$ \\
\hline $\begin{array}{l}\text { More than 3x } \\
\text { Per Week }\end{array}$ & 1 & 3 & 0 & 4 & $6.45 \%$ \\
\hline Total & 22 & 20 & 20 & 62 & $100.00 \%$ \\
\hline
\end{tabular}

A chi-square test was conducted for restrained and unrestrained eaters by how often participants eat at Burger King $\left(\mathrm{X}^{2}(6,62)=7.12, \mathrm{p}=.310\right)$. There were no significant differences between restrained and unrestrained eaters (See Tables 11.3 and 11.4). Similarly, a chi-square test was conducted for restrained and unrestrained eaters by 
how often participants frequent fast food restaurants in general $\left(\mathrm{X}^{2}(6,62)=4.42\right.$, $\mathrm{p}=.620$ ) with no significant differences emerging (See Tables 11.3 and 11.4).

Table 11.3. Restrained and Unrestrained Eaters Eating at Burger King

\begin{tabular}{|l|c|c|c|c|}
\hline & Restrained & Unrestrained & Total & Percent \\
\hline Never & 5 & 5 & 10 & $16.13 \%$ \\
\hline 1-2 times Per Year & 3 & 14 & 17 & $27.42 \%$ \\
\hline 1x Per Month & 8 & 9 & 17 & $27.42 \%$ \\
\hline 2x Per Month & 6 & 9 & 15 & $24.19 \%$ \\
\hline 1x Per Week & 0 & 1 & 1 & $1.61 \%$ \\
\hline 2x Per Week & 1 & 0 & 1 & $1.61 \%$ \\
\hline $\begin{array}{l}\text { More than 3x Per } \\
\text { Week }\end{array}$ & 0 & 1 & 1 & $1.61 \%$ \\
\hline Total & 23 & 39 & 62 & $100.00 \%$ \\
\hline
\end{tabular}

Table 11.4. Restrained and Unrestrained Eaters Eating Fast Food

\begin{tabular}{|l|c|c|c|c|}
\hline & Restrained & Unrestrained & Total & Percent \\
\hline Never & 1 & 1 & 2 & $3.23 \%$ \\
\hline 1-2 times Per Year & 2 & 3 & 5 & $8.06 \%$ \\
\hline 1x Per Month & 3 & 4 & 7 & $11.29 \%$ \\
\hline 2x Per Month & 9 & 9 & 18 & $29.03 \%$ \\
\hline 1x Per Week & 6 & 11 & 17 & $27.42 \%$ \\
\hline 2x Per Week & 1 & 8 & 9 & $14.52 \%$ \\
\hline $\begin{array}{l}\text { More than 3x Per } \\
\text { Week }\end{array}$ & 1 & 3 & 4 & $6.45 \%$ \\
\hline Total & 23 & 39 & 62 & $100.00 \%$ \\
\hline
\end{tabular}


During the exit questionnaire, participants were asked about the impact of the combination of calories and exercise equivalents. Approximately $92 \%(n=57)$ said that they believe that a combination of calories and exercise equivalents would influence the foods they choose at a fast food restaurant (Table 12).

Table 12. Calories and EE Influence Participant Choice

\begin{tabular}{|l|c|c|}
\hline \multicolumn{1}{|c|}{ Calories and EE Will Influence Choice } & Frequency & Percent \\
\hline Yes & 57 & 91.94 \\
\hline No & 4 & 6.45 \\
\hline Missing & 1 & 1.61 \\
\hline Total & 62 & 100 \\
\hline
\end{tabular}

$\mathrm{N}=62$ 


\section{CHAPTER V}

\section{DISCUSSION}

Research on calorie information at the point-of-purchase in restaurants has shown mixed results in terms of effectiveness (Harnack et al., 2009). One possible reason for this lack of effectiveness may be the lack of understanding of the value of a calorie or the lack of a reference amount for a calorie (Krukowski et al., 2006; Burton et al., 2006; Wansink \& Chandon, 2006; Lichtman et al., 1992).

Even though there has not been overwhelming proof of its effectiveness, other than consumer polls showing a desire for this information has influenced law makers (Technomic, Inc, 2009), calorie information at the point-of-purchase for restaurants is currently a law in New York City (Department of Health and Mental Hygiene, 2008) and the state of California (California Health and Safety Code, 2009). This law is also being considered in several other states within the U.S. (Center for Science in the Public Interest, 2009) as well as in the United Kingdom (U.K. Foods Standards Agency, 2009).

The current study explored the possibility of facilitating lower calorie choice by the use of exercise equivalents, along with calorie information, at the point-of-choice. For the purposes of this study, exercise equivalents were defined as the amount of activity needed to burn off foods after an individual exhausts his or her daily caloric budget (Trumbo, Schlicker, Yates, \& Poos, 2002). As discussed previously, exercise equivalents are based on metabolic equivalents or METS, which is a commonly used method for the demonstrating the energy cost of physical activity (Byrne, Hills, Hunter, Weinsier, \& Schutz, 2005). 
While there is currently no literature exploring the use of exercise equivalents as a calorie education tool, it has been discussed by nutrition experts as a potential method to inform consumers about calorie values (U.S. Food and Drug Administration, 1999). Exercise equivalents could potentially simplify food and/or restaurant nutrition labels, increase understanding of energy imbalance, and facilitate a decrease in overall energy intake. Obesity is a serious health concern, affecting as many as $66 \%$ of Americans who are considered overweight and the $32 \%$ who are considered obese (Flegal, Carroll, Ogden, \& Johnson, 2002; Ogden, Carroll, Curtin, McDowell, Tabak, \& Flegal, 2006). Obesity is associated with increased risk for cardiovascular disease, diabetes, and certain types of cancer, depression, as well as discrimination and weight-related bias (Katz et al., 2005).

The purpose of this three-group experimental study in 18-34 year old, overweight and obese women, was to examine whether presenting caloric information in the form of exercise equivalents (physical activity required to burn off the calories in the food) at the point-of-choice on fast food menus, would lead to lower calorie choices than presenting caloric information or no information at all. A secondary purpose of the study was to assess if there was a difference in the choices made among restrained and unrestrained women when presented with caloric information of fast food items translated into exercise equivalents.

\section{Hypothesis 1}

When presented with caloric information and exercise equivalents of fast food, at the point-of-choice, overweight and obese women, ages 18-34, will make lower calorie food 
choices compared to when only caloric information is provided or when no information is provided.

Results indicated that when study participants were shown menus with calorie information along with exercise equivalents, participants did not make significantly lower calorie choices over the no-information group. While there were several studies that did show lower calorie choices being made with caloric information at the point-of-purchase, these studies were not very rigorous in design, measured behavioral intentions as opposed to actual intentions to eat, and were not experimental or repeated measures (Gerend, 2009; Buscher, Martin, \& Crocker, 2001; Bassett et al, 2008). The findings of the current study replicates the findings of other researchers that found that having caloric information at the point-of-purchase at fast food restaurants does not lead to fewer caloric choices (Harnack et al., 2008; Sproul, Canter, \& Schmidt, 2003; Aaron, Evans, \& Mela, 1995; Yamamoto et al., 2005).

The current study found that even with the addition of information about exercise equivalents, food choices were not significantly influenced at the point-of-choice at fast food restaurants. This lack of effectiveness in reducing calories chosen at the point-ofchoice is similar to studies assessing the impact of nutrition labels on consumer purchasing (Cowburn \& Stockley, 2005; Steenhuis, van Assema, van Breukelen, \& Glanz, 2004; Lin, Lee, \& Yen, 2004).

Perhaps having calorie information at the point-of-purchase at fast food restaurants is only one of many steps that need to be taken to affect behavior leading to fewer calorie choices - a more comprehensive ecological approach might be necessary (McLeoroy, 1988; Holdsworth et al., 1998). In Bergen and Yeh (2006) and Buscher, 
Martin, and Crocker (2001), the researchers used the addition of motivational posters to positively influence fewer calorie choices, one example of a more comprehensive approach to encouraging fewer calorie choices at the point-of-choice. In another study by Allen and colleagues (2007), a 30-minute nutrition education program was included, prior to serving fast food to adolescents, which led to a significant decrease in total calories chosen. These studies give evidence of the need for a more comprehensive approach to influencing choice.

\section{Hypothesis 2}

Presentation of caloric information of fast food translated into exercise equivalents will have a greater impact on the food choices of 18-34 year old, restrained overweight and obese women than on unrestrained overweight and obese women.

In the current study, this hypothesis is not supported. Analyses did not reveal a significant group by time interaction between restrained and unrestrained eaters with calories chosen from Lunch 1 to Lunch 2.

However, in spite of the lack of overall significance, there was an interesting trend noted, specifically among unrestrained eaters. When unrestrained eaters were presented with calorie information and exercise equivalents combined, there was a trend that showed a decrease in their caloric choices by 274.55 calories versus 161.92 for those with calorie information only and 91.67 for those with no information (see Table 7). The net difference between the no information unrestrained eaters group and the calories and exercise equivalent unrestrained eaters group was 182.88 fewer overall calories chosen. 
This was a post-hoc analysis and the cell sizes were not large enough to be able to determine statistical significance. However, the impact of calorie information with exercise equivalents on unrestrained eaters should be further examined. Unrestrained eaters generally do not deliberately attempt to restrain their food intake (Rideout, McLean, \& Barr, 2004), therefore this trend may be especially noteworthy.

The current study's methodology was designed to control for restrained and unrestrained eaters because of the possibility that overweight and obese females with high restraint, classified as not dieting, would eat fewer calories than unrestrained eaters. Analyses of the difference in total calories eaten at Lunch 1 and Lunch 2 without accounting for menu condition, did show significant differences between restrained and unrestrained eaters with restrained eaters choosing fewer calories than unrestrained eaters. These results support the current study's methodology of controlling for restrained and unrestrained eaters, which is consistent with the current literature that restrained and unrestrained eaters respond differently in terms of eating behavior. The literature shows that restrained eaters choose lower calorie foods (Rideout, McLean \& Barr, 2004), specifically fewer pastries and starchy foods, and have a higher consumption of fruits and vegetables (Moreira et al, 2005).

\section{Additional Analysis: Calories Consumed}

Calorie consumption data, while not the primary purpose of the current study, was compared at pre-assessment and one week later, at post-assessment, using repeated measures analysis of covariance. The analysis did not reveal a significant group-by-time interaction for calories consumed from Lunch 1 to Lunch 2. This finding is consistent 
with other studies, for example, Harnack and colleagues (2008), whose research also found no reduction in consumption amongst participants after they were given calorie information.

\section{Additional Analysis: Number of Items Chosen}

Additional analyses also examined whether study participants would choose fewer items based on their experimental condition. In this study, there were no significant differences between the groups on the number of items chosen. In one Dutch worksite study, the labeling within six food product categories as low fat did not have a significant effect on the total number of low-fat food items chosen (i.e.., entrees, side-dishes, beverages); however, there was a reduction in high calorie desserts (Steenhuis et al, 2004).

\section{Additional Analysis: High to Low, Low to High, Same Foods Chosen}

The current study examined whether study participants made lower calorie food choices (high to low), higher calorie food choices (low to high) or if food choices stayed the same. These analyses revealed no differences from Lunch 1 to Lunch 2 for side dishes, desserts, condiments or drinks. However there was a significant finding in the chisquare analyses for entrées chosen from Lunch 1 to Lunch 2.

The calorie only group was more likely to go from Low to High calorie entrée choices. It is possible that when calorie information only was presented to study participants, they found that the calories of the entrees already chosen were not as high as originally thought, resulting in more participants moving from Low to High calorie entrée choices in Lunch 2 (Miller et al., 1998). 


\section{Activity Level}

Although there were no significant findings in the analyses with regard to activity level, one interesting observation noted was the discrepancy reported by participants between the IPAQ and a separate question asked on the demographic questionnaire about the participants' perceived level of activity. On the IPAQ, $87.10 \%$ of participants classified themselves as having high physical activity, whereas on the demographic question, $3.23 \%$ reported being extremely active, $14.52 \%$ very active, $29.03 \%$ moderately active, $41.94 \%$ lightly active, and $9.68 \%$ reported being sedentary. While the IPAQ is a validated questionnaire to assess physical activity levels (Craig et al., 2003; Brown et al., 2004), the demographic questionnaire elicited what appears to be more accurate and realistic assessment of participant activity levels. These contradictory reports are consistent with studies that have shown that people overestimate their levels of physical activity (Slootmaker, Schuit, Chinapaw, Seidell, \& van Mechelen, 2009), and perhaps more so on the IPAQ (Rzewnicki, Vanden Auweele \& De Bourdeaudhuij, 2003)

While there has been research on post-exercise eating with mixed results (Visona \& George, 2002; Lluch, King, \& Blundell, 1997), there has not been any research on an individual's response to exercise equivalents in relation to their physical activity level.

\section{Post-Hoc Analysis of Fast Food and Burger King Frequency}

After the study was complete, several questions were asked of participants upon exiting. In particular, whether there was any effect with the No Information, Calorie Only and Calories and Exercise Equivalent groups from Lunch 1 to Lunch 2 in relation to 
eating frequency at fast food restaurants in general and/or frequency of eating at Burger King specifically was examined. There were no significant effects.

Additionally, whether there was any effect with restrained and unrestrained eaters in relation to eating frequency at fast food restaurants in general and/or frequency of eating at Burger King specifically was examined. There were no significant effects. There is no specific literature that discusses frequency of fast food visits and effects of point-of-choice calorie information. However, fast food restaurant use was positively associated with an increase in calorie consumption amongst adolescents (French et al, 2001), adults (Satia et al, 2004), and women (French et al, 2004). In the current study, $80.6 \%$ of all participants ate at fast food restaurants at least twice per month.

\section{Limitations}

This study design called for baseline and post-experiment measurement from the experimental and comparison groups to provide information about participants' eating choices. This pre- and post-intervention design provides a more reliable picture of the effect of including caloric and exercise equivalent information compared to one-time measurement. Thus, this design, particularly with the inclusion of a randomly assigned comparison group, provided a strong picture of the outcomes of interest.

Nevertheless, there are some limitations of this study. For instance, the study sample size was small, which limits generalizability. Additionally, the age of the sample was not normally distributed, therefore the findings may be more indicative of individuals at the younger end of the age spectrum of the sample. 
Potential problems may have resulted from participants in the comparison group being incidentally exposed to the intervention prior to the program, or being more motivated than participants in the other group to choose lower calorie foods.

The fact that individuals were getting food at no cost might have influenced the total number of food items, and hence amount of calories chosen (French, 2003). The average calories for the foods chosen for Lunch 1 and Lunch 2 were 1215.16 and 1087.50, respectively. Dumanovsky and colleagues (2009) established baseline data on mean calorie intake at Burger King of 926.2. Participants in the current study chose approximately 225 more calories per meal on average than participants in Dumanovsky study, perhaps because the food was free. In future studies, participants should be asked to pay for their own lunch, as in the Harnack study (2008), where study participants were told that payment for their meal would be collected from them at the end of the study session, avoiding the potential bias related to participants not paying for their food and possibly over-indulging.

Another concern of this study was order effect. The order effect describes the possible bias that is introduced when questions, ideas, etc., are presented in a particular order (Welch et al., 1992). During the first Lunch session, participants were served a lunch without any nutritional information. Then during Lunch 2, the second lunch session, participants were given information (calories or calories plus exercise equivalents). There may have been potential order effects, since the participants were familiar with the food choices from Lunch 1. However, if the participants were served Lunch 1 with the information (calories, calories plus exercise equivalents) it would have 
tainted the study - giving the participants information about calories and exercise equivalents that they may then remember during their second lunch.

Another limitation of the study was that the conceptual framework and design did not utilize an ecological model. An ecological approach includes an environmental component and takes a more holistic approach to better duplicate real life conditions. However, since there have been very few studies on exercise equivalents, the purpose of this study was to evaluate the impact of exercise equivalents without including other variables that might have made analyses of the effects more difficult. This study was conducted in a controlled environment, to better assess the impact of the intervention. In addition, choosing fast foods, although considered a risk factor in obesity, lowered the ability to generalize the findings of the study to other types of food and restaurant settings.

There are a number of factors that may have skewed the results of the present study; such factors included participants who potentially were depressed, chemically dependent, or who had eating disorders. These conditions were part of the exclusion criteria, which should have helped control for confounding factors. However, in spite controlling for confounders, moderators that might have influenced the impact of calories and exercise equivalents at the point-of-choice included cultural influences, age of the participant, peer social norms, temptation, and positive association with high calories. Mediators included literacy and educational level (controlled by population), level of health awareness, and level of physical activities, dieting status, and BMI. The questionnaire facilitated the collection of data on these mediators, but self-report has some limitations. 
Another limitation of the study was the inability to collect pre- and postintervention food diaries. It is possible that participants who chose lower calorie foods during the intervention may have increased their intake later in the day to compensate. That is, participants may have been either hungrier, or simply thought they were hungrier after lunch, if they elected to eat lower-calorie foods at lunchtime. An increase in laterday calories could effectively undo the benefits of choosing lower-calorie foods due to the presentation of exercise equivalents at lunchtime.

Another potential limitation of using exercise equivalents to promote lower calorie food choices was that lower calorie content alone does not necessarily make one food item nutritionally "better" than another item. For example, consider peanut butter and cream cheese as potential toppings for a morning bagel. Strictly using calorie information or exercise equivalents, the cream cheese (51 calories) appears to be a "better" choice than the peanut butter (94 calories). However, upon closer examination, the comparison is not so simple. Peanut butter has more fat (8.1 grams vs. 5.1 grams), but only 1.6 grams of that amount is saturated fat (compared with 3.2 grams of saturated fat in the cream cheese). Additionally, peanut butter contains 4.0 grams of protein to cream cheese's 1.1 grams. Given the other nutrition information, peanut butter appears to be the better choice - the extra protein and "good" fats will likely keep a person satiated much longer than the cream cheese, which might lead to a reduction of caloric intake later in the day. However, a person using only exercise equivalents (which are based on calorie counts) would probably opt for the cream cheese. Thus, exercise equivalents may actually lead people astray at times by causing them to choose less healthy options. However, given that fast foods are typically high in fat and calories and low in 
substantive nutrition, picking lower calorie food choices in such a scenario is more likely to lead to healthier choices, than not.

The current study sample was recruited from Florida International University's campuses located in Miami Dade County, in South Miami. According to the university's Office of Planning and Institutional Effectiveness, 2008 Fact Book, Enrollment Data (Florida International University, 2008), the university-wide profile of female students revealed the largest constituencies of 59.91\% Hispanic students, 13.45\% African American students, 3.38\% Asian, and 16.58\% White students. The current study (45.16\% Hispanic, 27.42\% African American/Black), while consistent with universitywide racial data, has a homogenous population limited by recruitment from a college campus with a population primarily composed of Hispanic and African American participants. Research has shown that frequency of fast food restaurant is notably higher among younger women, those who are non-white, and are overweight or obese (French et al., 2000). There is a critical need to intervene in this population, considering African Americans (Blacks) have 51 percent higher prevalence of obesity, and Hispanics have 21 percent higher obesity prevalence compared with non-Hispanic Whites (Centers for Disease Control and Prevention, 2009).

\section{Power and Effect Size}

Although a prospective power analysis was conducted to estimate sample size, the sample size of 62 females was not large enough to detect statistically significant differences in these analyses. A post-hoc power analysis was conducted, and determined 
that a sample size of 690 would have been necessary to show statistical significance with the current calorie differences.

The current study was designed to have enough power to detect large interaction effects; however, calorie differences were not large enough to determine an effect. Cohen (1988) approximately defined a small effect as .15, a medium effect as .25 , and a large effect as .40. The effect size for the current study from Lunch 1 to Lunch 2 with group and time effects (Hypothesis 1) was .026, a small effect size. The effect size for restrained eaters and unrestrained eaters for Lunch 1 to Lunch 2 (Hypothesis 2) was .010, a small effect size.

\section{Future Research}

The use of exercise equivalents on menus to help explain and give consumers a reference point should be explored with a larger, more diverse sample size. The current study was a one time exposure and effects were likely to be small. However, the current study is in line with other well-designed studies which demonstrate a lack of evidence for calories on menus leading to fewer calorie choices.

That said, the use of calories and exercise equivalents should still be tested in a wide range of settings (e.g., geographical, restaurants) and with different population groups, including men who typically do not respond by choosing fewer calories when given calorie information (Gerend, 2008; Conklin et al., 2005) and who typically make higher calorie choices at fast food restaurants (Yamamoto et al., 2005). Additionally, calories along with exercise equivalents may resonate with female, overweight or obese unrestrained eaters. This is a difficult group to target with public health interventions, 
considering unrestrained eaters are not as motivated to control their weight (Vartanian, Herman, \& Polivy, 2006).

Research in a fast food restaurant setting, that is, duplicating a "real world" environment, would help to determine if point-of-choice calorie and calorie and exercise equivalent interventions would lead to fewer calorie purchases. Most studies conducted on point-of-purchase were completed at a work place or at a university (including the current study), not in restaurants (Harnack et al., 2008).

It is possible that even though a great deal of planning and effort went into showing the calories only, and the calorie with EE information on the actual menus (highlighting the information in a separate column), it is possible that participants were unaware and did not notice the information. In the Harnack study (2008), only 54\% of those in the calorie information condition noticed the calories even though the calories were highlighted in yellow. It might therefore take several attempts before participants notice calorie information or calorie information and exercise equivalents. In the Bassett study (2008), Subway customers who saw caloric information chose meals with an average of 52 fewer calories than customers who said they did not see the caloric information. Thirty-seven percent of Subway customers reported seeing caloric information and reported that it affected their purchases; those customers chose 99 fewer calories than those who saw the information and reported it had no impact. Future studies, might consider using additional promotional and marketing materials (e.g., posters, announcements, etc.) for greater impact.

Future studies should use a larger sample size so that small changes can be ascertained. 


\section{Implications}

Eating at fast food restaurants is associated with higher than normal calorie intake (French, Story , Neumark-Sztainer, Fulkerson, \& Hannan, 2001) according to government guidelines (US Department of Health and Human Services, 2005), as well as fewer calories from fruits and vegetables (French et al, 2001). However, fast food consumption will more than likely increase in popularity because of the convenience, cost, taste and palatability (Dumanovsky et al., 2009).

In a survey among New York City residents, $82 \%$ reported that calorie information affects what they order; of these, $71 \%$ said they look for lower-calorie options, and 51\% stopped ordering higher calorie items. If exercise equivalent information were added to the menu, it could potentially influence even more people than information on calories alone. In the current study, an exit questionnaire was completed by study participants; $91.9 \%$ reported that a combination of calories and exercise equivalents would influence the foods they choose at a fast food restaurant - though this study did not find this outcome.

Having exercise equivalents and calories at fast food restaurants may also help to encourage restaurants to create lower calorie food items as well as reformulations of lower calorie foods or smaller portion sizes (Burton et al., 2006). Exercise equivalents could create an easily-understandable reference point for consumers with regard to the calorie (energy) content of foods. Exercise equivalents could also help consumers understand the value and importance of calories. Ultimately, knowledge of exercise equivalents could lead to lower calorie food choices. 
While this current study indicates that providing calorie information with the addition of exercise equivalents for foods at the point-of-choice may have little effect on food choice, additional research should be conducted. It might also be helpful to create education programs to teach people about exercise equivalents. Lastly, calorie information at point-of-choice should be researched with nutrition education programs to assess whether it has a significant impact. 


\section{LIST OF REFERENCES}

Aaron, J. I., Evans, R. E., \& Mela, D. J. (1995). Paradoxical effect of a nutrition labelling scheme in a student cafeteria. Nutrition Research, 15, 1251-1261.

Ainsworth, B. E., Haskell, W. L., Leon, A. S., Jacobs, D. R., Montoye, H. J., Sallis, J. F., \& Paffenbarger, R.S. (1993). Compendium of physical activities: Classification of energy costs of human physical activities. Medicine and Science in Sports and Exercise, 25, 71-80.

Ainsworth, B. E., Haskell, W. L., Whitt, M. C., Irwin, M. L., Swartz, A. M., Strath, S. J., O'Brien, W. L., Bassett, D. R., Jr., Schmitz, K. H., Emplaincourt, P. O., Jacobs, D. R., Jr., \& Leon, A. S. (2000). Compendium of physical activities: An update of activity codes and MET intensities. Medicine and Science in Sports and Exercise, 32, S498-S516.

Albright CL, Flora JA, Fortmann SP. (1990) Restaurant menu labeling: impact of nutrition information on entree sales and patron attitudes. Health Education Quarterly. Summer;17(2):157-67.

Allen KN, Taylor JS, Kuiper R. (2007) Effectiveness of nutrition education on fast food choices in adolescents. J Sch Nurs. Dec;23(6):337-41

American College Health Association. (2007) American College Health Association National College Health Assessment (ACHA-NCHA) Web Summary. Updated August 2007. Retrieved February 11, 2008, from http://www.achancha.org/data_highlights.html. 2007.

Ashley, B. D., Davidson, B., Wilkins, J., \& Thompson, N. P. (2004). Counting calories-how good are health care professionals? Nutrition, 20, 817-820.

Bassett MT, Dumanovsky T, Huang C, Silver LD, Young C, Nonas C, Matte TD, Chideya S, Frieden TR. (2008) "Purchasing Behavior and Calorie Information at Fast-Food Chains in New York City, 2007. American Journal of Public Health. 98.

Backstrand J, Wootan MG, Young LR, Hurley J. (1997) Fat chance. Washington DC: Center for Science in the Public Interest.

Beardsworth, A., Bryman, A., Keil, T., Goode, J., Haslam, C., \& Lancashire, E. (2002). Women, men and food: the significance and gender for nutritional attitudes and choices. British Food Journal, 104(7), 470-491. 
Bergen, D. \& Yeh, M. C. (2006). Effects of energy-content labels and motivational posters on sales of sugar-sweetened beverages: Stimulating sales of diet drinks among adults study. Journal of the American Dietetic Association, 106(11), 18661869.

Block, G. (2004). Foods contributing to energy intake in the US: Data from NHANES III and NHANES 1999-2000. Journal of Food Composition and Analysis, 17, 439447.

Blundell, J. E., Stubbs, R. J., Hughes, D. A., Whybrow, S., \& King, N. A. (2003). Cross talk between physical activity and appetite control: Does physical activity stimulate appetite? Proceedings of the Nutrition Society, 62(3), 651-61. Review

Briefel, R. R., Sempos, C. T., McDowell, M. A., Chien, S., \& Alaimo, K. (1997). Dietary methods research in the third National Health and Nutrition Examination Survey: Underreporting of energy intake. American Journal of Clinical Nutrition, 65, 1203S-1209S.

Brown, W. J., Trost, S. G., Bauman, A., Mummery, K. \& Owen, N. (2004). "Test-retest reliability of four physical activity measures used in population surveys." Journal of Science and Medicine in Sport, 7, 205-215.

Brown, W.U., Williams, L, Ford, J.H., Ball, K,. \& Dobson, A.J. (2005). Identifying the energy gap: Magnitude and determinants of five-year weight gain in mid-age women. Obesity Research, 13, 1431-1441

Borg, P., Fogelholm, M., \& Kukkonen-Harjula, K. (2004). Food selection and eating behaviour during weight maintenance intervention and 2-y follow-up in obese men. International Journal of Obesity and Related Metabolic Disorders, 28(12), $1548-1554$.

Boutelle, K. N., Fulkerson, J. A., Neumark-Sztainer, D., Story, M., \& French, S. A. (2007). Fast food for family meals: Relationships with parent and adolescent food intake, home food availability and weight status. Public Health Nutrition, 10(1), 16-23.

Bowman, S. A. \& Vinyard, B. T. (2004). Fast food consumption of U.S. adults: Impact on energy and nutrient intakes and overweight status. Journal of the American College of Nutrition, 23(2), 163-168. Burger King Corporation.

Burger King USA Nutritionals May 2009. Available at http://www.bk.com/Nutrition/PDFs/NutritionalBrochure.pdf. Accessed May 15, 2009. 
Buscher, L. A., Martin, K. A., \& Crocker, S. (2001). Point-of-purchase messages framed in terms of cost, convenience, taste, and energy improve healthful snack selection in a college foodservice setting. Journal of the American Dietetic Association, 101(8) 909-913.

Burton, S., Creyer, E. H., Kees, J., \& Huggins, K. (2006). Attacking the obesity epidemic: The potential health benefits of providing nutrition information in restaurants. American Journal of Public Health, 96(9), 1669-1675.

Byrne, N. M., Hills, A. P., Hunter, G. R., Weinsier, R. L., \& Schutz, Y. (2005). Metabolic equivalent: One size does not fit all. Journal of Applied Physiology, 99(3), 1112-1119.

California Health and Safety Code, Section 114094, (2009) Retrieved on July 22, 2009, from http://www.leginfo.ca.gov/cgibin/waisgate?WAISdocID $=31431218500+0+0+0 \&$ WAISaction=retrieve

Carels, R. A., Harper, J., \& Konrad, K. (2006). Qualitative perceptions and caloric estimations of healthy and unhealthy foods by behavioral weight loss participants. Appetite, 46, 199-206.

Center for Science in the Public Interest (2009) Menu Labeling, Retrieved on July 22, 2009 from http://www.cspinet.org/menulabeling/

Centers for Disease Control and Prevention (2006). Behavioral Risk Factor Surveillance System Survey Data. Atlanta, Georgia: U.S. Department of Health and Human Services, Centers for Disease Control and Prevention. Retrieved on February 11, 2008, from

http://apps.nccd.cdc.gov/brfss/Trends/agechart.asp?qkey=10010\&state=US

Centers for Disease Control and Prevention (2009). Differences in prevalence of obesity among black, white, and Hispanic adults - United States, 2006-2008. MMWR Morb Mortal Wkly Rep. Jul 17;58(27):740-4. Retrieved July 25, 2009, from http://www.cdc.gov/mmwr/preview/mmwrhtml/mm5827a2.htm.

Centers for Disease Control and Prevention (1988) National Health and Nutrition Examination Survey: body measurements (anthropometry). Retrieved July 23, 2009, from http://www.cdc.gov/nchs/data/nhanes/nhanes3/cdrom/NCHS/MANUALS/ANTH RO.PDF. 
Centers for Disease Control and Prevention. (2005). U.S. Obesity Trends: 1985-2004. Retrieved March 13, 2006, from http://www.cdc.gov/nccdphp/dnpa/obesity/trend/maps

Chandon, P. \& Wansink, B. (2005). The low-calorie curse: Confirmation bias, calorie estimation, and calorie consumption for vice and virtue fast-food meals INSEAD working paper 2005/59/MKT. (revised for resubmission to Journal of Consumer Research).

Conklin, M.T., Cranage, D.A., \& Lambert C.U. (2005). College students' use of point of selection nutrition information. Topics in Clinical Nutrition, 20, 97-108.

Cox, D. N., Perry, L., Moore, P. B., Vallis, L., \& Mela, D. J. (1999). Sensory and hedonic associations with macronutrient and energy intakes of lean and obese consumers. International Journal of Obesity and Related Metabolic Disorders, 23, 403-410.

Cox, D. N., van Galen, M., Hedderley, D., Perry, L., Moore, P.B., \& Mela, D. J. (1998). Sensory and hedonic judgments of common foods by lean consumers and consumers with obesity. Obesity Research, 6, 438-47

Cowburn, G., \& Stockley, L. (2005). Consumer understanding and use of nutrition labelling: A systematic review. Public Health Nutrition, 8, 21-28.

Craig C. L., Marshall, A. L., Sjöström, M., Bauman, A. E., Booth, M. L., Ainsworth, B. E., Pratt, M., Ekelund, U., Yngve, A., Sallis, J. F., \& Oja, P. (2003) International physical activity questionnaire: 12-country reliability and validity. Medicine and Science in Sports Exercise. 35(8), 1381-1395

Cohen J. Statistical Power Analysis for the Behavioral Sciences. 2nd ed. Lawrence Erlbaum; Mahwah, NJ: 1988

Cranage, D., Conklin, \& Lambert, C. (2005). Effect of nutrition information in perceptions of food quality, consumption behavior and purchase intentions. Journal of Foodservice Business Research, 7(1), 43-61.

Department of Health and Mental Hygiene, The City of New York. (2008). Notice of Adoption of A Resolution To Repeal And Reenact $\S 81.50$ of The New York City Health Code. Retrieved on February 11, 2008, from http://www.nyc.gov/html/doh/downloads/pdf/public/notice-adoption-hc-art81-500108.pdf

Department of Health and Mental Hygiene, The City of New York. (2008) Press release. Board Of Health Votes To Require Chain Restaurants To Display Calorie 
Information In New York City. Retrieved on February 11, 2008 from, http://www.nyc.gov/html/doh/html/pr2008/pr008-08.shtml

Diliberti, N., Bordi, P. L., Conklin, M. T., Roe, L. S., \& Rolls, B. J. (2004). Increased portion size leads to increased energy intake in a restaurant meal. Obesity Research, 12(3), 562-568.

Drichoutis, A., Laziridis, P., \& Nayga, R. M. (2006). Consumers' use of nutritional labels: a review of research studies and issues, Academy of marketing science reviews, no.9. Review http://www.amsreview.org/articlesdrichoutis09-2006.pdf 10-03-07

Dubbert PM, Johnson WG, Schlundt DG, Montague NW. (1984) The influence of caloric information on cafeteria food choices. J Appl Behav Anal. Spring;17(1):85-92.

Dumanovsky T, Nonas CA, Huang CY, Silver LD, Bassett MT. (2009). What People Buy From Fast-food Restaurants: Caloric Content and Menu Item Selection, New York City 2007. Obesity (Silver Spring). Jul;17(7):1369-74.

Dykes J, Brunner EJ, Martikainen PT, Wardle J. (2004) Socioeconomic gradient in body size and obesity among women: the role of dietary restraint, disinhibition and hunger in the Whitehall II study. Int J Obes Relat Metab Disord. Feb;28(2):262-8.

Eating Inventory Manual. (1988). (The Psychological Corporation) AJ Stunkard, S Messick - Harcourt Brace Jovanovich, San Antonio, TX, USA

Edwards, J. S. A., \& Meiselman, H. L. (2005). The influence of positive and negative cues on restaurant food choice and food acceptance. International Journal of Contemporary Hospitality Management, 17(4), 332-344.

Eisenmann, J. C., Bartee, R. T., \& Wang, M. Q. (2002). Physical activity, TV viewing, and weight in U.S. youth: 1999 Youth Risk Behavior Survey. Obesity Research, $10,379-442$.

Fedoroff, I., Polivy, J., \& Herman, C. P. (2003). The specificity of restrained versus unrestrained eaters' responses to food cues: general desire to eat, or craving for the cued food? Appetite, 41, 7-13.

Fisher, J. D., \& Fisher, W. A. (2002). The Information-Motivation-Behavioral Skills Model. In R. DiClemente, R. Crosby, \& M. Kegler (Eds.), Emerging Theories in Health Promotion Practice and Research (pp. 40-70). San Francisco, CA: Jossey Bass Publishers. 
Fisher, W. A., Fisher, J. D., \& Harman, J. (2003). The Information-MotivationBehavioral skills model as a general model of health behavior change. In J. Suls \& K. Wallston (Eds.), Social Psychological Foundations of Health (pp. 82-106). London : Blackwell Publishing.

Flegal, K. M., Carroll, M. D., Ogden, C. L., \& Johnson, C. L. (2002). Prevalence and trends in obesity among US adults, 1999-2000. Journal of the American Medical Association, 288, 1723-1727.

Florida International University (2008) Office of Planning \& Institutional Effectiveness (OPIE) 2008 Fact Book. Retrieved on July 15, 2009, from http://w3.fiu.edu/irdata/_Fact\%20Book/Headcount/enrollment.pdf

French SA. (2003) Pricing effects on food choices. Journal of Nutrition. Mar;133(3):841S-843S. Review.

French, S. A., Jeffery, R. W., \& Murray, D. (1999). Is dieting good for you?: Prevalence, duration and associated weight and behaviour changes for specific weight loss strategies over four years in US adults. International Journal of Obesity Related Metabolic Disorders, 23(3), 320-327.

French SA, Story M, Neumark-Sztainer D, Fulkerson JA, Hannan P. (2001) Fast food restaurant use among adolescents: associations with nutrient intake, food choices and behavioral and psychosocial variables. Int J Obes Relat Metab Disord. Dec;25(12):1823-33.

Fisher, W. A, Fisher, J. D. \& Harman, J. J. (2003). The Information-MotivationBehavioral skills model: a general social psychological approach to understanding and promoting health behavior. In J. Suls \& K. Wallston (Eds.), Social Psychological Foundations of Health (pp. 82-106). United Kingdom: Blackwell Publishers.

Fisher JD, Fisher WA, Misovich SJ, Kimble DL, Malloy TE. (1996) Changing AIDS risk behavior: effects of an intervention emphasizing AIDS risk reduction information, motivation, and behavioral skills in a college student population. Health Psychology. Mar;15(2):114-23.

Gerend MA., (2009) Does calorie information promote lower calorie fast food choices among college students? Journal of Adolescent Health. Jan;44(1):84-6.

Glanz, K., Basil, M., Maibach, E., Goldberg, J., \& Snyder, D. (1998). Why Americans eat what they do: Nutrition, cost, convenience, and weight control concerns as 
influences on food consumption. Journal of the American Dietetic Association, 98(10), 1118-1126.

Goris, A. H., \& Westerterp, K. R. (1999). Underreporting of habitual food intake is explained by undereating in highly motivated lean women. Journal of Nutrition, $129,878-882$.

Grundy, S. M. (1998). Multifactorial causation of obesity: Implications for prevention. American Journal of Clinical Nutrition, 67, 563S-572S.

Harnack, L. J., \& French, S. A. (2008). Effect of point-of-purchase calorie labeling on restaurant and cafeteria food choices: A review of the literature. International Journal of Behavioral Nutrition and Physical Activity, 5, 63.

Harnack, L. J., French, S. A., Oakes, J. M, Story, M. T., Jeffery, R.W., \& Rydell, S. A. (2008). Effects of calorie labeling and value size pricing on fast food meal choices: Results from an experimental trial. Int J Behav Nutr Phys Act. 5(1), 63.

Hawks, S. R., Madanat, H. N. \& Christley, HS. (2008). Behavioral and biological associations of dietary restraint: A review of the literature. Ecology of Food and Nutrition, 47(5), 415-449.

He, S., Fletcher, S. M., \& Rimal, A. (2004). Nutrition consideration in food choice. Journal of Food Distribution Research, 35(1), 124-126.

Hill J.O. (2009) Can a small-changes approach help address the obesity epidemic? A report of the Joint Task Force of the American Society for Nutrition, Institute of Food Technologists, and International Food Information Council. American Journal Clinical Nutrition. Feb;89(2):477-84. Review.

Hill, J.O., Wyatt, H. R., Reed, G. W., \& Peters, J. C. (2003). Obesity and the environment: Where do we go from here? Science, 299(5608), 853-855.

Hoefling A, Strack F. (2008) The tempting effect of forbidden foods. High calorie content evokes conflicting implicit and explicit evaluations in restrained eaters. Appetite. Nov;51(3):681-9. Epub 2008 Jun 22.

Holdsworth, M., \& Haslam C. (1998) A review of point-of-choice nutrition labelling schemes in the workplace, public eating places and universities. Journal of Human Nutrition and Dietetics, 11 (5), 423-445. 
Jeffery, R. W, Baxter, J., McGuire, M., \& Linde, J. (2006). Are fast food restaurants an environmental risk factor for obesity? International Journal of Behavioral Nutrition and Physical Activity, 3, 2.

Johnson W. G., Corrigan, S. A., Schlundt, D. G., \& Dubbert, P. M. (1990) Dietary restraint and eating behavior in the natural environment. Addictive Behavior, 15(3), 285-290.

Johnston, C. S. (2005). Uncle Sam's diet sensation: MyPyramid--an overview and commentary. Medscape General Medicine, 7(3), 78.

Katz, D. L., O'Connell, M., Yeh, M. C., Nawaz, H., Njike, V., Anderson, L. M., Cory, S., \& Dietz, W. (2005). Public health strategies for preventing and controlling overweight and obesity in school and worksite settings: A report on recommendations of the Task Force on Community Preventive Services. MMWR Recommendations and Reports, 54, 1-12.

Kersh, R., \& Morone, J. (2002). The politics of obesity: Seven steps to government action. Health Affairs, 21(6), 142-153.

Kim, S. Y., Nayga Jr., R. M., \& Capps Jr., O. (2000). The effect of food label use on nutrient intakes: An endogenous switching regression analysis. Journal of Agricultural and Resource Economics, 25(1), 215-231.

Kim, S. Y., Nayga Jr., R. M., \& Capps Jr., O. (2001). Food label use, self-selectivity, and diet quality. Journal of Consumer Affairs, 35(2), 346-363.

King, N. A., Tremblay, A., \& Blundell, J. E. (1997). Effects of exercise on appetite control: Implications for energy balance. Medicine and Science in Sports Exercise, 29(8), 1076-1089. Review

Koulouri, A. A., Tigbe, W. W., Lean, M. E. (2006). The effect of advice to walk 2000 extra steps daily on food intake. Journal of Human Nutrition and Dietetics, 19(4), 263-266.

Kreuter, M. W., Brennan, L. K., Scharff, D. P., \& Lukwago, S. N. (1997). Do nutrition label readers eat healthier diets? Behavioral correlates of adults' use of food labels. American Journal of Preventative Medicine, 13(4), 277-283.

Kristal, A. R., Levy, L., Patterson, R E., Li, S. S., \& White, E. (1998). Trends in food label use associated with new nutrition labeling regulations. American Journal of Public Health, 88(8), 1212-1215. 
Krukowski, R. A., Harvey-Berino, J., Kolodinsky, J., Narsana, R. T., \& Desisto, T. P. (2006). Consumers may not use or understand calorie labeling in restaurants. Journal of American Dietetics Association, 106, 917-920.

Kwan, M., Woo, J., \& Kwok, T. (2004). The standard oxygen consumption value equivalent to one metabolic equivalent $(3.5 \mathrm{ml} / \mathrm{min} / \mathrm{kg})$ is not appropriate for elderly people. International Journal of Food Sciences and Nutrition, 55(3), 179182.

Lando, A. M., \& Labiner-Wolfe, J. (2007). Helping consumers make more healthful food choices: Consumer views on modifying food labels and providing point-ofpurchase nutrition information at quick-service restaurants. Journal of Nutrition Education and Behavior, 39(3), 157-163.

Lichtman, S. W., Pisarska, K., Berman, E. R., Pestone, M., Dowling, H., Offenbacher, E., Weisel, H., Heshka, S., Matthews, D. E., \& Heymsfield, S. B. (1992).

Discrepancy between self-reported and actual caloric intake and exercise in obese subjects. New England Journal of Medicine, 327, 1893-1898.

Lin, B., Guthrie, J., \& Frazao, E. (1999). Away-from home foods increasingly important to quality of American diet. Washington DC: U.S. Department of Agriculture, Economic Research Service.

Lin, C. T., Lee, J. Y., \& Yen, S. T. (2004). Do dietary intakes affect search for nutrient information on food labels? Social Science and Medicine, 59, 1955-1967.

Lluch, A., King, N. A, \& Blundell, J. E. (1998). Exercise in dietary restrained women: No effect on energy intake but change in hedonic ratings. European Journal of Clinical Nutrition, 52(4), 300-307.

Lowe, M. R., \& Timko, C. A. (2004). What a difference a diet makes: towards an understanding of differences between restrained dieters and restrained nondieters. Eating Behavior, 5(3), 199-208.

Lowry, R., Galuska, D. A., Fulton, J. E., Wechsler, H., Kann, L., \& Collins, J. L. (2000). Physical activity, food choice, and weight management goals and practices among US college students. American Journal of Preventive Medicine, 18(1), 18-27.

Marietta, A. B., Welshimer, K. J., \& Anderson, S. L. (1999). Knowledge, attitudes, and behaviors of college participants regarding the 1990 Nutrition Labeling Education Act food labels. Journal of the American Dietetic Association, 99, 445-559. 
Macdiarmid, J. I, Vail, A., Cade, J. E., \& Blundell, J. E. (1998). The sugar-fat relationship revisited: Differences in consumption between men and women of varying BMI. International Journal of Obesity and Related Metabolic Disorders, 22, 1053-1061.

McClellan, M. B. (2003). Speech Before Harvard School of Public Health. Retrieved November 3, 2006, from www.fda.gov/oc/speeches/2003/harvard0701.html

McLeroy, K.R., Bibeau, D., Steckler, A. and Glanz, K., (1988) An Ecological Perspective on Health Promotion Programs Health Educ Behav,; 15: 351 - 377.

McCrory, M. A., Fuss, P. J., Hays, N. P., Vinken, A. G., Greenberg, A. S., \& Roberts, S. B. (1999). Overeating in America: Association between restaurant food consumption and body fatness in healthy adult men and women ages 19 to 80 . Obesity Research, 7(6), 564-71.

Menu Education and Labeling Act of 2007. Retrieved on June 23, 2007, from http://www.govtrack.us/congress/billtext.xpd?bill=h108-3444

Miller, D. L., Castellanos, V. H., Shide, D. J., Peters, J. C., \& Rolls, B. J. (1998). Effect of fat-free potato chips with and without nutrition labels on fat and energy intakes. American Journal of Clinical Nutrition, 68(2), 282-290.

Mills, J. S., \& Palandra, A. (2008). Perceived caloric content of a preload and disinhibition among restrained eaters. Appetite, 50(2-3), 240-245.

Mitka, M. (2005). Government unveils new food pyramid: Critics say nutrition tool is flawed. Journal of the American Medical Association, 293(21), 2581-2582.

Moreira, P., M. D. de Almeida, and D. Sampaio (2005). Cognitive Restraint Is Associated with Higher Intake of Vegetables in a Sample of University Students. Eating Behavior, 6, 229-237.

National Restaurant Association. (2007). Restaurant Industry Facts. Retrieved on March 9, 2007, from http://www.restaurant.org/research/ind_glance.cfm

Neuhouser, M. L., Kristal, A. R., \& Patterson, R. E. (1999). Use of food nutrition labels is associated with lower fat intake. Journal of the American Dietetic Association, 99, 45-53.

Nayga, R.M. (2000). Nutrition knowledge, gender, and food label use. The Journal of Consumer Affairs, 34(1), 97-112. 
Neumark-Sztainer D, Wall M, Guo J, Story M, Haines J, Eisenberg M. (2006) Obesity, disordered eating, and eating disorders in a longitudinal study of adolescents: how do dieters fare 5 years later? Journal American Dietetic Association. Apr;106(4):559-68.

O’Hegarty, M., Pederson, L. L., Yenokyan, G., Nelson, D., \& Wortley, P. (2007). Young adults' perceptions of cigarette warning labels in the United States and Canada. Prevention of Chronic Disease.

Paeratakul, S., Ferdinand, D. P., Champagne, C. M., Ryan, D. H., \& Bray, G.A. (2003). Fast-food consumption among US adults and children: Dietary and nutrient intake profile. Journal of the American Dietetic Association, 103(10), 1332-1338.

Pomeranz JL, Brownell KD. (2008) Legal and public health considerations affecting the success, reach, and impact of menu-labeling laws. Am J Public Health. Sep;98(9):1578-83.

Racette S. B., Deusinger, S. S., Strube, M. J., Highstein, G. R., \& Deusinger, R. H. (2005). Weight changes, exercise and dietary patterns during freshman and sophomore years of college. Journal of American College Health, 53(6), 245-251.

Raynor HA, Wing RR. (2007) Package unit size and amount of food: do both influence intake? Obesity (Silver Spring). Sep;15(9):2311-9.

Requirements of Laws and Regulations Enforced by the U.S. Food and Drug Administration. (2007). Food, nutrition, and cosmetics questions \& answers: When is nutrition labeling required? Retrieved on March 10, 2007, from http://www.cfsan.fda.gov/ dms/qa-indl2.html

Rideout, C. A., McLean, J. A., \& Barr, S. I. (2004). Women with high scores for cognitive dietary restraint choose foods lower in fat and energy. Journal of the American Dietetic Association, 104(7), 1154-1157.

Roberto CA, Agnew H, Brownell KD. (2009) An observational study of consumers' accessing of nutrition information in chain restaurants. American Journal of Public Health. May;99(5):820-1.

Rodearmel, S. J., Wyatt, H. R., Stroebele, N., Smith, S. M., Ogden, L. G., \& Hill, J. O. (2007). Small changes in dietary sugar and physical activity as an approach to preventing excessive weight gain: The America on the Move family study. Pediatrics, 120(4), e869-879. 
Rolls BJ, Morris EL, Roe LS. (2002) Portion size of food affects energy intake in normalweight and overweight men and women. Am J Clin Nutr;76:1207-1213.

Rothman, R. L., Housam, R., Weiss, H., Davis, D., Gregory, R., Gebretsadik, T., Shintani, A., \& Elasy, T. A. (2006). Patient understanding of food labels: The role of literacy and numeracy. American Journal of Preventative Medicine, 31(5), 391-398.

Rotenberg, K. J., and D. Flood (2000). Dietary Restraint, Attributional Styles for Eating, and Preloading Effects. Eat Behavior, 1, 63-78.

Rzewnicki R, Vanden Auweele Y, De Bourdeaudhuij I. (2003) Addressing overreporting on the International Physical Activity Questionnaire (IPAQ) telephone survey with a population sample. Public Health Nutrition. May;6(3):299-305

Satia, J. A., Galanko, J. A., \& Neuhouser, M. L. (2005). Food nutrition label use is associated with demographic, behavioral, and psychosocial factors and dietary intake among African Americans in North Carolina. Journal of the American Dietetic Association, 105, 392-402.

Satia, J. A., Galanko, J. A., \& Siega-Riz, A. M. (2004). Eating at fast-food restaurants is associated with dietary intake, demographic, psychosocial and behavioural factors among African Americans in North Carolina. Public Health Nutrition, 7(8), 10891096.

Salbe, A. D, DelParigi, A., Pratley, R. E., Drewnowski, A., \& Tataranni, P. A. (2004). Taste preferences and body weight changes in an obesity-prone population. American Journal of Clinical Nutrition, 79(3), 372-378.

Savage, P. D., Toth, M. J., \& Ades, P. A. (2007) A re-examination of the metabolic equivalent concept in individuals with coronary heart disease. Journal of Cardiopulmonary Rehabilitation and Prevention, 27(3), 143-148.

Schwartz, J., \& Byrd-Bredbenner, C. (2006). The ability of young adults to estimate portion size and calorie content. Topics in Clinical Nutrition, 21, 114-118.

Seymour, J. D., Yaroch, A. L., Serdula, M., Blanck, H. M., \& Khan, L. K. (2004). Impact of nutrition environmental interventions on point of purchase behavior in adults: A review. Preventative Medicine, 39(Suppl 2), S108-S136.

Simon P, Jarosz CJ, Kuo T, Fielding JE. (2008) Menu Labeling as a Potential Strategy for Combating the Obesity Epidemic: A Health Impact Assessment. Los Angeles 
County Department of Public Health. Accessed on July 18, 2008 at www.cspinet.org/new/pdf/la_co._menu_labeling_report.pdf

Simons, E., Weiss, C. C., Furlong, T. J., \& Sicherer, S. H. (2005). Impact of ingredient labeling practices on food allergic consumers. Annals of Allergy, Asthma, and Immunology, 95(5), 426-428.

Slootmaker SM, Schuit AJ, Chinapaw MJ, Seidell JC, van Mechelen W. (2009) Disagreement in physical activity assessed by accelerometer and self-report in subgroups of age, gender, education and weight status. International Journal of Behavioral Nutrition and Physical Activity. Mar 25;6:17

Smith, S. C., Taylor, J. G., \& Stephen, A. M. (2000). Use of food labels and beliefs about diet-disease relationships among university students. Public Health Nutrition, 3(2), 175-182.

Sproul, A., Canter, D., \& Schmidt J. (2003). Does point-of-purchase nutrition labeling influence meal selections? A test in an Army cafeteria. Military Media, 168(7), 556-60.

Steenhuis, I., van Assema, P., van Breukelen, G., \& Glanz, K. (2004). The effectiveness of nutrition education and labeling in Dutch supermarkets. American Journal of Health Promotion, 18(3), 221-224.

Steenhuis, I., Van Assema, P., Van Breukelen, G., Glanz, K., Kok, G., \& De Vries, H. (2004). The impact of educational and environmental interventions in Dutch worksite cafeterias. Health Promotion International, 19(3), 335-43.

Story, M., Neumark-Sztainer, D., Sherwood, N., Stang, J., \& Murray, D. (1998) Dieting status and its relationship to eating and physical activity behaviors in a representative sample of US adolescents. Journal American Dietetic Association, 10, 1127-35.

Strecher, V. J., \& Rosenstock, I. M. The Health Belief Model. In: Glanz K, Lewis FM, Rimer BK, eds. Health Behavior and Health Education: Theory, Research, and Practice. 2nd ed. San Francisco, Calif: Jossey-Bass Publishers; 1997:41-59.

Stunkard, A. J. (1981). "Restrained Eating": What It Is and a New Scale to Measure It. in L. A. Cioffi, W. P. T. James and T. B. Van Itallie (Eds.), The Body Weight Regulatory System: Normal and Disturbed Mechanisms. New York: Raven Press, 243-251. 
Stunkard, A. J., \& Messick, S. (1988). Eating inventory manual. San Antonio: The Psychological Corporation.

Sysko, R., Walsh, T. B., \& Wilson, T. G. (2007). Expectancies, dietary restraint, and test meal intake among undergraduate women. Appetite, 49(1), 30-37.

The SAS System for Mixed Models, RC Littell, GA Milliken, WW Stroup, RD Wolfinger. SAS Publishing; 2nd edition (February 21, 2006) PASS Help System for PASS 2008.

Technomic, Inc, (2009) Consumer Reaction to Calorie Disclosure On Menus/Menu Boards In New York City, Project Number 13267, February 2009

Thompson, O. M., Ballew, C., Resnicow, K., Must, A., Bandini, L. G., Cyr, H., \& Dietz, W. H. (2004). Food purchased away from home as a predictor of change in BMI z-score among girls. International Journal of Obesity Related Metabolic Disorders, 28(2), 282-289.

Togo, P., Osler, M., Sørensen, T. I., \& Heitmann, B. L. (2001). Food intake patterns and body mass index in observational studies. International Journal of Obesity and Related Metabolic Disorders, 25(12), 1741-1751. Review.

Trumbo, P., Schlicker, S., Yates, A. A., \& Poos, M. (2002). Dietary reference intakes for energy, carbohydrate, fiber, fat, fatty acids, cholesterol, protein and amino acids. Journal of the American Dietetic Association, 102, 1621-1630.

Variyam, J. (2005). U.S. Department of Agriculture. Nutrition Labeling in the FoodAway-From-Home Sector: An Economic Assessment (Economic Research Service Publication No. 4). Washington DC Variyam, J.

Urbszat, D., Herman, C. P., \& Polivy, J. (2002). Eat, drink, and be merry, for tomorrow we diet: Effects of anticipated deprivation on food intake in restrained and unrestrained eaters. Journal of Abnormal Psychology, 111(2), 396-401.

U.K. Food Standards Agency (2009) Restaurants and catering companies bring in calories on menus. Press release from April 6, 2009. Retrieved July 22, 2009, from http://www.food.gov.uk/news/pressreleases/2009/apr/companiescaloriesmenus.

U.S. Department of Health and Human Services, (2001). Centers for Disease, Control and Prevention, National Center for Health Statistics. Healthy People 2000 Final Review. Hyattsville, MD: U.S. Department of Health and Human Services, Centers for Disease Control and Prevention, National Center for Health Statistics, 
2001. DHHS Publication No. 01-0256. Retrieved on March 10, 2007, from http://www.cdc.gov/nchs/data/hp2000/hp2k01-acc.pdf

U.S. Department of Health and Human Services and US Department of Agriculture. Dietary Guidelines for Americans, 2005, 6th edn. US Government Printing Office: Washington, DC.

U.S. Food and Drug Administration. (2004). Counting Calories: Report of the Working Group on Obesity. Retrieved March 9, 2007, from http://www.cfsan.fda.gov/ dms/owg-appg.html

U. S. Food and Drug Administration. (1999). The Food Label. Retrieved on March 10, 2007, from http://www.cfsan.fda.gov/ dms/fdnewlab.html

Vartanian LR, Herman CP, Polivy J. (2006) Does regulatory focus play a role in dietary restraint? Eat Behavoir. Nov;7(4):333-41.

Verduin, P., Agarwal, S., \& Waltman, S. (2005). Solutions to obesity: Perspectives from the food industry. American Journal of Clinical Nutrition, 82, 259S-261S.

Visona, C., George, V. A. (2002). Impact of dieting status and dietary restraint on postexercise energy intake in overweight women. Obesity Research, 10(12), 1251-1258.

Wansink, B., \& Chandon, P. (2006). Meal size, not body size, explains errors in estimating the calorie content of meals. Annals of Internal Medicine, 145, 326332.

Wansink B, Painter JE, North J. (2005) Bottomless bowls: why visual cues of portion size may influence intake. Obes Res;13:93-100.

Welch, J. L., \& Swift, C. O. (1992). Question order effects in taste testing of beverages. Journal of the Academy of Marketing Science, 20(3), 265-268.

Online publication date: 1-Jul-1992.Wootan, M. G. \& Osborn, M. (2006). Availability of nutrition information from chain restaurants in the United States. American Journal of Preventive Medicine, 30(3), 266-268.

Wootan, M. G., Osborn, M., \& Malloy, C. J. (2006). Availability of point-of-purchase nutrition information at a fast-food restaurant. Preventative Medicine, 43(6), 458459. 
Yamamoto, J. A., Yamamoto, J. B., \& Yamamoto, B. E., et al. (2005). Adolescent fast food and restaurant ordering behavior with and without calorie and fat content menu information. Journal of Adolescent Health, 37, 397- 402.

Zhai F, Wang H, Wang Z, Popkin BM, Chen C. (2008) Closing the energy gap to prevent weight gain in China. Obes Rev. Mar;9 Suppl 1:107-12. 


\section{APPENDICES}

Appendix A

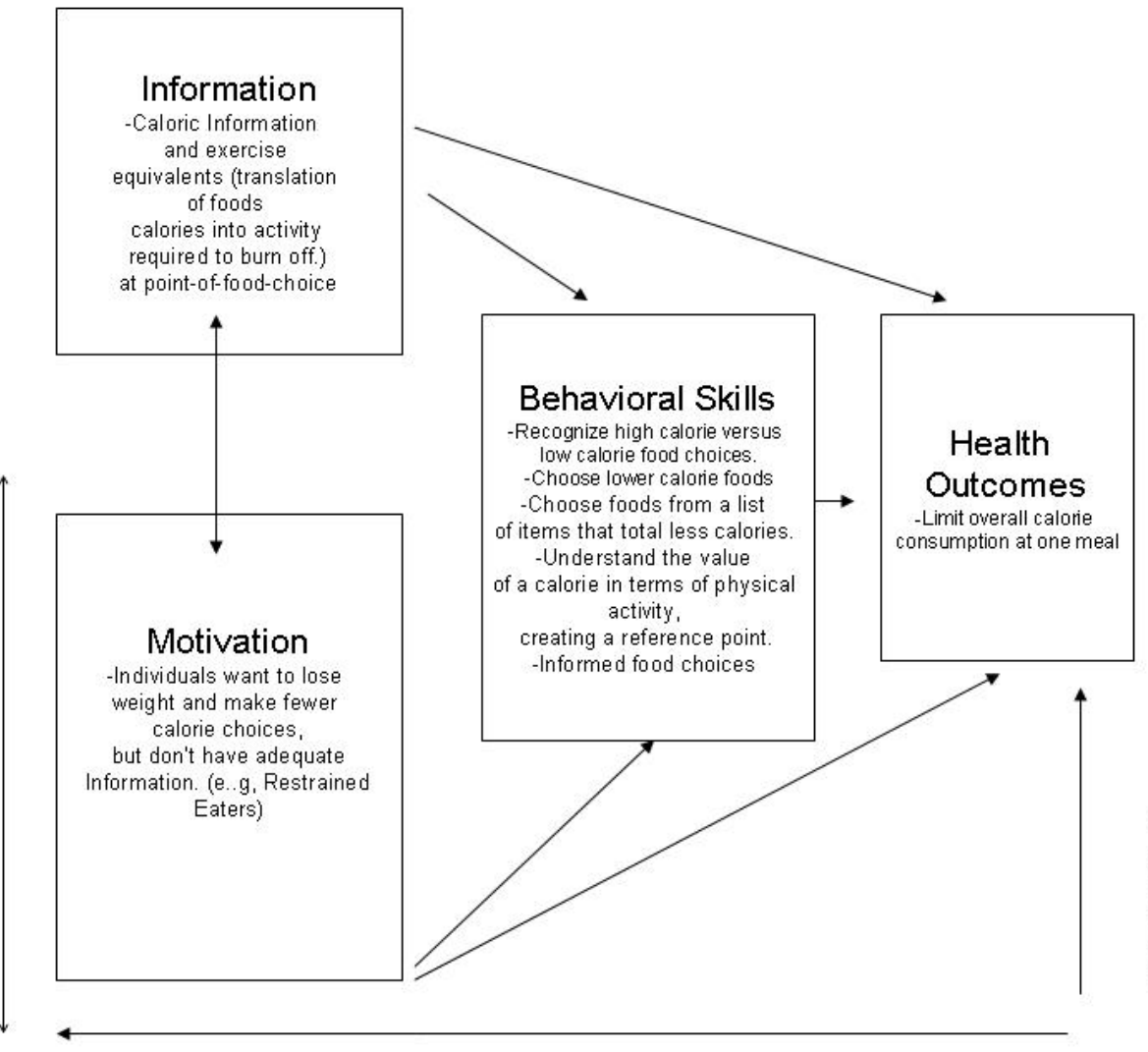

IMB Model: Calories and Exercise Equivalents at The Point-of-Choice at One Fast Food Meal

Moderating and Mediating Factors -Depression Chemical dependency -Eating Disorder -Body Mass Index - Gender - Literacy and Education Level -Peer Influences -Dieting Status -Physical Activity Level 


\section{Appendix B}

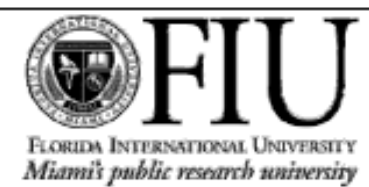

This is a confidential survey as part of the Platkin Lunch Study being conducted by Charles Stuart Platkin. The information provided will be held in confidence with the study's researchers from FIU's Robert Stempel College of Public Health and Social Work. Please review and sign consent form first.

Name __ Study \#__ Group

Office Number

Cell Phone Number

Address:

City:

State

Zip:

Best time to contact you E-mail

Sex (circle one) Male Female FIU Status: (Circle one) Student Faculty Staff

Age Birth date

Weight (by Researcher)

Height (by Researcher)

Please circle the best response:

1. What is vour total household income, including all earners in your household? (Circle one)

Less than $\$ 10,000$

$\$ 10,000-\$ 29,999$

$\$ 30,000-\$ 49,999$

$\$ 50,000-\$ 69,999$

$\$ 70,000-\$ 89,999$

$\$ 90,000-\$ 119,999$

$\$ 120,000-\$ 149,000$

More than $\$ 150,000$

Don't know / Not sure

2. What level of education have you completed? (Circle one)

Less than High School

High School/GED

Some College

2-Year College Degree (Associates)

4-Year College Degree (BA,BS)

Master's Degree

Doctoral Degree

Professional Degree (MD,J)

Don't know / Not sure 
3. What is your race/ ethnicity? (Circle all that apply)

White, non-Hispanic

Black or African-American

Caribbean, non-Hispanic

Hispanic or Latino

Asian-Pacific Islander

Native American

Don't know / Not sure

4. What is your current marital status? (Circle one)

Single, Never Married

Married

Separated

Divorced

Widowed

Member of an unmarried couple
5. What is your religious affiliation? (Circle one)

Christian

Catholic

Jewish

Muslim

Hindu

Buddhist

Other

6. Do you classify yourself as? (Circle one)

Nonsmoker

Occasional Smoker

Former Smoker

Current Cigarette Smoker

7. Are you currently on a diet or weight loss program? (Circle one)

Yes

No

Don't know / Not sure

8. During the past 3 months, have you tried to lose weight? (Circle one)

Yes

No

Don't know / Not sure 
9. How would you rate your everyday physical activity (including work)? (Circle One) Activity Level (please circle)

Sedentary You sit, drive, lie down or stand in one place for most of the day and don't do any type of

Lightly Active You're sedentary for most of the day and do light activity, such as walking, for no more than two hours daily.

Moderately You're on your feet most of the workday, with light lifting only, and do no structured exercise. Active

Your typical workday includes several hours of physical labor, such as light industry and

Very Active construction-type jobs, and / or you have a regular daily exercise program such as walking for an hour each day.

Extremely You do heavy manual labor, Anny and Marine recruit training or are a competitive athlete.

Active

Thank you for completing this survey. 
Appendix C

International Physical Activity Questionnaire -

Fast Food Lunch Study_Charles Stuart Platkin -Doctoral Research (AFTER

CONSENT ONLY)

Name

Participant Number

We are interested in finding out about the kinds of physical activities that people do as part of their everyday lives. The questions will ask you about the time you spent being physically active in the last 7 days. Please answer each question even if you do not consider yourself to be an active person. Please think about the activities you do at work, as part of your house and yard work, to get from place to place, and in your spare time for recreation, exercise or sport.

Think about all the vigorous activities that you did in the last $\mathbf{7}$ days. Vigorous physical activities refer to activities that take hard physical effort and make you breathe much harder than normal. Think only about those physical activities that you did for at least 10 minutes at a time.

1. During the last $\mathbf{7}$ days, on how many days did you do vigorous physical activities like heavy lifting, digging, aerobics, or fast bicycling? days per week $\square$ No vigorous physical activities $\longrightarrow$ Skip to question 3

2. How much time did you usually spend doing vigorous physical activities on one of those days? hours per day minutes per day

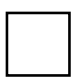

Don't know/Not sure

Think about all the moderate activities that you did in the last 7 days. Moderate activities refer to activities that take moderate physical effort and make you 
breathe somewhat harder than normal. Think only about those physical activities that you did for at least 10 minutes at a time.

3. During the last $\mathbf{7}$ days, on how many days did you do moderate physical activities like carrying light loads, bicycling at a regular pace, or doubles tennis? Do not include walking. days per week

$\square$ No moderate physical activities $\longrightarrow$ Skip to question 5

4. How much time did you usually spend doing moderate physical activities on one of those days?

$$
\begin{aligned}
& \text { hours per day } \\
& \text { minutes per day }
\end{aligned}
$$

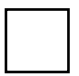

Don't know/Not sure

Think about the time you spent walking in the last 7 days. This includes at work and at home, walking to travel from place to place, and any other walking that you might do solely for recreation, sport, exercise, or leisure.

5. During the last $\mathbf{7}$ days, on how many days did you walk for at least 10 minutes at a time? days per week

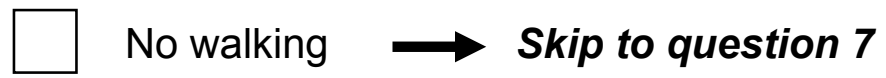

6. How much time did you usually spend walking on one of those days?

hours per day minutes per day 


\section{Don't know/Not sure}

The last question is about the time you spent sitting on weekdays during the last 7 days. Include time spent at work, at home, while doing course work and during leisure time. This may include time spent sitting at a desk, visiting friends, reading, or sitting or lying down to watch television.

7. During the last 7 days, how much time did you spend sitting on a week day?

hours per day

minutes per day

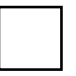

Don't know/Not sure

\section{This is the end of the questionnaire, thank you for participating.}




\section{Appendix D}

Date

Time

\section{Lunch Study Menu}

Please Fill Out The Information On Top With Pen- Use The Highlighter To Mark Your Order. Make Sure To Highlight The Entire Box So Your Order Is Clear. And Make One Duplicate Copy Of This Order - -That's Why You Have Two (2) Order Sheets. Thanks!

\begin{tabular}{|c|c|c|c|c|}
\hline Food & $\checkmark$ & Food & $\checkmark$ & \\
\hline BURGERS & & CHICKEN SANDWICHES & & \\
\hline WHOPPER & & TENDERGRIL Chicken & & \\
\hline w/Cheese & & No Mavo & & \\
\hline \multirow{2}{*}{ No Mavo } & & & & \\
\hline & & TENDERCRISP Chicken & & \\
\hline DOUBLE WHOPPER & & No Mayo & & \\
\hline \multicolumn{5}{|l|}{ No Mayo } \\
\hline DOUBLE WHOPPER WITH CHEESE & & OTHER FAVORITES & & \\
\hline \multirow[t]{2}{*}{ No Mayo } & & BK BIG FISH Sandwich & & \\
\hline & & No Tarter & & \\
\hline \multicolumn{5}{|l|}{ TRIPLE WHOPPER WITH CHEESE } \\
\hline No Cheese & & BK VEGGIE Burger & & \\
\hline \multirow[t]{2}{*}{ No Mayo } & & w/Cheese & & \\
\hline & & No Mayo & & \\
\hline & & & & \\
\hline WHOPPER JR. & & BK CHICKEN FRIES ( $6 \mathrm{PC}$ ) & & \\
\hline w/Cheese & & BK CHICKEN FRIES ( 9 PC) & & \\
\hline No Mayo & & Barbecue Dipping Sauce & & \\
\hline Hamburger & & Honey Mustard Dipping Sauce & & \\
\hline Double Hamburger & & Sweet and Sour Dipping Sauce & & \\
\hline Chesseburger & & Ranch Dipping Sauce & & \\
\hline \multicolumn{5}{|l|}{ Double Cheeseburger } \\
\hline \multicolumn{5}{|l|}{ BK Stacker } \\
\hline No Bacon & & FRIES \& ONION RINGS & & \\
\hline No Sauce & & French Fries (Sm) & & \\
\hline \multirow{3}{*}{ No Cheese } & & French Fries (Med) & & \\
\hline & & French Fries (Lrg) & & \\
\hline & & Onion Rings (Med) & & \\
\hline SALADS & & Onion Rings (Lrg) & & \\
\hline \multicolumn{5}{|l|}{ TENDERGRILL Chicken Garden Salad } \\
\hline TENDERCRISP Chicken Garden Salad & & DESSERTS & & \\
\hline \multirow[t]{2}{*}{ Garden Salad (no chicken) } & & Dutch Apple Pie & & \\
\hline & & HERSHEY'S Sundae Pie & & \\
\hline \multicolumn{5}{|l|}{ DRESSING } \\
\hline \multicolumn{5}{|l|}{ KEN'S Light Itallan Dressing } \\
\hline KEN'S Ranch Dressing & & DRINKS & & \\
\hline KEN'S Creamy Caesar Dressing & & Vanilla Milk Shake (Med) & & \\
\hline KEN'S Honey Mustard Dressing & & Vanilla Milk Shake (Lrg) & & \\
\hline \multirow[t]{3}{*}{ Garlic Parmesan Croutons } & & Chocolate Milk Shake (Med) & & \\
\hline & & Chocolate Milk Shake (Lrg) & & \\
\hline & & $\operatorname{COCA} \operatorname{COLA}(\mathrm{Sm})$ & & \\
\hline VALUE MEALS & & COCA COLA (Med) & & \\
\hline (Comes w/ Med Fries \& Med Soda) & & COCA COLA (Lrg) & & \\
\hline 1-WHOPPER & & SPRITE $(\mathrm{Sm})$ & & \\
\hline 2-DOUBLE WHOPPER & & SPRITE (Med) & & \\
\hline 3 - TRIPLE WHOPPER W/ CHEESE & & SPRITE (Lrg) & & \\
\hline 4-WHOPPER JR & & DIET COKE $(\mathrm{Sm})$ & & \\
\hline 5 - BK DOUBLE STACKER & & DIET COKE (Med) & & \\
\hline 6 - TENDERCRISP CHICK SANDWICH & & DIET COKE (Lrg) & & \\
\hline 7 - BK CHICKEN FRIES $(9$ pc.) & & Apple Juice & & \\
\hline $\begin{array}{l}8 \text { - TENDERGRILL CHICKEN } \\
\text { SANDWICH }\end{array}$ & & Bottled Water & & \\
\hline & & & & \\
\hline EXTRAS & & $\begin{array}{l}\text { Zesty Onion Ring Dipping } \\
\text { Sauce }\end{array}$ & & \\
\hline Ketchup (Packet) & & Mayonnaise (Packet) & & \\
\hline
\end{tabular}


Name

PLEASE FILL OUT THE INFORMATION ON TOP WITH PEN- USE THE HIGHLIGHTER TO MARK YOUR ORDER. MAKE SURE TO HIGHLIGHT THE ENTIRE BOX SO YOUR ORDER IS CLEAR. AND MAKE ONE DUPLICATE COPY OF THIS ORDER - - THATS WHY YOU HAVE TWO(2) ORDER SHEETS. THANKS!

\begin{tabular}{|c|c|c|c|c|c|}
\hline Food & 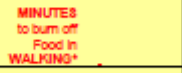 & Calonies & Food & 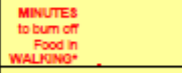 & Calories \\
\hline BUROERS & & & CHCKEN SANOWCHES & & \\
\hline WHOPPER & 187.5 Mn Wak of & $670 \quad$ Coss & TENDERORUL COKKKEn & 122.6 Mn Wak on & $490 \quad$ cast \\
\hline wicheese & 182.5 Mn Wak of & 770 cas & Nonloyo & 96 Mn Wak on & 380 Cas: \\
\hline No101000 & 130 Mn Wak of & $520 \quad$ Cos & & & \\
\hline & & & TENDERCEISP CONCKEN & 2000 Mn Wak on & $800 \quad$ Cas \\
\hline DOUBLE WHOFPER & 230 Mn Wak or & $920 \quad \cos s$ & Nolloyo & 147.6 Mn Wak on & 590 cas \\
\hline No Mayo & 187.5 Mn Wak on & $670 \cos$ & & & \\
\hline & & & OTHER FAMOBIIE: & & \\
\hline DOUBLE WHOPPER WITH CHEESE & 252.5 Mn Wak of & 1010 Cass & EK B) FISH smowich & 150 Mn Wax on & 640 cass \\
\hline Noloyo & 212.5 Mn Wak of & $850 \quad \cos 5$ & No Tanter & 116 Mn Wak on & $450 \quad$ case \\
\hline TRPLE WHOFPER WITH CHEESE & 312.5 Mn Wak of & 1250 Cass & gKVEOOIE Burer & 106 Mn Wax on & $420 \quad \cos \theta$ \\
\hline Nob Creese & 290 Mn Wak of & 1150 coss & woreese & 117.6 Mn Wak on & $470 \quad \cos$ \\
\hline Noleve & 272.6 Mn Wak or & 1090 Coss & No llovo & 86 Mn Wak on & 340 cas \\
\hline & & & EK CHCXEN FRES $(6 \mathrm{PC})$ & 62.5 Mn Wak on & 250 Cas: \\
\hline WHOFPER. $\mathbb{R}$. & 82.6 Mn Wak of & $3 \pi 0$ Cas & EK CHICXEN FRES (9PC) & 96 Mn Wak on & $390 \quad$ Cass \\
\hline woreese & 105 Mn Wak on & $420 \quad \cos$ & \begin{tabular}{|c|} 
Sardecue Dlpoing Sauce \\
\end{tabular} & 10 Mn Wak on & $40 \quad \cos$ \\
\hline Nolayo & 72.5 Mn Wak of & $290 \quad \cos$ & Honey Huztard Digaing Sauce & 22.6 Mn Wak on & $90 \quad \cos$ \\
\hline Hambures & 72.5 Mn Wak of & $290 \quad$ Cass & Sweer and Sour Dlpging Sauce & 11.26 Mn Wak on & $45 \quad \cos$ \\
\hline Double Hamburger & 105 Mn Wak of & 420 Cass & Fanch Dlgoing Sauce & 36 Mn Wak on & ino cas \\
\hline crescoburper & 85 Mn Wak of & $340 \quad \cos$ & & & \\
\hline Double Chesezburper & 127.6 Mn Wak of & $510 \quad \cos 2$ & & & \\
\hline EK sbocker & 165 Mn Wak of & $620 \quad \cos 5$ & FRES \& ONION RINOS & & \\
\hline No Bscon & 140 Mn Wak or & $560 \quad \cos$ & French Finea (Aved) & 120 Mn Wak or & $490 \quad$ cas \\
\hline No Ssuce & 137.6 Mn Wak of & 550 cass & French Finea (Lr) & 145 Mn Wak of & 580 Case \\
\hline no Creese & 132.5 Mn Wak on & $530 \quad \cos$ & Onion Ringa (Nes) & 112.6 Mn Wak on & $450 \quad$ cass \\
\hline 9ALAOR & 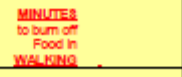 & $\begin{array}{l}\frac{5}{8} \\
\frac{8}{8} \\
\end{array}$ & Onion Ringa (Lr) & 127.6 Mn Wak on & 510 \\
\hline 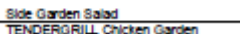 & $10 \mathrm{Mn}$ Wak on & $40 \quad \cos$ & & & \\
\hline 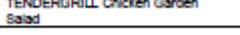 & 62.5 Mn Wak or & $210 \quad$ Cass & DEQMERTE & & \\
\hline $\begin{array}{l}\text { TENDERCRisP Chicken Carden } \\
\text { Salod }\end{array}$ & 102.6 Mn Wak of & $410 \quad$ cas a & Duth Apole Pe & 80 Mn Wak on & 320 cas \\
\hline Orrden Sasd ino chicken) & 17.5 Mn Wak of & 70 Cass & HERSHEYrs Sundse PVE & $\pi .6$ Mn Wak on & $310 \quad$ Cass \\
\hline \multicolumn{6}{|l|}{ DFEsasino } \\
\hline KENS Laper mivn Diesshe & so Mn Wak on & $120 \quad \cos$ & PEIALS & & \\
\hline KENS Fanch Dressing & 47.5 Mn Wak of & $190 \quad \cos$ & Varlla MR shore areosi & 120 Mn Wak on & 490 Cass \\
\hline KENS Creany coesar Dressing. & 52.5 Mn Wak of & $210 \quad \cos$ & Varlla Mr shoke(G) & 180 Mn Wak on & $720 \mathrm{cos}$ \\
\hline KENS Honey Lestord Dressing & 87.5 Mn Wak of & $270 \quad \cos$ & Chocolate Mik shake atesi) & 187.5 Mn Wak on & $670 \cos$ \\
\hline Grilc Pamresan Cooutons & 16 Mn Wak or & 60 coss & Chocoute Mik shake (IS) & 247.6 Mn Wak on & $990 \quad$ Cas \\
\hline & & & $\cosh \cos (8 m)$ & 62.6 Mn Wak on & $210 \quad$ cas \\
\hline YALUE MEALS & & & coch conariest & 72.6 Mn Wak on & $290 \quad$ cass \\
\hline 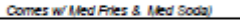 & & & $\cos \cos (\operatorname{lig})$ & 87.6 Mn Wak or & 390 Case \\
\hline 1-WHOPFER & 387.5 Mn Wak of & 1550 cas & SPFITE $(8 m)$ & 62.6 Mn Wak on & $210 \quad$ cas \\
\hline 2- DOUELE WHOPFER & $47.5 \mathrm{Mn}$ Wak of & $1790 \quad$ Cas & SPATE (MVOST) & 72.6 Mn Wak on & $290 \quad$ Cas \\
\hline 3-TFIPLE WHOFPER W/ CHEESE & 632.5 Mn Wak of & 2130 Cas & SPATE (IR) & 87.6 Mn Wak on & $390 \quad \cos 5$ \\
\hline 4-WHOPFER JR & 310 Mn Wak or & 1240 Cas & DET CONE $(\mathrm{sm})$ & 0 Mn Wak on & $0 \quad \cos s$ \\
\hline 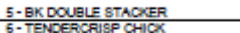 & 372.5 Mn Wak of & 1490 Cass & DET COKE OMEO & 0 Mn Wak on & a cas: \\
\hline $\begin{array}{l}\text { 6.TFEDEACUISP CHICK } \\
\text { SNOWICH }\end{array}$ & 417.5 Mn Wak of & 1670 Cas & DET COKE (IVR) & 0 Mn Wak on & $0 \quad \cos$ \\
\hline 7-BKCHICKEN FFIES $(9 \mathrm{PC})$ & 32.5 Mn Wak of & 1330 Cas & \begin{tabular}{|l|l|} 
Agoie Nusce \\
\end{tabular} & 26 Mn Wak on & 100 case \\
\hline $\begin{array}{l}\text { 8-TENDEACRLLL CHICKEN } \\
\text { SWNOWOH }\end{array}$ & 3es Mn Wak or & $1360 \quad$ cas & Boted Water & 0 Mn Wak on & \\
\hline
\end{tabular}

* In the $2^{\text {sd }}$ column are the Exercise Equivalents - How long it take to actually BURN OFF the food you've just eaten in minutes - yes, these are the minutes you would have to WALK to burn off that food. The corresponding calonies are in the next column 
Name

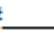

Date

Time

Lunch Study Menu

USE THE HIGHUIGHTER TO MARK YOUR ORDER MAKE SURE TO HIGHUIGHT THE ENTIRE BOX SO YOUR ORDER IS CLEAR. AND MAKE ONE DUPLICATE COPY OF THIS ORDER - -THAT'S WHY YOU HAVE TWO(2) ORDER SHEETS. THANKS!

\begin{tabular}{|c|c|c|c|c|c|}
\hline Food & 1 & Calories & Food & 1 & Calories \\
\hline \multicolumn{6}{|l|}{ BURGERS } \\
\hline WHOPPER & & $670 \quad$ Cals & CHICKEN SANDMMCHES & & \\
\hline wcheese & & 770 Cals & TENDERGRILL ChIcken & & $490 \quad$ Cals \\
\hline No Mayo & & $520 \quad \mathrm{Ca} 15$ & No layo & & $380 \quad$ Cals \\
\hline & & & & & \\
\hline DQUBLE WHOPPER & & $920 \quad \mathrm{Ca} / 5$ & TENDERCRISP ChICken & & 800 Cals \\
\hline No layo & & $670 \quad \mathrm{Ca} 15$ & No Mayo & & $590 \quad$ Cals \\
\hline DOUBLE WHOPPER WITH CHEESE & & & & & \\
\hline \multirow[t]{2}{*}{ No Mayo } & & 850 Cals & BK BIG FISH Sandialch & & $640 \quad$ Cals \\
\hline & & & No Tanter & & $460 \quad$ Cals \\
\hline TRIPLE WHOPPER WITH CHEESE & & $1250 \quad$ Cals & & & \\
\hline No Cheese & & 1160 Cals & BK VEGGIE Burger & & $420 \quad$ Cals \\
\hline \multirow{2}{*}{ No Mayo } & & $1090 \quad \mathrm{Cal} 5$ & wCheese & & $470 \quad$ Cals \\
\hline & & & Nongyo & & $340 \quad$ Cals \\
\hline \multirow{2}{*}{ WHOPPER JR } & & & & & \\
\hline & & 370 Cals & BK CHICKEN FRIES (6 PC) & & $250 \quad$ Cals \\
\hline \multirow{2}{*}{$\begin{array}{l}\text { whCheese } \\
\text { No Mavo }\end{array}$} & & 420 Cals & BK CHICKEN FRIES ( 9 PC) & & 380 Cals \\
\hline & & 290 Cals & Bardecue Dipoing Sauce & & $\triangle 0 \quad$ Cals \\
\hline Hamburger & & 290 Cals & $\begin{array}{r}\text { Honey Mustard Dopping } \\
\text { Sauce }\end{array}$ & & 90 Cals \\
\hline Double Hamburger & & 420 Cals & $\begin{array}{r}\text { Sweet and Sour Digping } \\
\text { Sauce }\end{array}$ & & $45 \quad$ Cals \\
\hline Chesseourger & & $340 \quad$ Cals & Ranch Dipoing Sauce & & $140 \quad$ Cals \\
\hline Double Cheeseburger & & $510 \quad$ Cals & & & \\
\hline BK Stacker & & $620 \quad$ Cals & FRIES \& ONION RINGS & & \\
\hline No Bacon & & $560 \quad$ Cals & French Fries (SM) & & 340 \\
\hline No Sauce & & $550 \quad$ Cals & French Files (Med) & & 490 \\
\hline \multirow[t]{2}{*}{ No Cheese } & & Cals & French Frles $(\mathrm{Lg})$ & & 580 Cals \\
\hline & & & Orion Rings (Med) & & $450 \quad$ Cals \\
\hline \multicolumn{2}{|l|}{ SALADS } & & Onion Rings (Lra) & & $510 \quad$ Cals \\
\hline \multicolumn{2}{|l|}{ TENDERGFILL Chicken Garden Salad } & $210 \quad$ Cals & & & \\
\hline \multicolumn{2}{|l|}{ TENDERCRISP Cricken Garden Salad } & $410 \quad$ Cals & DESSERTS & & \\
\hline \multirow[t]{3}{*}{ Garden Salad (no cricken) } & & 70 Cals & Dutch Apple Ple & & $320 \quad$ Cals \\
\hline & & & HERSHEYS SUndae Ple & & $310 \quad$ Cais \\
\hline & & & & & \\
\hline \multicolumn{6}{|l|}{ DRESSSING } \\
\hline \multicolumn{2}{|l|}{ KENS Light Italan Dressing } & $120 \mathrm{Ca} 15$ & & & \\
\hline KENS Ranch Dressing & & $190 \quad \mathrm{Ca} / \mathrm{s}$ & DRINIKS & & \\
\hline KENS Creamy Caesar Dressing & & 210 Cals & Vanlla Milk Shake (Med) & & 480 \\
\hline KENS Honey Mustard Dressing & & 270 Cals & Vanlla MIIk Shake (Lm) & & 720 \\
\hline Garlic Pamesan Croutons & & Cals & Chocolate Mik Shake (Med) & & 670 \\
\hline & & & Chocolate MIIK Shzke (Lr) & & 990 \\
\hline & & & COCA COLA $(S m)$ & & $210 \quad$ Cals \\
\hline YALUEEMEALS & & & COCA COLA(MeO) & & 290 Cals \\
\hline Comes W' Med Files \& Med Soda) & & & COCA COLA (Irg) & & 390 \\
\hline 1-WHOPPER & & 1550 Cals & SPRITE $(\mathrm{Sm})$ & & $210 \quad$ Cals \\
\hline 2- DOUBLE WHOPPER & & 1790 Cals & SPRITE (Med) & & $290 \quad$ Cals \\
\hline 3-TRIPLE WHOPPER WI CHEESE & & $2130 \quad$ Cals & SPRITE (LM) & & $390 \quad$ Cals \\
\hline 4-WHOPPER JR & & $1240 \quad$ Cals & DIET COKE $(\mathrm{Sm})$ & & Cals \\
\hline 5-BK DOUBLE STACKERR & & 1490 Cals & DIET COKE (Med) & & Cals \\
\hline 6-TENDERCRISP CHICK SANDWICH & & $1670 \quad$ Cals & DIET COKE (Lrq) & & 0 Cals \\
\hline 7 - BK CHICKEN FRIES (9 PC.) & & $1330 \quad$ Cals & Apple Julce & & 140 \\
\hline $\begin{array}{l}\text { 8-TENDERGRIL CHICKEN } \\
\text { SANDWCH }\end{array}$ & & 1360 Cals & Bottled Water & & Cals \\
\hline & & & & & \\
\hline EXTRAS & & & $\begin{array}{l}\text { Zesty Onion Ring Dipping } \\
\text { Sauce }\end{array}$ & & 150 \\
\hline Ketchup (Packet) & & $10 \quad \mathrm{Ca} / 5$ & Mayonnaise (Packet) & & 80 Cais \\
\hline
\end{tabular}




\section{CHARLES STUART PLATKIN}

2007-2009

Host and Nutrition, Fitness and Health Advocate

"I Want To Save Your Life" Series

WE Television

2006-Present

Founder and Editor

DietDetective.com, Nutrition, Fitness and Health Advocacy

2004

Masters of Public Health

Florida International University, Miami, FL

2002-Present

Founder and CEO

Integrated Wellness Solutions

$2000-2004$

CEO, Personal wellness counseling with registered dietitians via email

Nutricise

1993-1998

Co-founder and CEO, Healthcare Consulting, Public Relations Marinex

1991

Juris Doctorate

Fordham University School of Law, New York, New York

1984

Bachelor of Science

Cornell University, Ithaca, New York

\section{SELECTED PROFESSIONAL PRESENTATIONS AND PUBLICATIONS}

Platkin, Charles S (2008), The Diet Detective's Calorie Bargain Bible, New York, Simon and Schuster/Pocket Books (Mass Market edition)

Platkin, Charles S (2007), "Per Se, Per Calorie,” New York Magazine, June

Platkin, Charles S (2007), The Diet Detective's Calorie Bargain Bible, New York, Simon and Schuster/Fireside

Platkin, Charles S (2006), The Diet Detective's Count Down, New York, Simon and Schuster/Fireside 
Platkin, Charles S (2006), Breaking the Fat Pattern. New York: Penguin/Plume

Platkin, Charles S (2006), Lighten Up. New York: Penguin/Razorbill

Platkin, C.S., Frindell, K. Think before you eat: A six month worksite program to increase nutrition and physical activity. Oral Presentation at 134th Annual APHA Meeting, "Successful Strategies in Worksite Health Promotion" November 4-8, 2006, Boston, MA.

Platkin, C.S., Barraclough, T. Think Before You Eat. Poster Presentation at Florida's Public Health Association's 2004 Joint Annual Educational Meeting \& Trade Show: Building an Environment for Healthy Communities, July 26-30, 2004, Orlando, FL.

Platkin, Charles S. (2001) (2005), Breaking the Pattern: The 5 Principles You Need to Remodel Your Life. New York: Red Mill Press; New York: Plume (paperback)

Platkin, Charles S. (2002). "Déjà Vu All Over Again," Men's Health, December 2003.

Platkin, Charles S. (2002-Present), The Diet Detective, A syndicated nutrition and fitness column which appears in more than 100 daily newspapers nationally.

\section{PROFESSIONAL MEMBERSHIPS AND HONORS}

- American Council on Exercise (Certified Personal Trainer)

- American Obesity Association

- American Public Health Association (APHA)

- American Society for Nutritional Sciences

- Delta Omega Society (Honorary Public Health Society)

- North American Association for the Study of Obesity

- Sigma Xi (Scientific Research Society)

- Society for Nutrition Education

- Society for Public Health Education 